\title{
Regulation of adipocyte lipolysis
}

\author{
Gema Frühbeck ${ }^{1,2,3 *}$, Leire Méndez-Giménez ${ }^{1,2}$, José-Antonio Fernández-Formoso ${ }^{2}$, \\ Secundino Fernánde $z^{2,4}$ and Amaia Rodríguez $z^{1,2}$ \\ ${ }^{1}$ Metabolic Research Laboratory, Clinica Universidad de Navarra, Pamplona, Spain \\ ${ }^{2}$ CIBER Fisiopatología de la Obesidad y Nutrición (CIBERobn), ISCIII, Spain \\ ${ }^{3}$ Department of Endocrinology and Nutrition, Clinica Universidad de Navarra, Pamplona, Spain \\ ${ }^{4}$ Department of Otorbinolaryngology, Clinica Universidad de Navarra, Pamplona, Spain
}

\section{Abstract}

In adipocytes the hydrolysis of TAG to produce fatty acids and glycerol under fasting conditions or times of elevated energy demands is tightly regulated by neuroendocrine signals, resulting in the activation of lipolytic enzymes. Among the classic regulators of lipolysis, adrenergic stimulation and the insulin-mediated control of lipid mobilisation are the best known. Initially, hormone-sensitive lipase (HSL) was thought to be the rate-limiting enzyme of the first lipolytic step, while we now know that adipocyte TAG lipase is the key enzyme for lipolysis initiation. Pivotal, previously unsuspected components have also been identified at the protective interface of the lipid droplet surface and in the signalling pathways that control lipolysis. Perilipin, comparative gene identification-58 (CGI-58) and other proteins of the lipid droplet surface are currently known to be key regulators of the lipolytic machinery, protecting or exposing the TAG core of the droplet to lipases. The neuroendocrine control of lipolysis is prototypically exerted by catecholaminergic stimulation and insulin-induced suppression, both of which affect cyclic AMP levels and hence the protein kinase A-mediated phosphorylation of HSL and perilipin. Interestingly, in recent decades adipose tissue has been shown to secrete a large number of adipokines, which exert direct effects on lipolysis, while adipocytes reportedly express a wide range of receptors for signals involved in lipid mobilisation. Recently recognised mediators of lipolysis include some adipokines, structural membrane proteins, atrial natriuretic peptides, AMP-activated protein kinase and mitogen-activated protein kinase. Lipolysis needs to be reanalysed from the broader perspective of its specific physiological or pathological context since basal or stimulated lipolytic rates occur under diverse conditions and by different mechanisms.

Key words: Catecholamines: Insulin: Hormone-sensitive lipase: Adipocyte TAG lipase: Perilipin: Adipokines: Lipid mobilisation

\section{Introduction}

Under normal conditions, the adipose tissue is able to finetune a series of neuroendocrine signals to precisely adapt the balance between TAG synthesis (lipogenesis) and breakdown (lipolysis) to meet physiological needs. In higher eukaryotes adipocyte TAG depots represent the major energy reserve of the organism as a result of the constant flux between lipolysis and re-esterification ${ }^{(1-5)}$. During energy surplus adipocytes accomodate the excess fuel as TAG for retrieval during periods of negative energy balance such as fasting, starvation or long-term exercise. The hydrolysis of TAG produces NEFA and glycerol that are released into the vasculature for use as energy substrates by other organs. Since TAG are not able to pass through biological membranes they need to be cleaved by TAG hydrolases, also termed lipases, before entering or exiting cells ${ }^{(6,7)}$. The ability to rapidly mobilise lipid reserves as NEFA to subvene energy demands represents a highly adapted metabolic response. In addition, the balance between the lipogenic drive and the lipolytic rate prevents an exaggerated elevation of plasma NEFA, which is considered a key aetiological factor in the development of insulin resistance ${ }^{(8,9)}$. Thus, the fat-storing ability of adipocytes prevents the appearance of lipotoxicity (lipid-induced dysfunction) and lipoapoptosis (lipid-induced programmed cell death) in other

Abbreviations: ACSL1, long-chain acyl-CoA synthetase 1; AMPK, AMP-activated protein kinase; AQP, aquaporin; ATGL, adipocyte TAG lipase; cAMP, cyclic AMP; CB, cannabinoid receptor; CD36, fatty acid translocase; CGI-58, comparative gene identification-58; Cide, cell death-inducing DFFA (DNA fragmentation factor- $\alpha$ )-like effector; COPI, coat protein complex I; DAG, diacylglyerol; ERK, extracellular signal-related kinase; FABP4, fatty acidbinding protein 4; FATP, fatty acid transport protein; GOS2, G0/G1 switch gene 2; GH, growth hormone; G peptide-1; HSL, hormone-sensitive lipase; IRS, insulin receptor substrate; LC3, light chain 3; LPL, lipoprotein lipase; MAP, mitogen-activated protein; MGL, monoacylglycerol lipase; mTOR, mammalian target of rapamycin; PDE-3B, phosphodiesterase-3B; PI3K, phosphatidyl inositol 3-kinase; PKA, protein kinase A; PTH, parathyroid hormone; RNAi, RNA interference; ZAG, Zn- $\alpha_{2}$-glycoprotein. 
tissues (especially skeletal muscle and liver) ${ }^{(10-12)}$. While the metabolic importance of lipolysis remains unchanged, established models of adipose tissue lipolysis have undergone substantial revision lately. Notably, adipocyte lipid droplets are now considered dynamic organelles critical for the handling of lipid stores, containing specific structural proteins and lipid-metabolising enzymes involved in the modulation of both basal and hormone-regulated lipolysis ${ }^{(13-17)}$. Current knowledge in this field is reviewed from the broader perspective of providing an overview of the classic lipolytic factors as well as by focusing on the recently identified influence of the subcellular compartmentalisation of lipases, the relevance of lipid droplet proteins and lipid-binding proteins, as well as the activation of the different signalling pathways together with their regulation.

\section{Control of lipolysis}

Lipolysis constitutes the catabolic process leading to the breakdown of TAG into glycerol and NEFA in the adipose tissue $^{(2)}$. Basal lipolytic activity of adipocytes is conditioned by sex, age, physical activity, fat depot location, species and genetic variance, whereas stimulated adipocyte lipolysis is regulated by multiple factors, which are depicted in Fig. $1^{(18,19)}$. Interestingly, fat cell lipolysis exhibits species-unique characteristics based on the predominance of specific receptors and their relative density and expression ${ }^{(20,21)}$. A decreased lipolytic rate is observed both in the early years of life and the elderly in relation to the action of catecholamines and insulin ${ }^{(22-25)}$. For the same BMI, women exhibit higher NEFA circulating concentrations than men due to their constitutively larger fat depots and subcutaneous adipocytes ${ }^{(26)}$. Regional differences in the sensitivity to catecholamine-stimulated and insulin-inhibited lipolysis further underlie these sexspecific characteristics, which will be described more extensively below. An increased basal lipolysis together

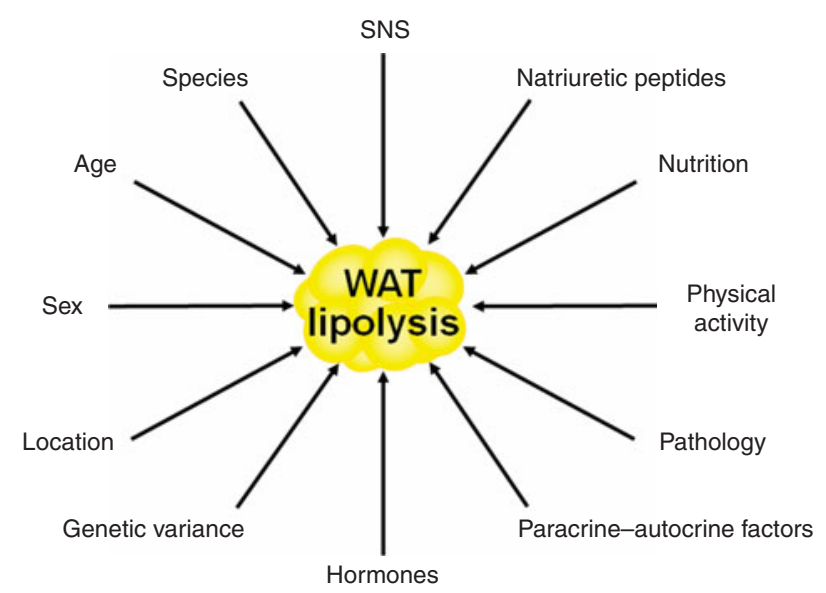

Fig. 1. Main factors influencing adipocyte lipolysis. SNS, sympathetic nervous system; WAT, white adipose tissue. (A colour version of this figure can be found online at http://www.journals.cambridge.org/nrr) with an enhanced lipolytic sensitivity to catecholamines take place during situations of negative energy balance such as fasting, starvation or semi-starvation, contributing to the increased mobilisation of NEFA from adipocytes and the subsequent fat mass loss when maintained over time $^{(2)}$. As in situations of energy deprivation, during prolonged exercise plasma NEFA increase in response to the elevated release of catecholamines and decreased production of insulin ${ }^{(27)}$. Both short- and long-term endurance training make adipocytes more sensitive to catecholamine stimulation via adrenoceptor signal transduction changes ${ }^{(28-31)}$.

Some dietary compounds also have the capacity to exert a direct impact on lipolysis regulation. The well-known lipolytic effect of caffeine and other methylxanthines occurs by elevating the cyclic AMP (cAMP) intracellular levels by two mechanisms. On the one hand, this is through $\mathrm{A}_{1}$-adenosine receptor antagonism, leading to a reduction of adenylyl cyclase activity and subsequent increased lipolysis. On the other hand, methylxanthines further prevent the breakdown of cAMP by inhibiting phosphodiesterase activity ${ }^{(3)}$. Thus, coffee consumption increases lipid turnover and raises plasma NEFA, while a high intake of methylxanthines may also contribute to weight loss and maintenance through an enhanced fat oxidation and thermogenesis ${ }^{(32,33)}$. Another dietary compound influencing adipocyte lipolysis is $\mathrm{Ca}$, with high intakes being associated with decreased adiposity and a reduced risk of obesity in diverse epidemiological studies ${ }^{(3)}$. Ca supplementation reportedly favours weight loss in both obese mice and human subjects undergoing energy-restricted diets, stimulating lipolysis via inhibition of the secretion of parathyroid hormone $(\mathrm{PTH})^{(34)}$ and the subsequent activation of 25-hydroxycholecalciferol to 1,25-dihydroxycalciferol ${ }^{(35-38)}$. While acute ethanol intake exerts an anti-lipolytic effect, chronic ethanol consumption suppresses the $\beta$-adrenergic receptor-mediated lipolytic action via an increased activation of phosphodiesterase, resulting in a decreased protein kinase A (PKA) stimulation and a diminished activating phosphorylation of perilipin-1 and hormone-sensitive lipase $(\mathrm{HSL})^{(39)}$.

Genetic variance also plays a role in determining lipolytic rate ${ }^{(5,18,40)}$. Variations in adrenoceptors have been intensely analysed for their putative functional effects on lipolysis and association with the development of obesity. The most studied are the polymorphisms in codon 64 of the $\beta_{3}$-adrenergic receptor and in codons 16 , 27 and 164 of the $\beta_{2}$-adrenoceptor. The Trp64Arg missense mutation of the $\beta_{3}$-adrenergic receptor gene was reportedly associated with decreased lipolysis induced by $\beta_{3}$-adrenoceptor agonists ${ }^{(41)}$. However, other studies have failed to show any phenotypic effect of this polymorphism, so its true pathophysiological contribution to fat metabolism and energy homeostasis in humans remains controversial $^{(18)}$. Noteworthy, variations in non-coding regions of calpain 10 lead to a decreased $\beta_{3}$-adrenergic receptor 
function. In the $\beta_{2}$-adrenergic receptor gene the Arg16Gly mutation has been shown to be associated with altered $\beta_{2}$-adrenergic receptor function, with carriers of this mutation showing a five-fold increased agonist sensitivity ${ }^{(18)}$. The Gln27Glu substitution was found to be twice as common in obese than in non-obese subjects in some populations, with homozygotes exhibiting an average excess fat mass of $20 \mathrm{~kg}$ and about $50 \%$ larger fat cells $^{(42)}$. On the contrary, the rare Thr164Ile substitution in the $\beta_{2}$-adrenergic receptor gene has not been consistently observed in obese individuals. Polymorphisms in the $\mathrm{G}-\beta_{3}$ gene, encoding for a specific $\mathrm{G}$-coupling protein that links $\alpha$ - as well as $\beta$-adrenergic receptors to adenylate cyclase, alter catecholamine-induced lipolysis in human fat cells, improving the lipolytic function of $\beta$-adrenoceptors at the same time as enhancing the anti-lipolytic activity of $\alpha_{2}$-adrenoceptors. Furthermore, variations in intronic dinucleotide repeats of the HSL gene are accompanied by a decreased function of the lipase with a reduced lipolytic effect of catecholamines ${ }^{(43,44)}$.

\section{Classic factors}

In humans the main elements controlling lipolysis are the activity of the autonomic nervous system and the endocrine influence derived from the release of insulin ${ }^{(2,18,45)}$. Adipose tissue is richly innervated by both the sympathetic and parasympathetic nervous systems with nerve terminals running along blood vessels and a certain number of adipocytes in direct contact with nerve varicosities. Thus, electrical stimulation of sympathetic nervous system nerve endings results in an increase in lipolytic activity, while surgical sympathectomy reportedly reduces lipolysis in the denervated adipose depot $^{(46-49)}$. Although the parasympathetic nervous system has been shown to also innervate white adipose tissue and decrease lipolysis, stimulating an increase in insulin sensitivity $^{(50,51)}$, its true functional role has been subsequently questioned $^{(52)}$.

Catecholamine-induced regulation. Catecholamines, adrenaline and noradrenaline, exert their impact on lipolysis upon binding to the diverse adrenergic receptor subtypes located on the plasma membrane of adipocytes ${ }^{(2,45,53)}$. These receptors are linked to G-proteins, with G-protein receptor complexes regulating adenylate cyclase in the cell membrane. In mammals at least four adrenoceptors exert their action with marked species characteristics ${ }^{(4)}$. In humans $\beta_{1^{-}}$and $\beta_{2}$-adrenoceptors are the most active lipolytic elements, while the contribution of $\beta_{3}$-adrenergic receptors remains to be better established. The presence of $\beta_{3}$-adrenoceptors in human white adipocytes has been clearly proven with tissue and subcellular distribution as well as response to stimulators being consistent with participation in lipolysis ${ }^{(54)}$. However, the failure of $\beta_{3}$-adrenoceptor agonists to elicit clear-cut lipolytic and weight-loss effects in obese patients casted doubts on the true physiological relevance of this $\beta$-adrenoceptor subtype in humans ${ }^{(55,56)}$. Contrarily, $\beta_{3}$-adrenoceptors are abundantly expressed in adipocytes of rodents ${ }^{(57)}$. Upon binding to their ligand, $\beta$-adrenergic receptors initiate the activation of the lipolytic cascade through the stimulation of cAMP production and subsequent activation of the cAMP-dependent PKA, which is followed by the phosphorylation of perilipin and HSL, ultimately leading to lipolysis stimulation (Fig. 2). Another peculiarity of human adipocytes resides in the presence of abundant $\alpha_{2}$-adrenoceptors, which are coupled to G-inhibitory proteins $\left(G_{i}\right)$, thereby inhibiting cAMP production and, thus, lipolysis $^{(58,59)}$. Therefore, the balance between the lipolytic effect of $\beta$-adrenergic receptors and the opposing anti-lipolytic activity of $\alpha_{2}$-adrenoceptors also determines the net outcome of catecholamine-induced fat mobilisation in humans. The identification of brown adipose tissue in human adults beyond the vestigial amounts originally acknowledged and its association with BMI and adiposity has triggered a re-focusing of attention to the true relevance of $\beta_{3}$-adrenoceptors in lipid metabolism and energy homeostasis ${ }^{(60,61)}$.

Hormone-mediated control. A number of hormones are known to participate in the regulation of lipolysis. Among all endocrine factors, insulin is quantitatively and qualitatively the most relevant one. The impact of growth hormone $(\mathrm{GH})$, adrenocorticotropic hormone, cortisol, thyroid hormones, PTH and glucagon is comparatively much more reduced than that of insulin. The mechanisms of action of all are briefly discussed below.

Hormone-mediated control: insulin. Insulin is a key regulator of white adipose tissue biology, controlling not only lipogenesis but also the rate of lipolysis and NEFA efflux. Insulin regulates glucose uptake by adipocytes and triggers fatty acid transport protein translocation as well as fatty acid uptake by fat cells ${ }^{(62)}$. Binding of insulin to its specific cell-surface receptor produces tyrosine phosphorylation and activation of the insulin receptor, which leads to the interaction with the insulin receptor substrates (IRS-1 and IRS-2), in turn activating the phosphatidyl inositol 3-kinase (PI3K) complex ${ }^{(2)}$. Insulin powerfully inhibits basal and catecholamine-induced lipolysis through phosphorylation (via a PKB/Akt-dependent action) and activation of phosphodiesterase-3B (PDE-3B). The phosphodiesterase catalyses the breakdown of cAMP to its inactive form, thereby decreasing cAMP levels, which in turn reduces PKA activation and, therefore, also translates into preventing HSL stimulation. Insulin may also suppress lipolysis through phosphorylation of the regulatory subunit of protein phosphatase-1 (PP-1), which once activated rapidly dephosphorylates and deactivates HSL, thus decreasing the lipolytic rate ${ }^{(63)}$. The anti-lipolytic effect of insulin is observed already minutes upon binding of the hormone to its receptors.

Hormone-mediated control: growth hormone. While insulin repesents the primary anabolic hormone exerting the main influence periprandially, GH operates directly and through stimulation of insulin growth factor-1, insulin 


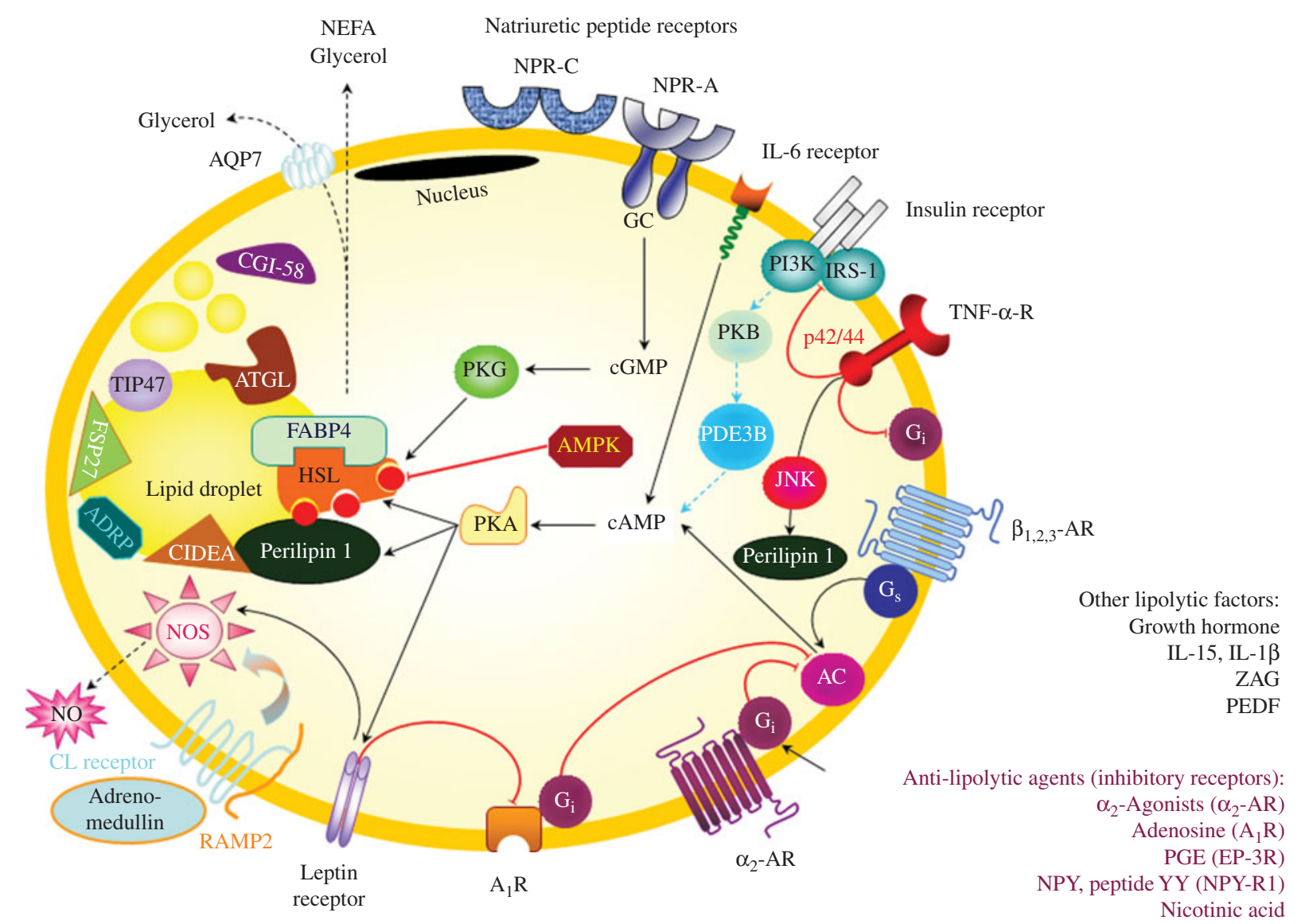

Fig. 2. Principal regulators and major pathways involved in adipocyte lipolysis. $A_{1} R, A_{1}$ adenosine receptor; $A C$, adenylyl cyclase; $A D R P$, adipophilin/adipocyte differentiation-related protein; AMPK, AMP-activated protein kinase; AQP7, aquaporin 7; AR, adrenoreceptor; ATGL, adipocyte TAG lipase; cAMP, cyclic AMP; CGI-58, comparative gene identification-58; cGMP, cyclic GMP; CIDEA, cell death-inducing DFFA (DNA fragmentation factor- $\alpha$ )-like effector A; CL, calcitonin receptor-like; EP-3R, PGE receptor 3; FABP4, fatty acid binding protein 4; FSP27, fat-specific protein 27; GC, guanylyl cyclase; $\mathrm{G}_{\mathrm{i}}$, inhibitory GTP-binding proteins; $\mathrm{G}_{\mathrm{s}}$, stimulatory GTP-binding proteins; HSL, hormone-sensitive lipase; IRS-1, insulin receptor substrate-1; JNK, Jun kinase; NOS, NO synthase; NPR, natriuretic peptide receptor; NPY, neuropeptide Y; NPY-R1, neuropeptide Y receptor 1; PDE3B, phosphodiesterase 3B; PEDF, pigment epithelium-derived factor; PI3K, phospatidylinositol-3 kinase; PKA, protein kinase A; PKB, protein kinase B; PKG, protein kinase G; RAMP2, receptor activity modifying protein-2; TIP47, tail-interacting protein of $47 \mathrm{kDa}$; TNF- $\alpha-\mathrm{R}$, TNF- $\alpha$ receptor; ZAG, zinc- $\alpha_{2}$-glycoprotein. (A colour version of this figure can be found online at http://www.journals.cambridge.org/nrr)

and NEFA during stress and fasting ${ }^{(64)}$. Thus, GH represents a less potent though critically important regulator of lipolysis, which influences body composition, stimulating muscle mass accretion at the same time as reducing adiposity by a direct lipolytic effect using cAMPand PKA-dependent pathways. GH-deficient individuals can experience up to a $40 \%$ reduction in plasma NEFA and lipolysis that are returned to normal values by $\mathrm{GH}$ replacement therapy. Interestingly, $\mathrm{GH}$ activates adenylyl cyclase by selectively shifting the $\mathrm{G}_{\mathrm{i}} \alpha_{2}$ subunit and removing cAMP production inhibition ${ }^{(65)}$. Exogenous $\mathrm{GH}$ administration produces an increase in NEFA after $2-3 \mathrm{~h}$, thus reflecting a delayed lipolytic effect when compared with that of catecholamines. In this context, small physiological GH pulses reportedly increase interstitial glycerol levels in abdominal and femoral fat ${ }^{(66)}$. In addition, suppression of the normal nocturnal rise in GH is followed by a reduction in subsequent lipolysis in subcutaneous adipose tissue ${ }^{(67)}$. Endogenous GH has been shown to play a limited metabolic role during the daily fed-fast cycle, whereas it is essential for the increased lipolytic rate observed with more prolonged fasting ${ }^{(68)}$. Recently, adipocyte-specific disruption of JAK2 (JAK2A) in mice has been shown to result in GH resistance in adipocytes, with reduced lipolysis and increased body fat, thereby offering complementary mechanistic insights into the wellrecognised effects of GH on lipid flux ${ }^{(69)}$.

Hormone-mediated control: other hormones. Cortisol also exerts a lipolytic effect, which is less potent than that of catecholamines at the same time as being delayed (minutes in the case of adrenaline $v$. hours for cortisol) ${ }^{(62,70)}$. Importantly, the in vivo lipolysis stimulation is counteracted by the corticoid-induced insulin release $^{(71,72)}$, whereby the net outcome of a short-term treatment with a standard dose of corticosteroids is an increase in abdominal adipose tissue lipolysis, without changes in GH concentrations, hyperglucagonaemia and insulin resistance. While a stimulation of lipolysis in human adipose tissue has been also ascribed to $\mathrm{PTH}^{(20,73)}$, it has also been suggested that a PTH excess 
may promote weight gain by impeding catecholamineinduced lipolysis ${ }^{(34)}$. Whereas in rodents testosterone up-regulates catecholamine-induced lipolysis ${ }^{(74)}$, in humans testosterone in physiological concentrations causes a depot-specific reduction of catecholaminestimulated lipolysis in subcutaneous fat cells, probably due to reduced protein expression of $\beta_{2}$-adrenoceptors and $\mathrm{HSL}^{(75-77)}$. The relevance of androgen signalling in lipolysis regulation became evident from the observation that late-onset obesity development in androgen receptor-null male mice was caused in part by a decreased lipolytic activity ${ }^{(78)}$. The direct molecular mechanism accounting for the hypertrophic adipocytes and expanded white adipose tissue of these mice depends on an altered lipid homeostasis characterised by a decreased lipolysis but not an increased lipogenesis. Interestingly, transcripts for HSL were strikingly decreased, whereas those for lipogenic genes were unchanged or decreased. Androgens slightly decrease lipoprotein lipase (LPL) activity in human adipose tissue organ cultures, but markedly inhibit adipogenesis in primary preadipocyte cultures obtained from subcutaneous and omental depots of both sexes ${ }^{(79)}$. Thus, the androgenic effects on adipose tissue in men as opposed to women may differ more in terms of the magnitude of their negative impact on adipogenesis and lipid synthesis rather than in the direction of the lipolytic action.

Although commonly acting in rodent fat cells as lipolytic agents via stimulatory GTP-binding protein ( $G_{s}$ protein)coupled receptors, thyrotropin-stimulating hormone, adrenocorticotropic hormone and $\alpha$-melanocyte-stimulating hormone are either ineffective or very weak stimulators of lipolysis in human adipocytes ${ }^{(62)}$. Neither glucagon nor glucagon-like peptide-1 (GLP-1) has been clearly shown to stimulate lipolysis in vitro. Likewise, no significant effects of glucagon or GLP-1 on lipolytic rate or adipose tissue blood flow following local or experimental intravenous normoand hyperglucagonaemia have been observed ${ }^{(80,81)}$. However, during the present decade the role of the GLP-1/GLP-1 receptor system in lipolysis has experienced renewed interest ${ }^{(82)}$. A dose-dependent lipolytic effect of GLP-1 in 3T3-L1 adipocytes in a receptor-dependent manner involving downstream adenylate cyclase/cAMP signalling has been shown ${ }^{(83)}$.

\section{Cytokines and other 'newcomers'}

Over the past years adipose tissue has been recognised as an extraordinarily active endocrine organ with the ability to secrete numerous products of diverse nature such as hormones, cytokines, enzymes, complement factors, vasoactive peptides and growth factors, among others ${ }^{(84-87)}$. All these adipose-derived factors, collectively termed adipokines, are involved in a pleiad of physiological functions ranging from energy homeostasis to reproduction, including inflammation and immunity as well as angiogenesis and bone metabolism, among others ${ }^{(88-94)}$. The dynamic cross-talk of adipokines with other non-metabolic biological processes extends to the cardiovascular ${ }^{(95-99)}$, gastrointestinal $^{(100-103)}$, respiratory ${ }^{(104-106)}$ and muscular ${ }^{(107-110)}$ systems. In addition to their participation in plentiful diverse physiological functions, many of the recently identified hormones and adipokines have also been shown to be able to directly affect lipolysis.

Cytokine regulation of lipolysis. Cytokine release by both adipocytes and stromovascular cells underlies the participation of adipose tissue in a dynamic cross-talk and potent feedback signalling with key neuroendocrine organs involved in the regulation of food intake, lipid metabolism, glucose disposal, energy expenditure and the stress response ${ }^{(111,112)}$. The complex secretory activities of adipose tissue also contribute to the development of insulin resistance and atherogenic processes ${ }^{(113-115)}$. The release of cytokines further exerts important local autocrine and paracrine effects, mainly involved in adipose tissue remodelling, adipogenesis, angiogenesis, inflammation and immunity. Noteworthy, cytokines, like $\mathrm{TNF}-\alpha$, as well as some interleukins and adipokines, are important regulators of spontaneous lipolysis.

Cytokine regulation of lipolysis: TNF- $\alpha$. TNF- $\alpha$ is produced in large amounts by adipocytes and other cell types within adipose tissue ${ }^{(84,116)}$. In humans, contrarily to rodents, TNF- $\alpha$ is not released from adipose tissue into the circulation but rather acts predominantly as a local factor $^{(117-119)}$. As with other lipolytic agents, important species differences have also been observed as regards TNF- $\alpha$ action. TNF- $\alpha$ is able to stimulate lipolysis by at least three separate mechanisms ${ }^{(117,120,121)}$. First, it inhibits insulin receptor signalling, thereby counteracting the antilipolytic effect of the hormone. In this respect, TNF- $\alpha$ operates via the inactivation of IRS-1. This can be brought about by the inhibition of tyrosine phosphorylation and by a reduction in the amount of IRS-1 in adipocytes. In fact, TNF- $\alpha$ counteracts tyrosine phosphorylation by promoting serine phosphorylation of IRS-1. The most important TNF- $\alpha$ effect on adipocyte IRS-1 is mediated through the p42/44 mitogen-activated protein (MAP) kinase (Fig. 2). Second, TNF- $\alpha$ is able to stimulate lipolysis by inhibiting the $\mathrm{G}_{\mathrm{i}}$-protein-coupled adenosine receptor signalling to counteract the anti-lipolytic effect of adenosine. TNF- $\alpha$ markedly decreases the protein content of all three $G_{i} \alpha$ subtypes in rodent fat cells, without changing the amount of $G_{s}$ protein or $\beta$-subunit of the $G$-protein complex. This decrease in $G_{i}$ protein mitigates the anti-lipolytic effect of adenosine. Interestingly, TNF- $\alpha$ decreases $\mathrm{G}_{\mathrm{i}}$-protein content through an induction of protein degradation by the proteasomal pathway $^{(122)}$. However, the $\mathrm{TNF}-\alpha-\mathrm{G}_{\mathrm{i}}$ interaction appears to be specific for rodents because it has not been observed in human fat cells. The third way by which TNF- $\alpha$ induces lipolysis is via direct stimulation of basal lipolysis through interactions with the lipid-binding protein perilipin. Only TNF- $\alpha$ receptor 1 and MAP kinases promote lipolytic effects in fat cells leading to phosphorylation and 
decreased production of perilipin, the adipose lipid droplet coating protein that protects it from being hydrolysed by HSL $^{(117,123,124)}$. Three MAP kinases, namely $\mathrm{p} 44 / 42$, Jun kinase (JNK) and p38, are activated by TNF- $\alpha$ in fat cells but only the first two have been linked to lipolysis so far.

Mechanistically, TNF- $\alpha$ can stimulate lipolysis in the absence of insulin, thus providing evidence that it does not simply antagonise the anti-lipolytic effects of insulin. Moreover, extracellular glucose is required for the TNF- $\alpha$ induced lipolytic effect, suggesting that a certain nutritional state or substrate availability is required ${ }^{(119)}$. The downstream signals of the TNF- $\alpha$ receptor 1-dependent pathway involve the activation of extracellular signal-related kinases (ERK1/2), JNK, AMP-activated protein kinase (AMPK), inhibitor of $\mathrm{\kappa B}$ kinase (IKK) and PKA ${ }^{(119,125,126)}$. However, in fat cells the TNF- $\alpha$-induced activation of ERK1/2, JNK and IKK is rapid and transient, while TNF- $\alpha$-induced lipolysis takes more than $6 \mathrm{~h}$, suggesting the existence of more distant events that are likely to be controlled by transcriptional regulation ${ }^{(119,127)}$.

Cytokine regulation of lipolysis: IL-6 and IL-15. The IL-6 receptor and glycoprotein 130, key elements of the cytokine pathway, are expressed in human adipocytes, pointing to a direct autocrine/paracrine action of IL- 6 on fat cells ${ }^{(62)}$. Infusions of recombinant human IL- 6 have been reported to increase plasma NEFA and glycerol concentrations, leading the authors to conclude that IL-6 represents a novel lipolytic factor that operates as a potent stimulator of lipolysis ${ }^{(128,129)}$. Interestingly, IL-6 infusions were accompanied by parallel increases in plasma cortisol and adrenaline levels, whereas the potential effect on GH concentrations was not analysed. In this regard, it is difficult to establish whether the increased lipolysis depends on the direct action of IL- 6 or rather reflects the effects of other lipolytic factors such as $\mathrm{GH}$, cortisol and noradrenaline ${ }^{(130)}$. A more recent study has shown that higher circulating IL- 6 concentrations are associated with an increased isoproterenol-stimulated lipolysis especially in omental adipocytes in women ${ }^{(131)}$. In any case, the reported effect on lipolysis of IL-6 is relatively modest compared with that elicited by catecholamines and insulin. The potential involvement of IL-6 during the practice of exercise or other situations related to severe illness, where a clear need for an elevated lipid fuel takes place, has been set forward ${ }^{(132,133)}$.

Another member of the interleukin family has been proposed to participate in the modulation of lipolysis. The administration of IL-15 has been shown to produce a significant reduction in white adipose tissue via both a decreased rate of lipogenesis and a reduction in LPL activity, without a concomitant decrease in food intake ${ }^{(134)}$. Comparative studies with other cytokines revealed that IL-15 is apparently more potent in its acute stimulation of lipolysis than IL- 6 and TNF- $\alpha^{(135)}$. Noteworthy, when specific inhibitors of PKA or Janus kinase were present an attenuation of the lipolytic effect of IL-15 was observed. IL-15 is known to be highly expressed in skeletal muscle, exerting a potent anabolic effect on muscle protein accretion while decreasing fat depots in adipose tissue ${ }^{(136)}$. Taking these observations together, it can be speculated that IL-15 may operate as a homeorhectic factor that mobilises and directs energy away from the adipocyte to other cells during the acute phase of the inflammatory response.

Interestingly, IL- $1 \beta$ and TNF- $\alpha$ have been shown to activate MAP3K8, also called Tpl2, which is expressed in adipocytes and is implicated in cytokine-induced lipolysis ${ }^{(127)}$. Pharmacological inhibition or silencing of $\mathrm{Tpl} 2$ was able to prevent MAP kinase kinas/ERK1/2 activation by these cytokines but not by insulin, thereby providing evidence of its involvement in ERK1/2 activation particularly in response to inflammatory stimuli ${ }^{(127)}$.

Cytokine regulation of lipolysis: leptin. More than a decade ago the identification of functional leptin receptors (OB-R) in white adipose tissue suggested the involvement of leptin in the direct peripheral regulation of adipocyte metabolism ${ }^{(137-139)}$. In fact, leptin was shown to directly participate in lipid metabolism control through the inhibition of lipogenesis and the stimulation of lipolysis. Leptin reportedly exerts an autocrine-paracrine lipolytic effect on isolated white adipocytes both in vitro and ex vivo ${ }^{(140-143)}$.

Adenosine $\mathrm{A}_{1}$ receptors have been shown to be markedly expressed in adipocytes and influence fat cell metabolism via the regulation of adenylyl cyclase and, therefore, participate in lipolysis control via the inhibitory guanosine $5^{\prime}$-triphosphate (GTP) binding proteins, $G_{i}^{(144,145)}$. The adenosinergic system increases leptin secretion by directly activating adenosine $A_{1}$ in white adipose tissue ${ }^{(146)}$. In this respect, a defective leptin-induced stimulation of lipolysis that opposes the adenosine-mediated tonic inhibition was identified ${ }^{(143)}$. Interestingly, the lipolytic effect of leptin is located at the adenylyl cyclase-inhibitory $G$ protein step (Fig. 2), providing an explanation for the defective stimulation of adipocyte adenylate cyclase and the blunted lipolysis observed in leptin-deficient and OB-R-lacking rodents as well as in morbidly obese humans ${ }^{(147-149)}$. Moreover, storage of surplus energy in white adipose tissue and the development of diet-induced obesity require the blockade of a latent leptin-stimulated energy sump in white adipocytes ${ }^{(150)}$. In this regard, the pleiotropic effects of leptin in other metabolically relevant organs like brown adipose tissue, skeletal muscle, pancreas, liver and heart need to be

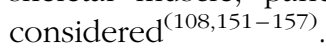

Cytokine regulation of lipolysis: adiponectin. Adiponectin, also known as Acrp30, AdipoQ, apM1 or GBP28, is a hydrophilic 30-kDa protein highly expressed and secreted by adipocytes ${ }^{(88,90)}$. The three-dimensional structure of the C-terminal globular domain of adiponectin shows a high structural homology with TNF- $\alpha$, another well-known lipolytic cytokine ${ }^{(158)}$. Interestingly, HSL activity has been shown to be positively correlated to adiponectin expression, with percentage body fat and adiponectin 
mRNA arising as the only independent predictors of adipose tissue HSL activity explaining $26 \%$ of its variability ${ }^{(159)}$. Increased adipose tissue mass has been suggested to explain the association between low adiponectin and reduced NEFA tolerance ${ }^{(160)}$. Adiponectin has been shown to inhibit spontaneous and catecholamine-induced lipolysis in human adipocytes of non-obese subjects through AMPK-dependent mechanisms $^{(161)}$. In contrast to most adipokines, which are markedly up-regulated in obesity, adipose tissue expression and circulating concentrations of adiponectin are decreased in both overweight and obesity, thereby implying a plausibly decreased impact on overall lipolysis. Adiponectin gene knockout mice and primary adipocytes obtained from these mice exhibit an increased lipolysis ${ }^{(162)}$. Moreover, adiponectin was shown to suppress HSL activation without modifying adipocyte TAG lipase (ATGL) and comparative gene identification-58 (CGI-58) expression in adipocytes. In addition, adiponectin reportedly reduced the type 2 regulatory subunit RII $\alpha$ protein levels of PKA by reducing its protein stability, with ectopic expression of RII $\alpha$ abolishing the inhibitory effects of adiponectin on lipolysis in adipocytes ${ }^{(162)}$. The proportion of secreted highmolecular-weight $v$. total adiponectin has been shown to be higher in visceral than in subcutaneous adipose tissue explants in non-obese individuals, while no differences were observed in obese individuals ${ }^{(163)}$. More recently, full-length adiponectin was shown to exert an anti-lipolytic effect in non-obese subcutaneous adipose tissue, while the globular and trimeric isoforms exhibited anti-lipolytic activity in obese subcutaneous and visceral adipose tissue, respectively ${ }^{(164)}$.

Other elements involved in lipolysis. Analysis of the involvement of other factors in the control of lipolytic pathways is unravelling a huge number of potential modulators, which vary greatly not only in their biochemical structure but also in their main physiological effect and the signalling cascade activated.

Other elements involved in lipolysis: nitric oxide. NO or related redox species have been described to act as regulators of lipolysis both in rodent and human adipocytes $^{(165-170)}$. Inhibition of NO release increased lipolysis independently of local blood flow changes. While chemical NO donors stimulate basal lipolysis, they block the characteristic isoproterenol-induced lipolytic activity via the inhibition of adenylyl cyclase and PKA. Inducible NO synthase has emerged as a negative modulator of lipolysis via an oxidative signalling pathway upstream of cAMP production ${ }^{(169)}$.

A functional relationship between leptin and NO has been established in several physiological processes ${ }^{(139,171-175)}$. Given the co-localisation of both factors in fat cells and their involvement in lipolysis, a potential role of $\mathrm{NO}$ in the leptin-induced lipolytic effect seemed plausible. In fact, $1 \mathrm{~h}$ after exogenous leptin administration a dose-dependent increase in both serum NO concentrations and basal adipose tissue lipolytic rate was observed ${ }^{(143)}$. Up to $27 \%$ of the variability taking place in lipolysis was attributable to the changes in NO concentrations. The leptin-induced NO production in white adipocytes was shown to be mediated through PKA and MAP kinase activation ${ }^{(176)}$. Inhibition of NO synthesis by $N^{\omega}$-nitro-L-arginine methyl ester (L-NAME) pretreatment was followed by a reduction in the leptinmediated lipolysis stimulation compared with leptin-treated control animals. Contrarily, in adipocytes obtained from rats under acute ganglionic blockade, the leptin-induced lipolytic effect did not show differences with the lipolytic rate achieved by leptin in control rats. The NO donor $S$-nitroso- $N$-acetyl-penicillamine (SNAP) was able to exert a significant inhibitory effect on isoproterenol-stimulated lipolysis. Thus, NO has emerged as a potentially relevant autocrine-paracrine physiological signal to fine-tune lipolysis by facilitating leptin-induced lipolysis and, at the same time, being able to inhibit catecholamine-induced lipolysis $^{(173)}$.

Other elements involved in lipolysis: natriuretic peptides. Until recently, human fat cell lipolysis was thought to be mediated essentially by a cAMP-dependent PKA-regulated pathway under the control of catecholamines and insulin. However, Lafontan et al. ${ }^{(177)}$ provided evidence that natriuretic peptides also have the ability to potently stimulate lipolysis in human adipocytes to the same degree as a non-selective $\beta$-adrenoceptor agonist. This lipolytic effect is mediated mainly by natriuretic peptide receptor type A through a cyclic GMP-dependent PKG (cGK-I) signalling pathway (Fig. 2) that does not involve PDE-3B inhibition or cAMP production and PKA activity ${ }^{(178-182)}$. Noteworthy, in vitro studies have shown that HSL can also be phosphorylated by the cyclic GMP-dependent signalling cascade. In fact, cGK-I phosphorylates perilipin and HSL. Increases in plasma atrial natriuretic peptide levels by physiological (exercise) or pharmacological stimuli are followed by an enhanced lipid mobilisation ${ }^{(183,184)}$. In humans atrial natriuretic peptide also reportedly induces postprandial lipid oxidation, energy expenditure, and concomitantly arterial blood pressure ${ }^{(185,186)}$. Taken together, this pathway that participates in lipid mobilisation and energy homeostasis becomes especially important during chronic treatment with $\beta$-adrenoceptor antagonists, which inhibit catecholamine-induced lipolysis but enhance cardiac atrial natriuretic peptide release.

Other elements involved in lipolysis: endocannabinoid system. Our understanding of the participation of the endocannabinoid system in energy homeostasis has progressed enormously over the past years ${ }^{(187-189)}$. In particular, the observation of the presence of $G$ proteincoupled cannabinoid receptor (CB) CB1 receptors in adipocytes provided a clue for the involvement of endocannabinoids in the peripheral control of lipid metabolism $^{(190-193)}$. Selective CB1 antagonism was shown to coordinately induce key genes of the fatty acid catabolic pathway, thereby favouring lipolysis and reducing fat storage in adipose tissue ${ }^{(191)}$. Interestingly, the selective 
antagonism of CB1 receptors reportedly induced $\beta_{3}$ adrenoceptors and $\mathrm{GH}$ receptors at the same time as repressing the expression of catechol-O-methyltransferase, an enzyme involved in the degradation of catecholamines. The reduced expression of this methyltransferase along with the induction of the receptors of two well-known hormones with lipolytic effects further supports the molecular basis for the participation of endocannabinoids in the modulation of lipolysis.

Amides of fatty acids with ethanolamine (FAE) are biologically active lipids participating in a variety of physiological effects, including appetite regulation. While the polyunsaturated FAE anandamide (arachidonoylethanolamide) increases food intake by activating $G$ proteincoupled cannabinoid receptors, the monounsaturated FAE oleoylethanolamide (OEA) reduces feeding as well as body-weight gain and stimulates lipolysis by activating the nuclear receptor PPAR- $\alpha^{(194,195)}$

Other elements involved in lipolysis: ghrelin. Beyond its strong orexigenic effect, the gastrointestinal twentyeight-amino acid octanoylated peptide ghrelin exerts a wide spectrum of actions including the inhibition of isoproterenol-induced lipolysis in rodent adipocytes ${ }^{(196)}$. Both ghrelin and des-acyl ghrelin have been shown to antagonise the catecholamine-stimulated lipolysis via a non-type $1 \mathrm{~A} \mathrm{GH}$ secretagogue receptor. Moreover, acylated and unacylated ghrelin have been also shown to attenuate isoproterenolinduced lipolysis in isolated rat visceral adipocytes through activation of phosphoinositide 3-kinase $\gamma$ and PDE-3B ${ }^{(197)}$. However, ghrelin infusion in human subjects was observed to induce acute insulin resistance and lipolysis independent of GH signalling ${ }^{(198)}$. All of the elements of the ghrelin system have been identified in human adipocytes, including receptors and isoforms as well as the ghrelin-O-acyltransferase or GOAT enzyme ${ }^{(199,200)}$. Interestingly, in differentiating omental adipocytes, incubation with both acylated and desacyl ghrelin increased PPAR- $\gamma$ and sterol regulatory element-binding protein-1 mRNA levels, as well as fat storage-related proteins, like acetyl-CoA carboxylase, fatty acid synthase, LPL and perilipin ${ }^{(199)}$. Consequently, both ghrelin forms stimulate intracytoplasmatic lipid accumulation at the same time as exhibiting an anti-lipolytic effect.

Other elements involved in lipolysis: other miscellaneous agents. The potent anti-lipolytic effect of nicotinic acid together with its specific binding to adipose tissue was firmly established more than half a century ago ${ }^{(201,202)}$. However, the mechanistic basis for this action on lipolysis control has been provided only more recently ${ }^{(203)}$. Activation of the nicotinic acid receptor triggers an inhibitory G-protein signal, which decreases cAMP concentrations in adipocytes, thereby inhibiting lipolysis. Continuous $24 \mathrm{~h}$ nicotinic acid infusion in rats reportedly alters gene expression and basal lipolysis in adipose tissue, producing a NEFA rebound and insulin resistance ${ }^{(204)}$ that are consistent with clinical observations following treatment with this compound.
Other agents originating from either adipocytes or surrounding cells are known to negatively control adenylyl cyclase activity and inhibit lipolysis via their interaction with plasma membrane receptors belonging to the seventransmembrane domain receptor family. Autacoid agents, as already mentioned including adenosine, prostaglandins and their metabolites, exert a clear anti-lipolytic effect. Whereas adenosine and neuropeptide Y reportedly inhibit lipolysis, for $\mathrm{PGE}_{2}$ a biphasic effect has been put forward with nanomolar concentrations suppressing lipolysis, but micromolar levels resulting in lipolysis stimulation ${ }^{(63)}$. On the contrary, $\mathrm{PGI}_{2}$ showed no effect or exerted also a biphasic effect, whereby nanomolar concentrations stimulated lipolysis, whereas at micromolar levels lipolysis was suppressed.

Cachexia-inducing tumours produce a lipid-mobilising factor (LMF) that causes an immediate glycerol release when incubated with murine adipocytes, with the stimulation of lipolysis by LMF being associated with an elevation in intracellular cAMP concentrations ${ }^{(205-207)}$. Zn- $\alpha_{2}$-glycoprotein (ZAG), a tumour-related LMF of 43 $\mathrm{kDa}$, has been found to be expressed in 3T3-L1 cells as well as in the major fat depots of mice, being up-regulated in rodents with cancer cachexia ${ }^{(208)}$. Both ZAG expression and protein have been also detected in human adipocytes of visceral and subcutaneous origin. Remodelling of adipose tissue together with decreased lipid storage constitute a hallmark of cancer patients with cachexia. In addition to ATGL- and HSL-enhanced lipolysis, in cancer other factors such as ZAG have been shown to participate in TAG degradation leading to white adipose tissue atrophy. ZAG expression and release by adipose tissue are up-regulated in weight-losing cancer patients, suggesting that ZAG operates both locally and systemically to stimulate lipid mobilisation ${ }^{(206)}$. However, ZAG did not display the thermogenic effects of the $\beta$-adrenoceptor agonist, nor did it increase $\beta_{3}$-adrenoceptor or UCP1 (uncoupling protein 1) gene expression in brown adipose tissue, thereby implying that it does not behave as a typical $\beta_{3 / 2}$-adrenoceptor agonist ${ }^{(209)}$. Thus, ZAG has emerged as a novel adipokine, being identified as an additional adipose tissue factor closely related to body weight loss not only via modulation of lipolysis in fat cells but also by activating AMPK in skeletal muscle cells ${ }^{(208,210)}$.

The octapeptide angiotensin II (Ang II) is the active component of the renin-angiotensin system (RAS). A local RAS is present in adipose tissue, with all the elements of the system, including angiotensinogen, renin and angiotensin-converting enzyme, having been identified in $\operatorname{adipocytes}^{(211)}$. Noteworthy, Ang II has been shown to decrease local blood flow in a dose-dependent manner and to inhibit lipolysis in adipose tissue with the effects being similar in both normal-weight and obese individuals $^{(212)}$. In the last decade evidence has been provided that adipose tissue is a source of vasoactive peptides that further exert metabolic actions ${ }^{(213)}$. Thus, endothelin-1 is 
a powerful vasoconstrictor primarily produced and secreted by endothelial cells to operate on the underlying vascular smooth muscle cell layer that can also act on adipocytes inducing lipolysis via the ERK pathway ${ }^{(214,215)}$. In human subjects endothelin-1 has been shown to selectively counteract insulin inhibition of visceral adipocyte lipolysis, decreasing the expression of insulin receptor, IRS-1 and PDE-3B and increasing the expression of the endothelin receptor- $\mathrm{B}$ $\left(\mathrm{ET}_{\mathrm{B}} \mathrm{R}\right)$ in visceral but not subcutaneous adipocytes ${ }^{(216)}$. The $\mathrm{ET}_{\mathrm{B}} \mathrm{R}$-mediated effects were signalled via the PKC and calmodulin pathways. Subsequently, it was further observed that long-term incubation of human adipocytes with endothelin-1 increases lipolysis via the activation of $\mathrm{ET}_{\mathrm{A}} \mathrm{R}^{(217)}$. Likewise, the fifty-two-amino acid vasoactive peptide adrenomedullin together with its receptor components (calcitonin receptor-like receptor and receptor activity modifying protein-2 (CRLR/RAMP2)) have been identified to be concomitantly expressed in adipose tissue (Fig. 2), exhibiting a tissue-specific up-regulation during the development of obesity ${ }^{(218,219)}$. Interestingly, in adipose tissue adrenomedullin acts as an autocrine-paracrine factor to regulate lipid mobilisation, inhibiting lipolysis through NO-mediated $\beta$-adrenergic agonist oxidation ${ }^{(22)}$. In this context, it has been proposed that adrenomedullin alone is devoid of lipolytic function and inhibits $\beta$-adrenergic-stimulated lipolysis by shifting the concentration-response curve for isoproterenol by a NO-dependent mechanism; specifically, adrenomedullin-induced NO modifies isoproterenol through an extracellular oxidative reaction to yield its aminochrome, isoprenochrome. However, other studies have provided evidence for adrenomedullin dose-dependently elevating cAMP levels and the lipolytic rate ${ }^{(221)}$. In this case, adrenomedullin was shown to increase the phosphorylation of PKA, ERK and Akt and would reportedly exhibit additive effects on isoproterenol-induced lipolysis.

Apelin represents a further peptide with vasoactive characteristics that has been subsequently shown to be secreted by adipocytes of both humans and rodents, being up-regulated in states of obesity ${ }^{(222)}$. The identification in adipocytes of apelin and the apelin receptor (APJ), a G-protein-coupled receptor, supported a plausible autocrine participation of this peptide in adipobiology. In this line, apelin was shown to dose-dependently stimulate AMPK phosphorylation in human adipose tissue, which was associated with increased glucose uptake ${ }^{(223)}$. Apelin reportedly decreased isoproterenol-induced NEFA and glycerol release in 3T3-L1 cells and isolated adipocytes abrogating the catecholamine-induced HSL phosphorylation via G-protein $\mathrm{q}$ polypeptide $\left(G_{q}\right), G_{i}$ pathways and AMPK activation ${ }^{(224)}$. The apelin-induced inhibition of basal lipolysis was exerted through AMPK-dependent enhancement of perilipin expression by preventing lipid droplet fragmentation and hormone-stimulated acute lipolysis inhibition mediated by decreasing perilipin phosphorylation ${ }^{(225)}$. Moreover, apelin also suppressed adipogenesis through MAP kinase kinase/ ERK signalling.
Pigment epithelium-derived factor (PEDF) is a $50-\mathrm{kDa}$ protein of the non-inhibitory serpin family of serine protease inhibitors originally identified as a regulator of hepatic TAG metabolism involved in the development of insulin resistance in obesity ${ }^{(6,226,227)}$. Subsequently it was tested whether this adipocyte-secreted factor also exhibits autocrine-paracrine lipolytic effects. PEDF was shown to stimulate TAG hydrolysis in adipose tissue, muscle and liver via ATGL ${ }^{(228)}$. The exact mechanisms underlying the participation of PEDF in insulin resistance, obesity and non-alcoholic fatty liver disease still need to be fully elucidated $^{(229-231)}$. The potential role of other recently identified adipose-related factors on lipolysis such as serum amyloid A, osteopontin, osteocalcin, osteoprotegerin, obestatin, lipocalin 2, visfatin, nerve growth factor-inducible derived peptides, omentin, mammalian chitinase-like protein YKL40, chemerin, vitamin D and tenascin C, among others, beyond their originally reported effects merits to be specifically investigated ${ }^{(111,227,232-245)}$.

\section{Influence of subcellular compartmentalisation of lipases}

Multicellular organisms ranging from insects to mammals have evolved specialised systems to store surplus lipid energy for subsequent mobilisation in times of need. In mammals the storage and mobilisation of lipids are fundamental functions of adipocytes. About $80 \%$ of the total adipose tissue weight is due to the fat content, with over $90 \%$ of lipids being stored as TAG ${ }^{(246)}$. The major secretory products of adipose tissue are $\mathrm{NEFA}^{(247)}$, which are derived from the lipolysis of stored TAG in a process involving three main steps and requiring, at least, three different lipases, which are regulated by both adipocyte and nonadipocyte factors ${ }^{(7)}$. Thus, the classic lipolytic pathway encompasses the three following consecutive steps: (i) TAG hydrolysation by ATGL to generate fatty acids and diacylglyerol (DAG) ${ }^{(248)}$; (ii) subsequently, HSL catalyses the hydrolysis of DAG to monoacylglycerol (MAG) and fatty acids ${ }^{(249,250)}$; (iii) monoacylglycerol lipase (MGL) is required to complete the hydrolysis of MAG into one fatty acid and glycerol ${ }^{(251)}$. HSL and ATGL are quantitatively the most important lipases based on the blunted isoprenaline-induced lipolysis observed in adipocytes of Atgl- and $\mathrm{Hsl}$-knockout mice ${ }^{(248,252)}$.

TAG hydrolysis. Only a decade ago the initiation of TAG hydrolysis was thought to be exclusively controlled by HSL ${ }^{(2-7,253-255)}$. However, the generation of $H s l$-knockout mice revealed the existence of residual HSL-independent TAG lipase activity, pointing to the existence of previously unidentified adipose tissue lipases. Currently, ATGL is well recognised to be the lipase responsible for initiating TAG breakdown to yield DAG ${ }^{(5,6)}$. ATGL is a 54-kDa TAG hydrolase, also named phospholipase A2 $\xi$ or desnutrin, belonging to the family of patatin-like phospholipase domain-containing proteins (PNPLA) with specificity for TAG as a substrate ${ }^{(6,248,256,257)}$. Atgl-knockout mice and 
knockdown studies in adipocytes provided evidence for the involvement of ATGL in TAG but not DAG hydrolysis. Atgl-null mice exhibited a blunted lipolysis, producing a more than $75 \%$ reduction in NEFA release and a significant TAG accumulation in adipocytes leading to obesity ${ }^{(248,258)}$. The co-activator of ATGL, CGI-58, also known as $\alpha / \beta$ hydrolase domain-containing protein 5 (ABHD5), was shown to stimulate TAG hydrolase activity in wild-type and $H s l$-deficient but not $A t g l$-deficient mice. ATGL and HSL are responsible for $95 \%$ of TAG lipase activity, thereby suggesting a complementary relationship between the two lipases ${ }^{(257-259)}$.

ATGL is highly expressed in adipose tissue, with its expression being profoundly elevated during adipocyte differentiation. Two phosphorylation sites (Ser404 and Ser428) have been identified within the C-terminal region of ATGL. Furthermore, the enzymic activity and its interaction with CGI-58 are dependent on the C-terminal region ${ }^{(260)}$. Overexpression of $A t g l$ elevates TAG hydrolysis as well as basal and catecholamine-stimulated lipolysis, while Atgl silencing decreases TAG hydrolase activity, TAG storage and lipid droplet size ${ }^{(257)}$. Alterations of $\mathrm{Atgl}$ expression resulted in dramatic changes in whole-cell lipolysis. Conversely, silencing of $A \operatorname{tgl}$ or CGI- 58 significantly reduced basal lipolysis and essentially abolished forskolin-stimulated lipolysis. Taken together, these findings suggest that in humans the ATGL-CGI-58 complex acts independently of HSL and precedes its action in the sequential hydrolysis of TAG.

Fasting, glucocorticoids and PPAR agonists increase Atgl mRNA expression, whereas food intake and insulin decrease it ${ }^{(261,262)}$. Cellular TAG lipolysis by ATGL produces essential mediators involved in lipid ligand generation for PPAR activation, with Atgl deficiency in mice reducing mRNA levels of PPAR- $\alpha$ and PPAR- $\delta$ target genes ${ }^{(263)}$. While mammalian target of rapamycin (mTOR)-dependent signalling has been observed to decrease Atgl mRNA expression, FoxO1 activation by SIRT1-mediated deacetylation elevated it ${ }^{(262,264-266)}$. However, the role of AMPK in lipolysis control remains controversial $^{(267-271)}$. In this sense, the precise mechanisms of ATGL regulation need to be fully established. Recently, a protein encoded by the G0/G1 switch gene 2 (GOS2) has been identified as a selective regulator of ATGL by attenuating its action both in vitro and in vivo ${ }^{(272,273)}$. GOS2 is highly expressed in adipose tissue and differentiated adipocytes interacting specifically with ATGL to inhibit its TAG hydrolase activity. While knockdown of endogenous GOS2 enhances both basal and stimulated lipolysis in adipocytes, overexpression of GOS2 decreases the lipolytic rate of adipocytes and adipose tissue explants. GOS2 has been further shown to regulate human lipolysis influencing ATGL activity and intracellular localisation by anchoring the lipase to lipid droplets (Fig. 3) independently of the C-terminal lipid-binding domain of ATGL ${ }^{(273)}$. Moreover, GOS2 expression has been observed to be diminished in poorly controlled type 2 diabetes, thereby establishing a potential link between adipose tissue GOS2 downregulation and insulin resistance. Given that the abovementioned characteristics reveal ATGL as an attractive therapeutic target, the development and characterisation of a selective small-molecule inhibitor of ATGL, atglistatin, may prove of interest for the pharmacological treatment of dyslipidaemic and metabolic disorders ${ }^{(274)}$

Diacylglycerol hydrolysis. HSL, an 84-kDa cytoplasmic protein with demonstrated activity for a wide range of substrates including TAG, DAG, cholesteryl esters and retinyl esters, was presumed to be the rate-limiting enzyme in the initial steps of the lipolytic process. However, several important findings challenged this view of the unique regulatory and rate-limiting role of HSL on lipolysis, pointing to the existence of alternative lipases targeting TAG molecules to counterbalance the strong affinity of HSL for DAG ${ }^{(4,5,7,250,257,275)}$ : (i) PKA-dependent HSL phosphorylation led only to a 2- to 3-fold increase in TAG hydrolase activity, while whole-cell lipolysis resulted in a 100-fold increase; (ii) $H s l$-null mice exhibited a normal body weight with decreased adiposity; (iii) these mutants further showed DAG adipocyte accumulation; (iv) the existence of residual TAG hydrolase activity and lipolysis despite HSL silencing or specific pharmacological inhibition; and (v) failure of HSL overexpression to promote whole-cell lipolysis. As mentioned previously, the identification of ATGL provided explanations for these findings $(250,254,276)$.

Fig. 3 illustrates ATGL and HSL regulation in basal and stimulated conditions. ATGL and HSL have the capacity to hydrolyse in vitro the first ester bond of TAG. ATGL exhibits 10-fold higher substrate specificity for TAG than DAG, selectively enabling the first step in TAG hydrolysis, leading to the formation of DAG and fatty acid. An important step in lipolysis activation comprises the translocation of HSL from a cytosolic compartment to the surface of the lipid droplet. Upon lipolytic stimulation, HSL moves from the cytosol to the surface of lipid droplets where it interacts with perilipin-1 and neutral lipids. Noteworthy, adipocytes lacking perilipin-1 are incapable of translocating HSL to the lipid droplet after increases in CAMP $^{(277,278)}$. Perilipin-1 operates as a dynamic scaffold to coordinate the access of enzymes to the lipid droplet in a way that is responsive to the metabolic state of the adipocyte $^{(279,280)}$. Thus, in basal conditions (Fig. 3(a)) perilipin-1 limits lipase access to the lipid droplet ${ }^{(281)}$. Lipolysis stimulation is followed by HSL translocation from the cytosol to lipid droplets and redistribution of ATGL, resulting in enriched colocalisation of the two lipases. Interestingly, the ATGL-CGI-58 complex acts independently of HSL and precedes its action in the sequential hydrolysis of TAG in humans. The increased number of ATGL-CGI-58 complexes formed following perilipin-1 phosphorylation (which releases CCI-58) and docked on small lipid droplets govern PKA-stimulated lipolysis (Fig. 3(b)). The association 
(a)

Cell membrane

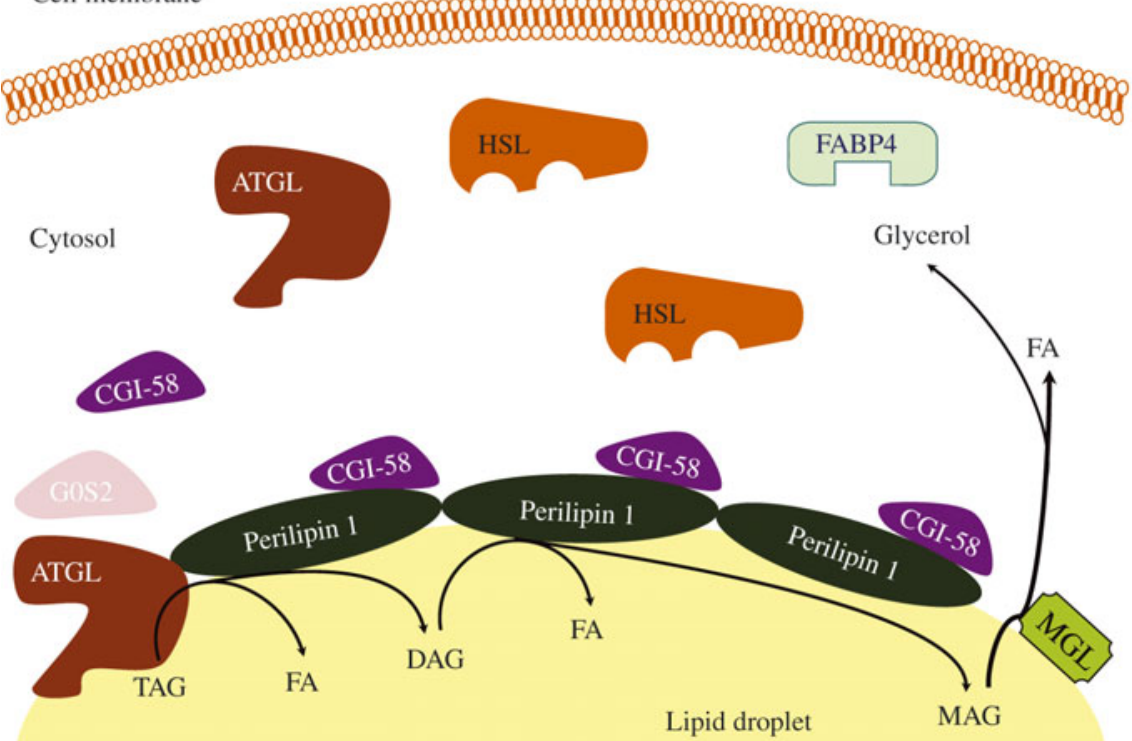

(b) $\quad$ B-Adrenergic receptor Stimulated lipolysis

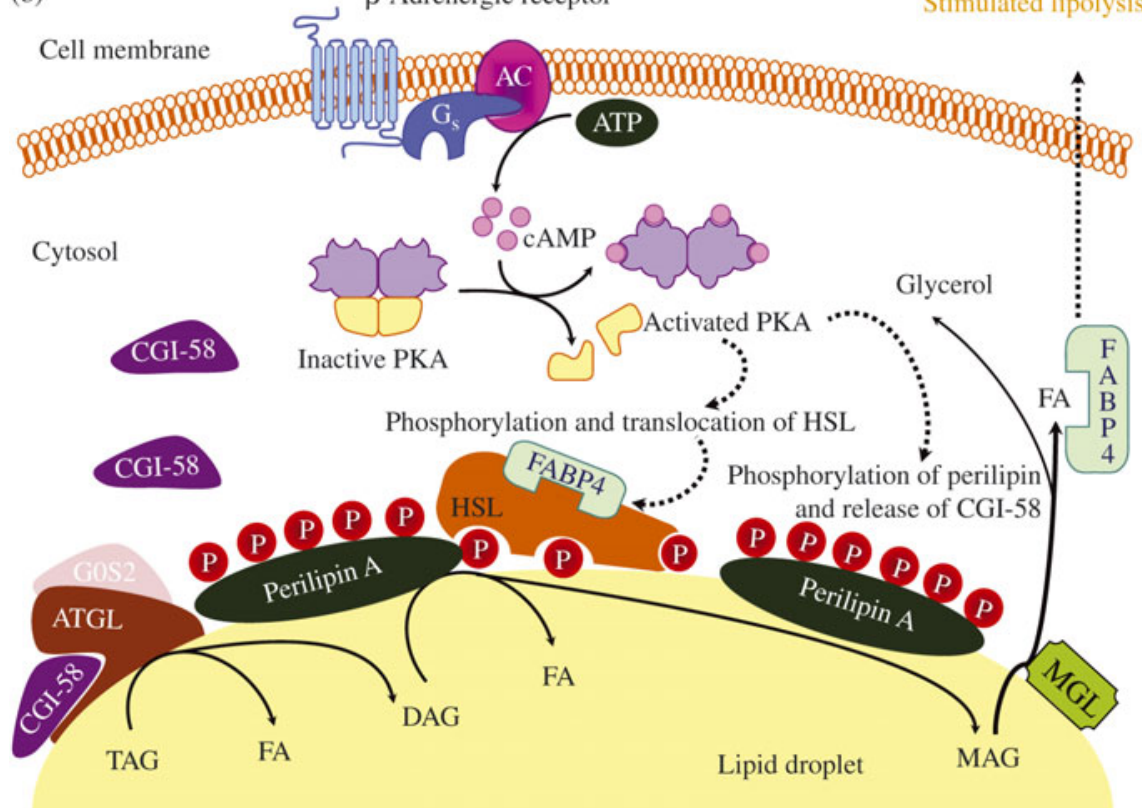

Fig. 3. Schematic representation of basal (a) and stimulated (b) lipolysis, the catabolic pathway by which TAG are hydrolysed into fatty acids (FA). AC, adenylyl cyclase; ATGL, adipocyte TAG lipase; CAMP, cyclic AMP; CGI-58, comparative gene identification-58; DAG, diacylglycerol; FABP4, fatty acid binding protein 4; G0S2, G0/G1 switch gene 2; $\mathrm{G}_{\mathrm{s}}$, stimulatory GTP-binding proteins; HSL, hormone-sensitive lipase; MAG, monoacylglycerol; MGL, monoacylglycerol lipase; $\mathrm{P}$, phosphate; PKA, protein kinase A. (A colour version of this figure can be found online at http://www.journals.cambridge.org/nrr)

between fatty acid binding protein 4 (FABP4) and HSL represents a further regulatory step. Fatty acid binding to FABP4 and HSL phosphorylation precede the association of FABP 4 and HSL. FABP4 also participates in the trafficking of fatty acids from the site of hydrolysis (i.e. the lipid droplet) to the plasma membrane. In addition to supporting fatty acid trafficking to the plasma membrane in a reaction that is independent of its physical association with HSL, FABP4 bound to fatty acids associates with activated, phosphorylated HSL on the surface of lipid droplets. The sequential effect of ATGL-accentuated TAG hydrolysis, phosphorylated HSL and MGL activity yields massive increases in NEFA release in response to PKA activation.

The expression profile of HSL basically mirrors that of ATGL, given that both enzymes coordinatedly hydrolyse TAG and, therefore, share some regulatory characteristics but differ in the mechanisms of enzyme control ${ }^{(6)}$. Whereas 
$\beta$-adrenergic stimulation exerts ATGL regulation mainly via CGI-58 recruitment, HSL constitutes the main target for PKA-catalysed phosphorylation ${ }^{(282)}$. Adipocyte HSL encompasses an N-terminal domain (that interacts with FABP4) and a C-terminal catalytic domain (that contains the active site as well as a regulatory module with all the known phosphorylation sites of HSL) ${ }^{(4,255,283)}$. Phosphorylation of HSL at Ser563, Ser659 and Ser660 by PKA and at Ser660 via the ERK pathway activate lipolysis ${ }^{(284)}$. The PKA-dependent lipolytic effect is exerted increasing HSL's intrinsic activity and promoting its access to TAG molecules within the adipocyte. Conversely, AMPK exerts an antilipolytic effect, blocking the translocation of HSL to the lipid droplets by its phosphorylation at Ser $565^{(261)}$. Deactivation of lipolysis mediated by insulin is associated with down-regulation of HSL and ATGL expression ${ }^{(285,286)}$. Moreover, insulin signalling phosphorylates and activates PDE isoforms via PKB, cAMP hydrolysis and PKA inhibition, resulting in the prevention of HSL and perilipin-1 phosphorylation, HSL activation and translocation as well as CGI-58-mediated ATGL activation. The peripheral control of insulin is accompanied by a central mechanism via the sympathetic nervous system that reduces the activitiy of both HSL and ATGL ${ }^{(287)}$.

Monoacylglycerol hydrolysis. The final step of lipolysis is catalysed by MGL, which is constitutively expressed in adipose tissue and has no affinity for DAG, TAG or cholesteryl esters ${ }^{(255)}$. The enzymic activity of MGL is required in the final hydrolysis of the 2-monoacylglycerols produced by HSL activation. Site-directed mutagenesis has shown the relevance of Ser122, Asp239 and His269 in the lipase and esterase activities of $\mathrm{MGL}^{255,288)}$

Other lipases. The contribution of alternative lipases to ATGL and HSL to the overall lipolytic capacity and maintenance of the highly dynamic TAG turnover has yet to be completely discerned. Potential TAG hydrolases have been identified within members of the carboxylesterase/ lipase and the patatin homology domain families ${ }^{(6)}$. Carboxylesterase-3/TAG hydrolase-1 is supposedly involved in HSL-independent lipolysis in adipocytes and participates in the assembly and secretion of VLDL in the liver (289,290). Among the patatin homology domain family, PNPLA 4 and PNPLA5 have been observed to exhibit TAG hydrolase, DAG transacylase and retinylester hydrolase activity in vitro, which needs to be confirmed in vivo ${ }^{(291)}$. Noteworthy, the member with the highest ATGL homology is PNPLA3 or adiponutrin ${ }^{(292-295)}$.

Lipid droplet proteins. Cytoplasmic lipid droplets are organelles in which cells store neutral lipids for use as an energy source in times of need, but they also play important roles in the regulation of key metabolic processes, with excess accumulation of intracellular lipids being associated with obesity, type 2 diabetes and atherosclerosis. Fat droplets may constitute up to $95 \%$ of the total adipocyte volume, being mainly composed by TAG. Intracellular TAG storage droplets have emerged as extraordinarily dynamic organelles, with signalling events underlying lipid mobilisation by shuttling protein trafficking to a specialised subset of these droplets ${ }^{(15)}$. Thus, lipid droplet scaffold proteins are key elements in organising and directing the lipolytic signalling cascade ${ }^{(15,246)}$.

The function of lipid droplets is regulated by their coating proteins, collectively termed PAT proteins after perilipin, adipophilin/adipocyte differentiation-related protein (ADRP), and tail-interacting protein of $47 \mathrm{kDa}$ (TIP47 $^{(4,296,297)}$. Further members of the family are S3-12, oxidative tissue-enriched PAT protein (OXPAT), myocardial lipid droplet protein (MLDP) and lipid storage droplet protein 5 (LSDP5) ${ }^{(298,299)}$. The members of this family share varying levels of sequence similarity, lipid droplet association and functions in stabilising lipid droplets.

Lipid droplet proteins: perilipin. Lipid droplets in most tissues are coated by two or more members of the perilipin family, which are now numbered according to the order of discovery ${ }^{(291)}$. Expression of perilipin-1 is mainly restricted to white and brown adipocytes and, to a lesser extent, steroidogenic cells of adrenal cortex, testes and ovaries. Perilipin-2 (formerly adipophilin or ADRP) and perilipin-3 (formerly TIP47) are ubiquitously expressed and, therefore, lipid droplet components of most tissues. While perilipin-4 (formerly S3-12) is primarily expressed in white adipocytes, perilipin-5 (formerly OXPAT, MLDP, or LSDP5) is expressed in brown adipocytes as well as myocytes of skeletal muscle and heart, all of which rely on lipolysis to provide fatty acids to mitochondria for $\beta$-oxidation to drive either ATP production or heat generation. Thus, the perilipin composition of lipid droplets within a specific tissue constitutes an important component of lipolysis regulation.

Perilipin is the best-known member of the PAT family, with perilipin-1 being the predominant isoform found in mature adipocytes, the most abundant protein on the lipid droplet surface and the major substrate for cAMPdependent PKA in lipolytically stimulated adipocytes ${ }^{(297,300-308)}$. Perilipin limits the access of cytosolic lipases to lipid droplets, thereby facilitating TAG storage under basal conditions (Fig. 3(a)). When energy is needed, perilipin is phosphorylated by PKA, facilitating maximal lipolysis by ATGL and HSL (Fig. 3(b)). Thus, perilipin expression and its phosphorylation state are key in lipolysis control, with phosphorylation of Ser 492 producing a lipid droplet remodelling, widely increasing the surface area for lipase binding, while Ser517 is essential for ATGL-dependent lipolysis in stimulated conditions ${ }^{(4)}$. Perilipin-1 is also phosphorylated by the cyclic GMPdependent PKG.

Perilipin ablation confers resistance to genetic or dietinduced obesity, producing a lean phenotype with smaller adipocytes, increased basal lipolysis and attenuated stimulated lipolysis ${ }^{(301)}$. Recently, perilipin-1 has been shown to move between the fat droplet and the endoplasmic reticulum ${ }^{(309)}$, which is physiologically reasonable given that 
lipid droplets are largely derived from the endoplasmic reticulum. In this regard, perilipin-mediated lipid droplet formation in adipocytes was demonstrated to promote sterol regulatory element-binding protein-1 (SREBP-1) processing and TAG accumulation, suggesting an interplay between lipid droplet formation and SREBP-1 activation via a positive feedback loop ${ }^{(310)}$. Therefore, the lysosomal protein degradation machinery of perilipin may constitute a target mechanism for enhancing adipocyte lipolysis. Interestingly, a genome-wide RNA interference (RNAi) screen in Drosophila S2 cells highlighted the relevance of elements of the vesicle-transport systems in lipolysis regulation through the identification of the vesicle-mediated coat protein complex I (COPI) as an evolutionary-conserved regulator of PAT protein composition at the lipid droplet surface ${ }^{(311,312)}$. In addition to regulating PAT protein composition, COPI promotes the association of ATGL with the lipid droplet surface to mediate lipolysis. These genes are conserved in mammalian cells, thus suggesting that a similar complex might be operative in adipocytes. Although COPI-mediated transport reportedly participates in delivery of ATGL to the lipid droplet surface, depletion of $\beta$-COP (a subunit of the COPI coat complex) does not affect association of ATGL with lipid droplets or ATGLmediated lipolysis, pointing to the possibility of alternative transport mechanisms implicated in the regulation of lipid homeostasis ${ }^{(313)}$

Lipid droplet proteins: coactivator comparative gene identification-58 (CGI-58) or $\alpha / \beta$-hydrolase domaincontaining protein 5 (ABHD5). CGI-58 lacks lipase activity in itself but potently and selectively stimulates lipolysis by activating ATGL. As mentioned above, in basal unstimulated conditions CGI-58 binds tightly to lipid droplets by interacting with perilipin-1 and is unable to activate $\mathrm{ATGL}^{(4)}$. However, following $\beta$-adrenoceptor stimulation CGI-58 is quickly dispersed to the cytosol, favouring ATGL co-localisation and migration to small lipid droplets. Thus, under stimulated conditions, the intracellular cAMP elevation and PKA activation promote perilipin-1 phosphorylation, which is followed by the dissociation from perilipin of CGI-58, which subsequently interacts with ATGL and activates TAG hydrolysis (Fig. 3(b)). In addition to ATGL activation, a further physiological function for CGI-58 in phospholipid synthesis with lysophosphatidic acid acyltransferase activity has been observed ${ }^{(4)}$.

Lipid droplet proteins: Cide domain-containing proteins. A further family of lipid droplet-associated proteins encompasses the cell death-inducing DFFA (DNA fragmentation factor- $\alpha$ )-like effectors (Cide), which includes three members (Cidea, Cideb and Cidec/Fsp27) with tissue-specific expression $^{(5)}$. In spite of Cidea and Cideb not being expressed in white adipose tissue, their deletion yielded rodents with lower body weight and improved insulin sensitivity as well as resistant to diet-induced obesity ${ }^{(314,315)}$. In the Cidea knockout model the elevated energy expenditure was attributable to brown adipose tissue via enhanced
AMPK activity leading to increased fatty acid oxidation (316) The Cideb mutants exhibited a decreased hepatic VLDL secretion and de novo fatty acid oxidation related to enhanced hepatic oxidative activity ${ }^{(317,318)}$. Cidea is also involved in human adipocyte lipolysis, TAG deposition and fatty acid oxidation via cross-talk with TNF- $\alpha$, which inhibits the transcription of the gene ${ }^{(319-321)}$. Cidea co-localises with perilipin around lipid droplets in fat cells. An increased lipolysis is observed in Cidea-depleted human adipocytes. Contrarily, ectopical expression of Cidea in preadipocytes markedly enhances lipid droplet size, promoting lipid accumulation ${ }^{(322)}$. Noteworthy, Cidea expression is elevated in human cancer cachexia, exhibiting a correlation with elevated NEFA concentrations and weight loss ${ }^{(323)}$. In humans Cidec, also referred to as fat-specific protein 27 , FSP27, is predominantly expressed in subcutaneous adipocytes, being down-regulated in response to a reduced energy intake ${ }^{(324)}$. Small interfering RNA-mediated knockdown of Cidec translated into an increased basal release of NEFA, and decreased responsiveness to adrenergic lipolysis stimulation ${ }^{(4,325)}$. The interaction between the diverse lipases is also starting to be unfolded. FSP27 and perilipin-1 interaction promotes the formation of large lipid droplets in human adipocytes $^{(326-329)}$. Recently, the unilocular to multilocular transformation that takes place during 'browning' of white adipose tissue has been related to Cide-triggered dynamic changes in lipid droplet-associated proteins ${ }^{(330)}$.

Lipid droplet proteins: other proteins (GPIHBP1 and Rab). Glycosylphosphatidylinositol-anchored HDL-binding protein (GPIHBP1) is a $28-\mathrm{kDa}$ glycosylphosphatidylinositol-anchored glycoprotein located on the luminal surface of endothelial cells in tissues where lipolysis takes place such as adipose tissue, skeletal muscle and heart $^{(7,331)}$. The expression of GPIHBP1 in mice is modulated by fasting and refeeding as well as by PPAR- $\gamma$ agonists. GPIHBP1 knockout mice exhibit chylomicronaemia, even on a low-fat diet, with highly elevated plasma TAG concentrations ${ }^{(332-334)}$. GPIHBP1 is highly expressed in the same tissues that express high levels of LPL, namely, heart, adipose tissue, and skeletal muscle where it binds both LPL and chylomicrons, suggesting that GPIHBP1 functions as a platform for LPL-dependent lipolytic processing of TAG-rich lipoproteins, stabilising LPL without activating it.

Rab GTPases, which are key regulators of membrane trafficking, have emerged as particularly relevant molecules in the highly dynamic cellular interactions involved in lipid mobilisation. In this sense, proteomic analyses have consistently identified the small GTPase Rab18 as a component of the lipid droplet coat ${ }^{(335)}$. Thus, Rab18 provides an excellent marker to follow the dynamics of lipid droplets in living cells as well as to gain insight into the complex regulatory mechanisms involved in lipid storage and release $^{(336-338)}$. In 3T3-L1 adipocytes, stimulation of lipolysis increases the association of Rab18 with lipid droplets, 
suggesting that Rab18 recruitment is regulated by the metabolic state of individual lipid droplets. Furthermore, Rab1a and its effector protein are reportedly involved in the CD36 trafficking signalling pathway ${ }^{(259)}$.

Integral membrane proteins and transporters. While the main signalling cascades and regulators of lipolysis have been identified, the cellular interactions involved in lipid mobilisation and release still remain to be completely disentangled. Except in adipocytes, lipid droplets are normally small, mobile and interact with other cellular compartments in cells. On the contrary, fat cells are composed mainly of very large, immotile lipid droplets. The striking morphological differences between lipid droplets in adipocytes and non-adipocytes suggest that key differences must exist in the way in which lipid droplets in different cell types interact with other organelles to facilitate lipid transfer. A plethora of molecules involved in these interactions are now emerging, with integral membrane proteins and fatty acid transporters standing out as pivotal elements operating at the dynamic plasma membrane-lipid droplet interface.

Integral membrane proteins and transporters: aquaporin-7. Aquaporins (AQP) are integral membrane proteins that function mainly as water channels. AQP7 belongs to the subfamily of aquaglyceroporins, which are permeable to both glycerol and water, being expressed in adipocytes ${ }^{(339-341)}$. Mouse and human AQP7 exhibit six prospective sites for PKA phosphorylation, suggesting a putative cAMP/PKA-dependent regulation. Aqp7-knockout mice show defective glycerol exit from fat cells, adipocyte hypertrophy due to TAG accumulation and moderate adult-onset obesity ${ }^{(342,343)}$. Short-term regulation and translocation of AQP7 to the plasma membrane is stimulated by catecholamines, while insulin exerts a long-term negative control. More recently, in addition to AQP7, the presence and functionality of other members of the aquaglyceroporin subfamily, AQP3 and AQP9, have been identified in adipose tissue and shown to be regulated by insulin and leptin via the PI3K/Akt/mTOR signalling cascade ${ }^{(344)}$.

Integral membrane proteins and transporters: caveolin-1. Caveolae account for over $25 \%$ of the adipocyte's membrane, being specialised plasma membrane microdomain invaginations involved in important cellular transport processes such as endo- and transcytosis as well as signal transduction $^{(345)}$. Three classes of caveolae formed by caveolin-1, the scaffolding hairpin-like protein facing the cytosol, have been identified, with high-density caveolae taking up exogenous fatty acids and converting them to TAG. These TAG-metabolising caveolae serve as a platform for FABP4, fatty acid transport protein (FATP) 1 and 4 (FATP1 and FATP4), long-chain acyl-CoA synthetase 1 (ACSL1) and CD36 (also known as fatty acid translocase). Noteworthy, these caveolae contain FATP1 and FATP4 together with the enzymes needed for TAG synthesis ${ }^{(346-348)}$. Furthermore, HSL and perilipin have been shown to be associated to these caveolae ${ }^{(349)}$, demostrating that TAG can be hydrolysed in them (Fig. 4). Caveolin-1 exerts an indirect structural role in caveolae formation, controlling surface availability or stability of CD36, a fatty acid transporter key to long-chain fatty acid uptake ${ }^{(350)}$. In response to NEFA, caveolin-1 reportedly translocates from the plasma membrane to lipid droplets. Caveolin-1 knockout mice lack caveolae in adipocyte plasma membranes, exhibiting increased circulating NEFA and TAG, reduced adipocyte lipid droplet size and resistance to diet-induced obesity ${ }^{(351)}$. Experiments with caveolin-1null mouse embryonic fibroblasts indicate that caveolin-1 deficiency is followed by a total loss of caveolae, absence of CD36 plasma membrane expression and a reduction in fatty acid uptake, which is reverted by re-expression of caveolin-1 ${ }^{(352)}$. Interestingly, caveolin-1 has been shown to exert inhibitory interactions with various proteins such as PKA, endothelial NOS and insulin receptors, with knockout mice exhibiting an attenuated lipolytic activity and decreased perilipin phosphorylation ${ }^{(349)}$. Caveolin-1 potently inhibits cAMP-dependent signalling in vivo, with a direct interaction between caveolin-1 and the catalytic subunit of PKA having been demonstrated both in vitro and in vivo.

Integral membrane proteins and transporters: fatty acid translocase (CD36). As mentioned above, CD36 localises to caveolae as well as to intracellular vesicles. CD36 is a glycoprotein belonging to the family of class B scavenger receptors predicted to have two transmembrane domains at the $\mathrm{N}$ - and C-terminal, a large extracellular domain loop and two short intracellular cytoplasmic tails ${ }^{(259)}$. CD36 is expressed in organs with high fatty acid metabolism rates, such as adipose tissue, operating as a NEFA scavenger. Insulin activation of the forkhead transcription factor and AMPK stimulation trigger CD36 translocation from intracellular stores to the plasma membrane, thereby enhancing NEFA uptake. CD36 deficiency is associated with increased basal lipolysis and responsiveness to the anti-lipolytic effect of insulin, with Cd36-null mice exhibiting an impaired fatty acid uptake in metabolic tissues (including adipocytes) and increased plasma NEFA and TAG concentrations ${ }^{(353,354)}$. Knockdown of CD36 by RNAi in 3T3-L1 adipocytes resulted in a profound reduction of both basal and insulin-stimulated NEFA uptake. Conversely, overexpression of CD36 led to mice with decreased adiposity and low circulating levels of NEFA, TAG and cholesterol, suggesting that a strict control of these molecules for an effective lipolysis is required.

Integral membrane proteins and transporters: adipose fatty acid binding protein. FABP4, also known as ALBP and aP2, is a cytosolic lipid-binding protein highly expressed in adipocytes involved in fatty acid and retinoic acid intracellular trafficking ${ }^{(259)}$. It acts as a molecular chaperone, facilitating NEFA uptake and lipolysis, interacting with HSL and shuttling fatty acids out of adipocytes (Fig. 4). Upon PKA activation the HSL-FABP4 complex translocates to lipid droplets. Consistently with this, in Fabp4-knockout mice basal and stimulated lipolysis are 


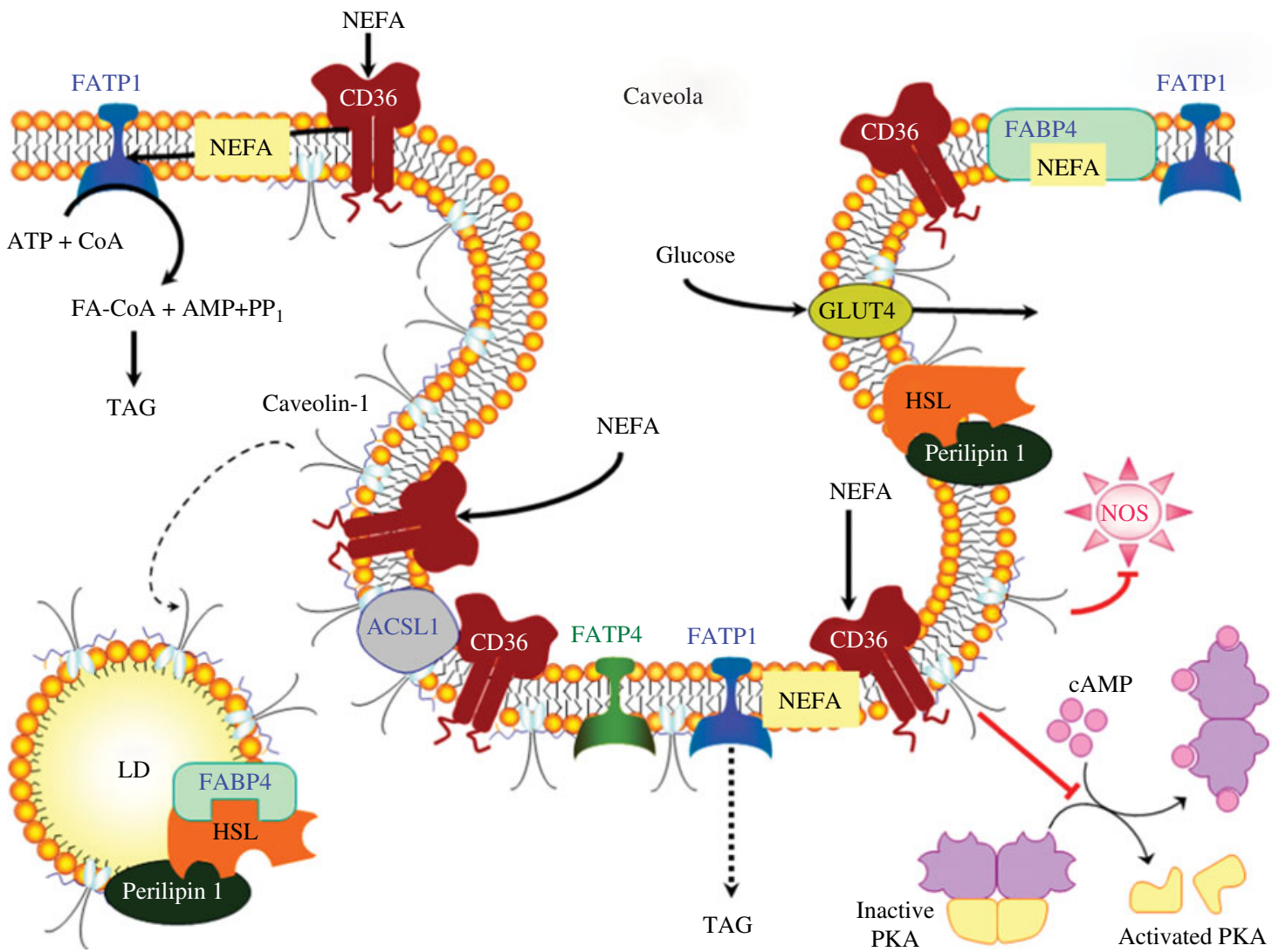

Fig. 4. Schematic diagram of a caveola present in the adipocyte's membrane and its participation in lipolysis. ACSL1, acyl coenzyme A synthetase 1; cAMP, cyclic AMP; CD36, fatty acid translocase; FA, fatty acid; FABP, fatty acid binding protein; FATP, fatty acid transport protein; HSL, hormone-sensitive lipase; LD, lipid droplet; NOS, NO synthase; PKA, protein kinase A; $\mathrm{PP}_{1}$, pyrophosphate. (A colour version of this figure can be found online at http://www.journals.cambridge.org/nrr)

attenuated $^{(291,355-357)}$. Interestingly, Fabp4-null mice have been shown to compensate FABP 4 deletion by increasing the expression of other FABP, thereby highlighting that lipolysis seems to be linked to total FABP content rather than to a specific FABP type ${ }^{(4)}$.

Integral membrane proteins and transporters: fatty acid transport protein 1. The underlying mechanism for fatty acid uptake by FATP1, an integral membrane protein of about $71 \mathrm{kDa}$ with a hydrophobic domain at the N-terminal that may be membrane-anchored and other membraneassociated domains peripherally associated with the inner leaflet of the membrane, is still unknown. In response to insulin, FATP1 may translocate to structurally disordered non-lipid raft regions of the plasma membrane. Subsequently, FATP1 may extract fatty acid from the inner membrane leaflet and esterify it to CoA, thereby preventing its efflux and driving a NEFA concentration gradient across the membrane ${ }^{(358,359)}$. Most of the incoming fatty acids are converted into acyl-CoA and preferentially shunted into TAG synthesis (Fig. 4). Noteworthy, the conversion of incoming long-chain fatty acids to TAG takes place on or around the plasma membrane in rat adipocytes, plausibly linking in a mechanistic way fatty acid influx to TAG synthesis ${ }^{(259,360)}$. Knockdown and knockout experiments revealed an absolute requirement for FATP1 in insulin-stimulated fatty acid uptake, whereas FATP1 overexpression led to a fatty acid uptake increase.

Integral membrane proteins and transporters: fatty acid transport protein 4 . FATP 4 presents a $60 \%$ identity to FATP1 and is expressed in adipose tissue, skin, heart, skeletal muscle, liver, as well as in the small intestine, where it was observed to work in intestinal lipid absorption ${ }^{(259,361)}$. FATP4 knockdown in 3T3-L1 adipocytes by RNAi did not affect basal and insulin-stimulated fatty acid uptake. FATP4 knockouts exhibit perinatal lethality due to restrictive dermopathy, suggesting a key role in the formation of the epidermal barrier rather than in fatty acid uptake and intestinal lipid absorption.

Integral membrane proteins and transporters: acyl-CoA synthetase long-chain 1. ACSL1, a 78-kDa membrane protein expressed in adipocytes and localised to various subcellular sites including the plasma membrane, lipid droplets, and GLUT4-containing vesicles, co-localises with FATP1 ${ }^{(259)}$. ACSL1 was found to be involved in the reacylation of fatty acids released from the lipid droplets during basal and hormone-induced lipolysis ${ }^{(359)}$. Overexpression of ACSL1 in fibroblasts is followed by an increase in NEFA uptake, thereby supporting a co-operative role in fatty acid transport across the adipocyte plasma membrane ${ }^{(362)}$. However, knockdown of ACSL1 expression 
by RNAi in 3T3-L1 adipocytes points to a role in fatty acid efflux but not influx.

\section{Depot-specific differences}

The main anatomical fat depots in humans include intraabdominal (greater and lesser omental and mesenteric depots, also known as visceral fat), lower-body (gluteal, subcutaneous leg and intramuscular fat) and upper-body subcutaneous fat ${ }^{(363,364)}$. Subcutaneous adipose tissue constitutes the largest site for fat storage (about $80 \%$ of total body fat), while under normal circumstances visceral adipose tissue accounts for a small fraction of body fat (about $20 \%$ in men, and $5-8 \%$ in women) ${ }^{(365)}$. Regional differences, including preadipocyte replication and differentiation, adipocyte size, blood supply, gene expression, basal metabolic activities and hormonal responsiveness, contribute to regional fat distribution ${ }^{(363-366)}$. Increased NEFA availability, resulting from increased effective adipose tissue lipolysis, plausibly undelies some of the visceral obesity-associated metabolic alterations ${ }^{(367,368)}$. Owing to its anatomical distribution, NEFA released from visceral fat are drained directly to the liver through the portal vein, whereas venous drainage of NEFA from subcutaneous adipose tissue is through systemic veins ${ }^{(369)}$. The venous drainage of fat via the portal system directly provides
NEFA as substrates for hepatic lipoprotein metabolism or glucose production. Excess NEFA favours the onset of dyslipidaemia, hyperinsulinaemia and insulin resistance by reducing hepatic degradation of apoB and insulin as well as by increasing VLDL production ${ }^{(4)}$.

Table 1 summarises regional variations in adipocyte lipolysis leading to increased NEFA release from visceral as compared with subcutaneous fat during hormone stimulation. Visceral adipocytes show the highest lipolytic responsiveness to catecholamines due to an increased function of the lipolytic $\beta_{1^{-}}, \beta_{2^{-}}$and $\beta_{3^{-}}$adrenoceptors $^{(370,371)}$. On the other hand, as mentioned above, several mechanisms have been linked to the weak lipolytic response to catecholamines in subcutaneous adipocytes, such as enhanced anti-lipolytic $\alpha_{2}$-adrenoceptor activity, decreased lipolytic $\beta_{2}$-adrenoceptor responsiveness as well as reduced expression or function of HSL, FABP 4 or perilipin ${ }^{(363,370)}$.

The anti-lipolytic effect of insulin is more prominent in subcutaneous adipocytes compared with visceral fat cells $^{(370,372)}$. Regional differences involve insulin receptor affinity, which is partly caused by variations in the insulin dissociation rate, but also by reduced insulin receptor phosphorylation and signal transduction via the IRS-1/PI3K pathway ${ }^{(370,372,373)}$. Testosterone has been reported to show both stimulatory ${ }^{(374)}$ (i.e. up-regulation

Table 1. Depot-specific differences of diverse factors regulating adipocyte lipolysis

\begin{tabular}{|c|c|c|c|}
\hline Regulatory factor & Activity & Main fat depot target & Reference \\
\hline \multicolumn{4}{|l|}{ Catecholamines } \\
\hline$\beta_{1}$-Adrenoreceptor & Lipolytic & Visceral adipose tissue & 370 \\
\hline$\beta_{2}$-Adrenoreceptor & Lipolytic & Visceral adipose tissue & 370 \\
\hline$\beta_{3}$-Adrenoreceptor & Lipolytic & Visceral adipose tissue & 370 \\
\hline $\begin{array}{l}\alpha_{2} \text {-Adrenoreceptor } \\
\text { Insulin }\end{array}$ & Anti-lipolytic & Subcutaneous fat & 370 \\
\hline Insulin receptor & Anti-lipolytic & Subcutaneous fat & 370 \\
\hline $\begin{array}{l}\text { Growth hormone receptor } \\
\text { Ghrelin/obestatin }\end{array}$ & Lipolytic & Unknown & 431 \\
\hline $\begin{array}{l}\text { Growth hormone secretagogue receptor } \\
\text { Testosterone }\end{array}$ & Anti-lipolytic & Visceral and subcutaneous fat & 432,433 \\
\hline $\begin{array}{l}\text { Androgen receptors } \\
\text { Oestrogens }\end{array}$ & Anti-lipolytic & Subcutaneous fat & 75 \\
\hline $\begin{array}{l}\text { Oestrogen receptor- } \alpha \\
\text { Endothelin }\end{array}$ & Anti-lipolytic & Subcutaneous fat & 375 \\
\hline Endothelin receptor $\mathrm{A}$ & Lipolytic & Unknown & 217 \\
\hline $\begin{array}{l}\text { Endothelin receptor B } \\
\text { TNF- } \alpha\end{array}$ & Lipolytic & Visceral adipose tissue & 216 \\
\hline $\begin{array}{l}\text { TNF receptor } 1 \\
\text { IL-6 }\end{array}$ & Lipolytic & Unknown & 434 \\
\hline $\begin{array}{l}\text { IL-6 receptor and glycoprotein } 130 \\
\text { Lipopolysaccharide }\end{array}$ & Lipolytic & Visceral adipose tissue & 131,435 \\
\hline $\begin{array}{l}\text { Toll-like receptor } 4 \\
\text { Leptin }\end{array}$ & Lipolytic & Unknown & 436 \\
\hline $\begin{array}{l}\text { Leptin receptor: OB-R } \\
\text { Adiponectin }\end{array}$ & Lipolytic & Subcutaneous fat & 376 \\
\hline Full-length adiponectin & Anti-lipolytic & Subcutaneous fat & 164 \\
\hline Globular adiponectin & Anti-lipolytic & Visceral and subcutaneous fat & 164 \\
\hline $\begin{array}{l}\text { Trimeric adiponectin } \\
\text { Natriuretic peptides }\end{array}$ & Anti-lipolytic & Visceral and subcutaneous fat & 164 \\
\hline Atrial natriuretic peptide & Lipolytic & Visceral and subcutaneous fat & 378 \\
\hline Brain natriuretic peptide & Lipolytic & Unknown & 377 \\
\hline C-type natriuretic peptide & Lipolytic & Unknown & 377 \\
\hline
\end{tabular}


of $\beta_{2}$-adrenoreceptors in visceral fat cells) and inhibitory $^{(75)}$ (i.e. down-regulation of $\beta_{2}$-adrenoceptors and HSL in subcutaneous adipocytes) effects on cathecolamine-induced lipolytic activity. Oestrogen attenuates the lipolytic response through up-regulation of a number of anti-lipolytic $\alpha_{2}$-adrenergic receptors ${ }^{(375)}$.

Leptin and adiponectin, the most abundant adipocytesecreted factors, show opposite actions on lipolysis regulation $^{(12)}$. Leptin produces a significantly greater stimulation of lipolysis in subcutaneous fat cells compared with omental adipocytes ${ }^{(376)}$. Adiponectin has recently emerged as an anti-lipolytic factor on binding adiponectin receptor type 1 and 2 (AdipoR1 and AdipoR2). Full-length adiponectin exerts an anti-lipolytic action in subcutaneous adipose tissue in non-obese subjects, while exhibiting no effect on visceral fat ${ }^{(163,164)}$. Atrial (ANP), brain (BNP) and C-type (CNP) natiruretic peptides also induce lipolysis in human abdominal adipocytes, with the potency order of the lipolytic effect being ANP $>\mathrm{BNP}>\mathrm{CNP}^{(377)}$. ANP-induced lipolysis is not subjected to primary regional regulation in differentiated human subcutaneous and visceral fat cells ${ }^{(378)}$. Fat-depot differences in the lipolytic effect of BNP and CNP remain to be established.

In addition to the physiological depot-specific differences in the neuroendocrine control of adipose tissue, it is important to consider the role of body fat distribution in the development of cardiometabolic alterations ${ }^{(363-366)}$. Adipose tissue distribution varies with sex, age, genetic background, nervous and endocrine factors, nutritional and pharmacological influences as well as disease state, which impinge on preadipocyte replication and differentiation, developmental gene expression, vascularity, inflammation, adipokine secretion and apoptosis. The excess visceral fat observed in obesity is closely linked with metabolic and cardiovascular co-morbidities, whereas increased subcutaneous fat may even exert protective effects. However, how interdepot differences in the molecular, cellular, histological and pathophysiological properties translate into co-morbidity development needs to be fully unravelled ${ }^{(379-381)}$.

\section{Lipophagy: role of autophagy in lipid metabolism}

Autophagy is a self-digestive process that entails the formation of double-membrane vesicles, termed autophagosomes, that sequester and target cytoplasmic cargo for lysosomal degradation ${ }^{(382-384)}$. In addition to quality control, autophagy also regulates lipid metabolism by degrading lipid droplets via lipophagy (Fig. 5). Small lipid droplets can be completely taken up by an autophagosome, or alternatively portions of large lipid droplets can be degraded ${ }^{(382)}$. Depletion of nutrients during starvation activates a second important cellular energy sensor, AMPK, that further activates unc51-like kinase 1 (ULK1) phosphorylation. Active ULK1 induces autophagy via the phosphorylation of beclin-1, a protein that recruits regulatory proteins to the VPS34 complex (class III PI3K), which is essential for the activity of the phagophore ${ }^{(385)}$. During the vesicle elongation process, ATG7 induces the conjugation of ATG12 to ATG5 as well as the conjugation of cytosolic light chain 3 (LC3)-I to phosphatidylethanolamine to generate LC3-II, one of the best-characterised components of autophagosomes. Once formed, autophagosomes engulf lipid droplets and eventually fuse with a hydrolase-containing lysosome, the lipases of which degrade lipids ${ }^{(382)}$. This process generates fatty acids that are released into the cytoplasm and can be oxidised in the mitochondria to generate ATP to maintain energy homeostasis. Under basal fed conditions, nutrients (particularly amino acids) or insulin and growth factors trigger the activity of class I PI3K that, in turn, activates mTOR, the best-characterised negative regulator of autophagy, and blocks autophagosome formation $^{(386,387)}$ (Fig. 5). As a result, lipid breakdown by autophagy is minimal in the fed state.

Autophagy also participates in adipocyte differentiation regulation ${ }^{(388)}$. Transgenic animals lacking the autophagyrelated proteins ATG5 and ATG7 show a reduction in adipose mass, supporting that autophagy is essential for normal adipogenesis ${ }^{(389,390)}$. Analogously, Atg5 and Atg 7 knockdown in 3T3-L1 adipocytes decrease intracellular lipid content and gene expression levels of the key adipogenic transcription factors, CCAAT/enhancer-binding protein $\alpha$ and $\beta(\mathrm{C} / \mathrm{EBP} \alpha$ and $\beta)$ and PPAR- $\gamma^{(389)}$. White adipocytes of Atg 7-deficient mice acquire some characteristics of brown adipocytes, such as higher mitochondrial content, multilocular lipid droplets and increased levels of the brown adipogenic factors PPAR- $\gamma$-coactivator $1 \alpha$ (PGC-1 $\alpha$ ) and uncoupling protein-1 (UCP-1), triggering adipose tissue fatty acid $\beta$-oxidation ${ }^{(390)}$. Interestingly, loss of Atg 7 disrupts brown fat differentiation and promotes the 'beige' (brown adipocyte-like) cell development in inguinal adipose tissue, thereby contributing to increased energy expenditure ${ }^{(391,392)}$

Human adipose tissue contains autophagosomes and obesity is associated with an altered expression of the autophagy-related molecules LC3-I, LC3-II, beclin-1, ATG5 and ATG $7^{(200,393,394)}$. Markers of autophagy are correlated with whole-body adiposity, visceral fat distribution and adipocyte hypertrophy. However, the altered expression of autophagy in human obesity appears to be related to the degree of insulin resistance, rather than to excess adiposity ${ }^{(200)}$. In this sense, insulin constitutes a major inhibitor of autophagy, with insulin resistance being a potential activator of this process, since patients with type 2 diabetes show elevated formation of autophagosomes in subcutaneous adipose tissue ${ }^{(395)}$. Adipocyte autophagy is also regulated by TNF- $\alpha$ and ghrelin, showing opposite effects on the regulation of fat storage in human adipocytes ${ }^{(200)}$. TNF- $\alpha$ plays an important role in the pathophysiology of deranged lipid metabolism through both the suppression of LPL activity and enhancement of lipolysis in human fat cells ${ }^{(396)}$. In addition, TNF- $\alpha$ also triggers autophagy by increasing the transcript levels of BECN1 


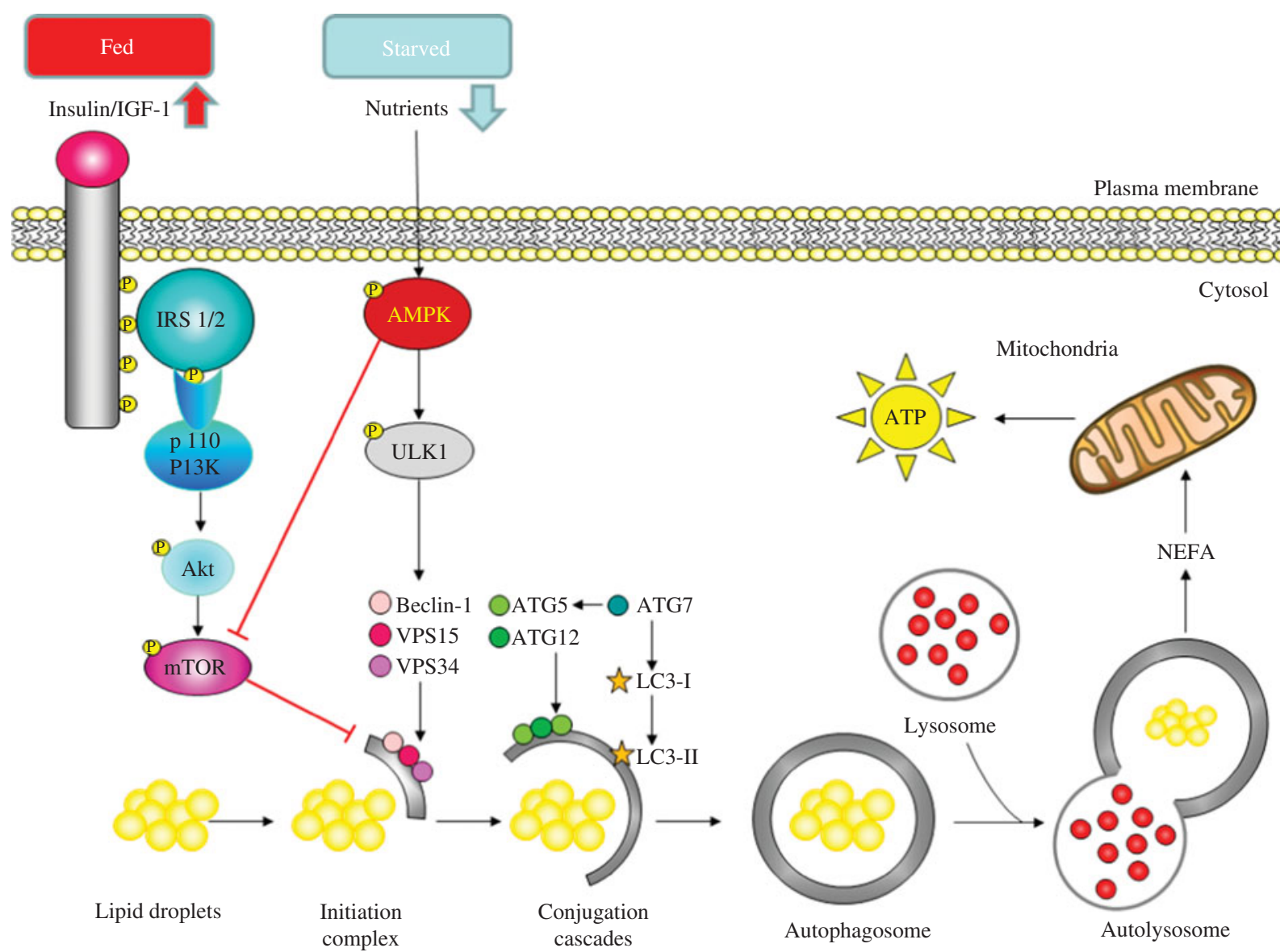

Fig. 5. Regulation of lipophagy. AMPK, AMP-activated protein kinase; Akt, protein kinase B; ATG, autophagy-related gene; IGF-1, insulin growth factor-1; IRS 1/2, insulin receptor substrate 1/2; LC3, light chain 3; mTOR, mammalian target of rapamycin; P, phosphate; PI3K, phospatidylinositol-3 kinase; ULK1, unc51-like kinase 1; VPS15, phosphoinositide-3-kinase, regulatory subunit 4; VPS34, class III phosphatidylinositol 3-kinase. (A colour version of this figure can be found online at http://www.journals.cambridge.org/nrr)

(beclin 1), required for the formation of the autophagosome initiation complex, as well as those of $A T G 5$, and $A T G 7$, the autophagy proteins involved in the conjugation cascades for autophagosome elongation in human adipocytes ${ }^{(200)}$. On the other hand, ghrelin is a gut-derived hormone that promotes adiposity through orexigenic and adipogenic actions $^{(199,397)}$. Ghrelin isoforms (acylated and desacyl ghrelin) stimulate the expression of several fat storage-related proteins such as acetyl-CoA carboxylase, fatty acid synthase, LPL or perilipin through central mechanims ${ }^{(397)}$ and directly acting on human adipocytes ${ }^{(199)}$, thereby stimulating intracellular lipid accumulation. Besides its lipogenic action, acylated ghrelin reduces basal $A T G 5$ and $A T G 7$, while desacyl ghrelin inhibits TNF- $\alpha$-induced expression of $A T G 5$, $A T G 7$ and BECN1. Taken together, ghrelin constitutes a negative regulator of basal and TNF- $\alpha$-induced autophagy in human visceral adipocytes ${ }^{(200)}$.

Novel fascinating findings in the field of adipocyte apoptosis have been recently reported ${ }^{(398,399)}$. White adipose tissue inflammation, a characteristic feature of obesity, results from the death of hypertrophic adipocytes that are subsequently cleared by macrophages, giving rise to crown-like structures (CLS). It has been recently shown that infiltrating macrophages actively take up remnant lipids of dead adipocytes ${ }^{(398)}$. Upon induction of adipocyte apoptosis, inflammatory cells infiltrate adipose tissue initially consisting of neutrophils followed by macrophages that are involved in CLS formation. Moreover, subcutaneous and visceral hypertrophic adipocytes obtained from obese mice exhibit ultrastructural abnormalities (cholesterol crystals and $\mathrm{Ca}$ accumulation), being more common in the hyperglycaemic $d b / d b v$. normoglycaemic $o b / o b$ mice and in the visceral $v$. subcutaneous depots. Data indicate that white adipocyte overexpansion induces a stress state that ultimately leads to death with NOD-like receptor family, pyrin domain containing 3 (NLRP3)dependent caspase-1 activation in hypertrophic adipocytes probably inducing obese adipocyte death by pyroptosis, a proinflammatory programmed cell death ${ }^{(399)}$.

\section{Lipolysis in human obesity}

Obesity is characterised by a marked secretion of proinflammatory adipokines, including $\mathrm{TNF}-\alpha$, and a profound decrease in adiponectin synthesis ${ }^{(234)}$. The increased TNF- $\alpha$ production in adipose tissue triggers MAP kinase 
activity in adipocytes, thus altering the action of perilipin and leading to an enhanced basal lipolytic rate ${ }^{(2,400)}$. Otherwise, adiponectin inhibits basal and cathecolamineinduced lipolysis in non-obese subjects, but this effect is lost in obesity ${ }^{(161)}$. The isoform-specific ability to prevent lipolysis is modified in obesity. While full-length adiponectin exerts an anti-lipolytic action in subcutaneous fat, without effect on visceral fat, in non-obese individuals, the lower adiponectin isoforms (globular and trimeric) become important actors in obesity, showing anti-lipolytic activity in obese subcutaneous and visceral adipose tissue, respectively $^{(164)}$.

Circulating NEFA and glycerol concentrations are elevated in obesity, suggesting an increase in overall lipolysis during fasting ${ }^{(34)}$. Several impairments in the control of lipolysis have been reported in obese individuals, including an altered responsiveness to catecholamines ${ }^{(2,4,53)}$. Obese subjects show a lower lipolytic effect of catecholamines in subcutaneous adipose tissue through decreased action of lipolytic $\beta_{2}$-adrenergic receptors and increased activity of the anti-lipolytic $\alpha_{2}$-adrenergic adrenoceptors ${ }^{(370,401)}$. In this regard, a blunted lipolytic response has been shown in abdominal subcutaneous adipose tissue of obese individuals during intravenous infusion of the non-selective $\beta$-agonist isoprenaline ${ }^{(402)}$. On the other hand, catecholamine-induced lipolysis is markedly increased in visceral fat due to increased activity of $\beta_{3}$-adrenergic receptors and decreased activity of $\alpha_{2}$-adrenoceptors ${ }^{(370,401)}$. In subjects with upper-body obesity these regional variations in the action of catecholamines on lipolysis are further enhanced ${ }^{(368,370)}$. These abnormalities in catecholamine function promote the release of NEFA from the visceral adipocytes through the portal system and might cause several of the metabolic complications of upper-body obesity. In addition, several polymorphisms in genes encoding $\beta_{1^{-}}(A D R B 1), \beta_{2^{-}}(A D R B 2)$ and $\beta_{3^{-}}(A D R B 3)$ adrenergic receptors have been associated with altered cathecolamineinduced adipocyte lipolysis and with obesity ${ }^{(403,404)}$. The polymorphisms in the ADRB2 gene are highly frequent in obesity and associated with altered $\beta_{2}$-adrenergic function (Arg16Gly and Gln27Glu) and catecholamine-induced lipolysis in subcutaneous fat cells (Arg16Gly and Thr164Ile) ${ }^{(42,405,406)}$. However, the ADRB1 (Ser49Gly and Arg389Gly) ${ }^{(404,407,408)}$ and ADRB3 (Trp64Arg) ${ }^{(409-411)}$ polymorphisms do not appear to be major determinants of $\beta_{1^{-}}$and $\beta_{3}$-adrenergic function for lipolysis or the pathophysiology of obesity.

It is not clear whether the anti-lipolytic effect of insulin is affected in obesity, since the altered catecholamine concentrations found in the obese state counteract the effect of insulin ${ }^{(2)}$. Consequently, normal, decreased and increased anti-lipolytic effects of insulin have been reported in obese patients ${ }^{(4)}$. Insulin sensitivity of adipose tissue lipolysis is normal or slightly impaired in the adipose tissue of obese individuals ${ }^{(4,412)}$. Modifications of other anti-lipolytic factors may also be altered in obesity.
The pathological enlargement of fat cells in obesity compromises angiogenesis and increases the formation of hypoxic areas that promote the apoptosis of adipocytes and induce the fibrotic and inflammatory programme ${ }^{(87)}$. Apoptotic adipocytes are surrounded by M1-stage macrophages that form CLS in the adipose tissue. This process is accompanied by a chronic inflammation due to the secretion by adipose tissue-embedded immune cells and the dysfunctional adipocytes of proinflammatory cytokines and acute-phase reactants, such as TNF- $\alpha$, C-reactive protein, IL-6, IL-8, leptin, serum amyloid A (SAA) and monocyte chemotactic protein (MCP)-1 ${ }^{(232,234)}$. As detailed in the Cytokines and other 'newcomers' section, the increase in proinflammatory adipokines, such as TNF- $\alpha$ or leptin, might be responsible for the high basal rate of lipolysis in obese patients.

Obesity is associated with a decreased expression and activity of HSL, but not ATGL, in visceral and subcutaneous adipocytes of obese individuals independently of age and sex, which may play an important role in the defective lipid mobilisation observed in obesity ${ }^{(413-415)}$. Furthermore, a decreased access of lipases to TAG due to alterations in lipid droplet-associated proteins cannot be ruled out ${ }^{(416-419)}$. In humans CGI-58 mutations have been identified in patients with Chanarin-Dorfman syndrome, a disorder characterised by the accumulation of abnormally large amounts of lipid droplets in several organs ${ }^{(420,421)}$. In these cases CGI-58 cannot be recruited to lipid droplets and fails to interact with perilipin, which may affect basal and PKA-stimulated lipolysis. Interestingly, CGI-58 gene silencing importantly reduces basal lipolysis by approximately $50 \%$ but also completely abrogates PKA-stimulated lipolysis in a human white adipocyte model ${ }^{(255,422)}$. The exact and complex dynamics involving CGI-58, the diverse perilipins and ATGL in basal as well as PKA-stimulated lipolysis has yet to be completely unravelled.

Finally, changes in the molecules involved in lipolysisderived metabolites, fatty acids and glycerol also contribute to lipolytic derangements in obesity. Several proteins like FABP, CD36 or FATP facilitate fatty acid transport across the membrane in adipocytes ${ }^{(423)}$. The transport of the other lipolysis-derived metabolite, glycerol, from adipocytes in response to the lipolytic stimuli is facilitated by AQP3 and AQP7 via their translocation from the cytosolic fraction (AQP3) or lipid droplets (AQP7) to the plasma membrane ${ }^{(341,344,424,425)}$. AQP7 expression is decreased in subcutaneous adipose tissue of obese subjects, resulting in an increase in intracellular glycerol accumulation, which is converted to glycerol-3-phosphate by the glycerol kinase enzyme and re-esterified into TAG, thereby promoting adipocyte hypertrophy ${ }^{(344,426)}$. On the other hand, the increased AQP3 and AQP7 expression in visceral fat in obese subjects suggests an overall increase in the lipolytic activity in this fat depot in obesity $(344,426,427)$ 


\section{Concluding remarks and future perspectives}

While adipose tissue elicited scarce interest for many decades $^{(428)}$, the identification in 1994 of leptin as an adiposederived hormone ${ }^{(429)}$ started a new era in adipobiology that recognises adipocytes as important dynamic endocrine cells. Essential lipolytic enzymes and a plethora of regulatory proteins and mechanisms have fundamentally changed our view of lipolysis and its impact, not only on adipose tissue but also more broadly on cellular metabolism ${ }^{(430)}$. Although the importance of lipolysis has been recognised for decades, many of the key proteins involved have been uncovered only recently. In this line, to further decipher the participation of lipolytic products and intermediates in many non-adipose tissues will be especially relevant to unravel previously underappreciated aspects of lipolysis and their relation to disease development. The regulation of lipolysis by numerous, and to some extent still incompletely identified, factors embodies the 'lipolysome', a complex metabolic network involved in ultimately controlling lipid mobilisation and fat storage. Information derived from the reactome linking the genome and metabolome via genome-sequence independent functional analysis of metabolic phenotypes and networks will be particularly fascinating. With the advent of systems biology a better integration of knowledge can be further expected to provide a more profound view of the true contribution of adipose tissue to health and disease.

\section{Acknowledgements}

The authors gratefully acknowledge the funding of the Spanish Instituto de Salud Carlos III, Fondo de Investigación Sanitaria - FEDER (project numbers CIBERobn CB06/03/1014, FIS PI10/01677 and PI12/00515) from the Ministerio de Economía y Competitividad, as well as the Plan de Investigación de la Universidad de Navarra (project PIUNA 2011-13). None of the funders had a role in the design, analysis or writing of this article.

All authors contributed fundamentally to the present paper. G. F. conducted the main review of the literature and drafted the manuscript. A. R. and L. M.-G. contributed significantly to the further drafting of the manuscript. All authors (G. F., L. M.-G., J. A. F.-F., S. F. and A. R.) made a critical review of the draft, provided input on data interpretation as well as commented on and approved the final manuscript.

The authors declare no conflicts of interest.

\section{References}

1. Frayn KN (2002) Adipose tissue as a buffer for daily lipid flux. Diabetologia 45, 1201-1210.

2. Arner P (2005) Human fat cell lipolysis: biochemistry, regulation and clinical role. Best Pract Res Clin Endocrinol Metab 19, 471-482.

3. Duncan RE, Ahmadian M, Jaworski K, et al. (2007) Regulation of lipolysis in adipocytes. Annu Rev Nutr 27, 79-101.
4. Lafontan M \& Langin D (2009) Lipolysis and lipid mobilization in human adipose tissue. Prog Lipid Res 48, 275-297.

5. Girousse A \& Langin D (2012) Adipocyte lipases and lipid droplet-associated proteins: insight from transgenic mouse models. Int J Obes (Lond) 36, 581-594.

6. Zechner R, Zimmermann R, Eichmann TO, et al. (2012) Fat signals - lipases and lipolysis in lipid metabolism and signaling. Cell Metab 15, 279-291.

7. Young SG \& Zechner R (2013) Biochemistry and pathophysiology of intravascular and intracellular lipolysis. Genes Dev 27, 459-484.

8. Guilherme A, Virbasius JV, Puri V, et al. (2008) Adipocyte dysfunctions linking obesity to insulin resistance and type 2 diabetes. Nat Rev Mol Cell Biol 9, 367-377.

9. Girousse A, Tavernier G, Valle C, et al. (2013) Partial inhibition of adipose tissue lipolysis improves glucose metabolism and insulin sensitivity without alteration of fat mass. PLoS Biol 11, e1001485.

10. Virtue S \& Vidal-Puig A (2010) Adipose tissue expandability, lipotoxicity and the metabolic syndrome - an allostatic perspective. Biochim Biophys Acta 1801, 338-349.

11. Unger RH, Clark GO, Scherer PE, et al. (2010) Lipid homeostasis, lipotoxicity and the metabolic syndrome. Biochim Biophys Acta 1801, 209-214.

12. Unger RH, Scherer PE \& Holland WL (2013) Dichotomous roles of leptin and adiponectin as enforcers against lipotoxicity during feast and famine. Mol Biol Cell 24, 3011-3015.

13. Gross DN, Miyoshi H, Hosaka T, et al. (2006) Dynamics of lipid droplet-associated proteins during hormonally stimulated lipolysis in engineered adipocytes: stabilization and lipid droplet binding of adipocyte differentiation-related protein/adipophilin. Mol Endocrinol 20, 459-466.

14. Ducharme NA \& Bickel PE (2008) Lipid droplets in lipogenesis and lipolysis. Endocrinology 149, 942-949.

15. Greenberg AS, Coleman RA, Kraemer FB, et al. (2011) The role of lipid droplets in metabolic disease in rodents and humans. J Clin Invest 121, 2102-2110.

16. Hashimoto T, Segawa H, Okuno M, et al. (2012) Active involvement of micro-lipid droplets and lipid-dropletassociated proteins in hormone-stimulated lipolysis in adipocytes. J Cell Sci 125, 6127-6136.

17. Walther TC \& Farese RV Jr (2012) Lipid droplets and cellular lipid metabolism. Annu Rev Biochem 81, 687-714.

18. Langin D, Lucas S \& Lafontan M (2000) Millennium fat-cell lipolysis reveals unsuspected novel tracks. Horm Metab Res 32, 443-452.

19. Frühbeck G \& Gómez-Ambrosi J (2003) Control of body weight: a physiologic and transgenic perspective. Diabetologia 46, 143-172.

20. Bousquet-Melou A, Galitzky J, Lafontan M, et al. (1995) Control of lipolysis in intra-abdominal fat cells of nonhuman primates: comparison with humans. J Lipid Res 36, 451-461.

21. Langin D, Portillo MP, Saulnier Blache JS, et al. (1991) Coexistence of three $\beta$-adrenoceptor subtypes in white fat cells of various mammalian species. Eur J Pharmacol 199, 291-301.

22. Blaak EE (2000) Adrenergically stimulated fat utilization and ageing. Ann Med 32, 380-382.

23. Imbeault P, Prud'Homme D, Tremblay A, et al. (2000) Adipose tissue metabolism in young and middle-aged men after control for total body fatness. J Clin Endocrinol Metab 85, 2455-2462.

24. Toth MJ \& Tchernof A (2000) Lipid metabolism in the elderly. Eur J Clin Nutr 54, Suppl. 3, S121-S125. 
25. Herrera E (2002) Lipid metabolism in pregnancy and its consequences in the fetus and newborn. Endocrine 19, $43-55$.

26. Blaak E (2001) Gender differences in fat metabolism. Curr Opin Clin Nutr Metab Care 4, 499-502.

27. Lange KH (2004) Fat metabolism in exercise - with special reference to training and growth hormone administration. Scand J Med Sci Sports 14, 74-99.

28. Mauriege P, Prud'Homme D, Marcotte M, et al. (1997) Regional differences in adipose tissue metabolism between sedentary and endurance-trained women. Am J Physiol 273, E497-E506.

29. Stich V, de Glisezinski I, Galitzky J, et al. (1999) Endurance training increases the $\beta$-adrenergic lipolytic response in subcutaneous adipose tissue in obese subjects. Int $J$ Obes Relat Metab Disord 23, 374-381.

30. De Glisezinski I, Crampes F, Harant I, et al. (1998) Endurance training changes in lipolytic responsiveness of obese adipose tissue. Am J Physiol 275, E951-E956.

31. De Glisezinski I, Marion-Latard F, Crampes F, et al. (2001) Lack of $\alpha_{2}$-adrenergic antilipolytic effect during exercise in subcutaneous adipose tissue of trained men. $J$ Appl Physiol 91, 1760-1765.

32. Westerterp-Plantenga MS, Lejeune MP \& Kovacs EM (2005) Body weight loss and weight maintenance in relation to habitual caffeine intake and green tea supplementation. Obes Res 13, 1195-1204.

33. Murosaki S, Lee TR, Muroyama K, et al. (2007) A combination of caffeine, arginine, soy isoflavones, and 1-carnitine enhances both lipolysis and fatty acid oxidation in 3T3-L1 and HepG2 cells in vitro and in KK mice in vivo. J Nutr 137, 2252-2257.

34. McCarty MF \& Thomas CA (2003) PTH excess may promote weight gain by impeding catecholamine-induced lipolysis implications for the impact of calcium, vitamin $\mathrm{D}$, and alcohol on body weight. Med Hypotheses 61, 535-542.

35. Shi H, Dirienzo D \& Zemel MB (2001) Effects of dietary calcium on adipocyte lipid metabolism and body weight regulation in energy-restricted aP2-agouti transgenic mice. FASEB J 15, 291-293.

36. Zemel MB, Thompson W, Milstead A, et al. (2004) Calcium and dairy acceleration of weight and fat loss during energy restriction in obese adults. Obes Res 12, 582-590.

37. Xue B, Greenberg AG, Kraemer FB, et al. (2001) Mechanism of intracellular calcium $\left(\left[\mathrm{Ca}^{2+}\right] \mathrm{i}\right)$ inhibition of lipolysis in human adipocytes. FASEB J 15, 2527-2529.

38. Major GC, Chaput JP, Ledoux M, et al. (2008) Recent developments in calcium-related obesity research. Obes Rev 9, 428-445.

39. Kang L \& Nagy LE (2006) Chronic ethanol feeding suppresses $\beta$-adrenergic receptor-stimulated lipolysis in adipocytes isolated from epididymal fat. Endocrinology 147, 4330-4338.

40. Arner P (2001) Genetic variance and lipolysis regulation: implications for obesity. Ann Med 33, 542-546.

41. Umekawa T, Yoshida T, Sakane N, et al. (1999) Trp64Arg mutation of $\beta_{3}$-adrenoceptor gene deteriorates lipolysis induced by $\beta_{3}$-adrenoceptor agonist in human omental adipocytes. Diabetes $\mathbf{4 8}, 117-120$.

42. Large V, Hellstrom L, Reynisdottir S, et al. (1997) Human $\beta-2$ adrenoceptor gene polymorphisms are highly frequent in obesity and associate with altered adipocyte $\beta$-2 adrenoceptor function. J Clin Invest 100, 3005-3013.

43. Klannemark M, Orho M, Langin D, et al. (1998) The putative role of the hormone-sensitive lipase gene in the pathogenesis of type II diabetes mellitus and abdominal obesity. Diabetologia 41, 1516-1522.
44. Magre J, Laurell H, Fizames C, et al. (1998) Human hormone-sensitive lipase: genetic mapping, identification of a new dinucleotide repeat, and association with obesity and NIDDM. Diabetes 47, 284-286.

45. Arner P (1999) Catecholamine-induced lipolysis in obesity. Int J Obes Relat Metab Disord 23, Suppl. 1, 10-13.

46. Dodt C, Lonnroth P, Fehm HL, et al. (1999) Intraneural stimulation elicits an increase in subcutaneous interstitial glycerol levels in humans. J Physiol 521, 545-552.

47. Dodt C, Lonnroth P, Wellhoner JP, et al. (2003) Sympathetic control of white adipose tissue in lean and obese humans. Acta Physiol Scand 177, 351-357.

48. Brito MN, Brito NA, Baro DJ, et al. (2007) Differential activation of the sympathetic innervation of adipose tissues by melanocortin receptor stimulation. Endocrinology $\mathbf{1 4 8}$, 5339-5347.

49. Bartness TJ \& Song CK (2007) Thematic review series: adipocyte biology. Sympathetic and sensory innervation of white adipose tissue. J Lipid Res 48, 1655-1672.

50. Kreier F, Fliers E, Voshol PJ, et al. (2002) Selective parasympathetic innervation of subcutaneous and intra-abdominal fat - functional implications. J Clin Invest 110, 1243-1250.

51. Bartness TJ (2002) Dual innervation of white adipose tissue: some evidence for parasympathetic nervous system involvement. J Clin Invest 110, 1235-1237.

52. Giordano A, Song CK, Bowers RR, et al. (2006) White adipose tissue lacks significant vagal innervation and immunohistochemical evidence of parasympathetic innervation. Am J Physiol Regul Integr Comp Physiol 291, R1243-R1255.

53. Jocken JW \& Blaak EE (2008) Catecholamine-induced lipolysis in adipose tissue and skeletal muscle in obesity. Physiol Behav 94, 219-230.

54. De Matteis R, Arch JR, Petroni ML, et al. (2002) Immunohistochemical identification of the $\beta_{3}$-adrenoceptor in intact human adipocytes and ventricular myocardium: effect of obesity and treatment with ephedrine and caffeine. Int $J$ Obes Relat Metab Disord 26, 1442-1450.

55. Buemann B, Toubro S \& Astrup A (2000) Effects of the two $\beta_{3}$-agonists, ZD7114 and ZD2079 on 24 hour energy expenditure and respiratory quotient in obese subjects. Int J Obes Relat Metab Disord 24, 1553-1560.

56. Redman LM, de Jonge L, Fang X, et al. (2007) Lack of an effect of a novel $\beta_{3}$-adrenoceptor agonist, TAK-677, on energy metabolism in obese individuals: a double-blind, placebo-controlled randomized study. J Clin Endocrinol Metab 92, 527-531.

57. Gómez-Ambrosi J, Frühbeck G, Aguado M, et al. (2001) Divergent effects of an $\alpha_{2}$-adrenergic antagonist on lipolysis and thermogenesis: interactions with a $\beta_{3}$-adrenergic agonist in rats. Int J Mol Med 8, 103-109.

58. Lafontan M \& Berlan M (1995) Fat cell $\alpha_{2}$-adrenoceptors: the regulation of fat cell function and lipolysis. Endocr Rev 16, 716-738.

59. Langin D (2006) Adipose tissue lipolysis as a metabolic pathway to define pharmacological strategies against obesity and the metabolic syndrome. Pharmacol Res 53, 482-491.

60. Frühbeck G, Becerril S, Sáinz N, et al. (2009) BAT: a new target for human obesity? Trends Pharmacol Sci 30, 387-396.

61. Frühbeck G, Sesma P \& Burrell MA (2009) PRDM16: the interconvertible adipo-myocyte switch. Trends Cell Biol 19, 141-146.

62. Lafontan M (2005) Fat cells: afferent and efferent messages define new approaches to treat obesity. Annu Rev Pharmacol Toxicol 45, 119-146.

63. Jaworski K, Sarkadi-Nagy E, Duncan RE, et al. (2007) Regulation of triglyceride metabolism. IV. Hormonal 
regulation of lipolysis in adipose tissue. Am J Physiol Gastrointest Liver Physiol 293, G1-G4.

64. Møller N \& Jørgensen JOL (2009) Effects of growth hormone on glucose, lipid, and protein metabolism in human subjects. Endocr Rev 30, 152-177.

65. Yip RG \& Goodman HM (1999) Growth hormone and dexamethasone stimulate lipolysis and activate adenylyl cyclase in rat adipocytes by selectively shifting $G_{\mathrm{i} \alpha 2}$ to lower density membrane fractions. Endocrinology 140, 1219-1227.

66. Gravholt CH, Schmitz O, Simonsen L, et al. (1999) Effects of a physiological GH pulse on interstitial glycerol in abdominal and femoral adipose tissue. Am J Physiol 277, E848-E854

67. Samra JS, Clark ML, Humphreys SM, et al. (1999) Suppression of the nocturnal rise in growth hormone reduces subsequent lipolysis in subcutaneous adipose tissue. Eur J Clin Invest 29, 1045-1052.

68. Sakharova AA, Horowitz JF, Surya S, et al. (2008) Role of growth hormone in regulating lipolysis, proteolysis, and hepatic glucose production during fasting. J Clin Endocrinol Metab 93, 2755-2759.

69. Nordstrom SM, Tran JL, Sos BC, et al. (2013) Disruption of JAK2 in adipocytes impairs lipolysis and improves fatty liver in mice with elevated GH. Mol Endocrinol 27, $1333-1342$.

70. Djurhuus CB, Gravholt CH, Nielsen S, et al. (2002) Effects of cortisol on lipolysis and regional interstitial glycerol levels in humans. Am $J$ Physiol Endocrinol Metab 283, E172-E177.

71. Samra JS, Clark ML, Humphreys SM, et al. (1998) Effects of physiological hypercortisolemia on the regulation of lipolysis in subcutaneous adipose tissue. J Clin Endocrinol Metab 83, 626-631.

72. Ottosson M, Lonnroth P, Björntorp P, et al. (2000) Effects of cortisol and growth hormone on lipolysis in human adipose tissue. J Clin Endocrinol Metab 85, 799-803.

73. Taniguchi A, Kataoka K, Kono T, et al. (1987) Parathyroid hormone-induced lipolysis in human adipose tissue. J Lipid Res 28, 490-494.

74. Xu XF, De Pergola G \& Bjorntorp P (1991) Testosterone increases lipolysis and the number of $\beta$-adrenoceptors in male rat adipocytes. Endocrinology 128, 379-382.

75. Dicker A, Ryden M, Naslund E, et al. (2004) Effect of testosterone on lipolysis in human pre-adipocytes from different fat depots. Diabetologia 47, 420-428.

76. Arner P (2005) Effects of testosterone on fat cell lipolysis. Species differences and possible role in polycystic ovarian syndrome. Biochimie 87, 39-43.

77. Zang H, Ryden M, Wahlen K, et al. (2007) Effects of testosterone and estrogen treatment on lipolysis signaling pathways in subcutaneous adipose tissue of postmenopausal women. Fertil Steril 88, 100-106.

78. Fan W, Yanase T, Nomura M, et al. (2005) Androgen receptor null male mice develop late-onset obesity caused by decreased energy expenditure and lipolytic activity but show normal insulin sensitivity with high adiponectin secretion. Diabetes 54, 1000-1008.

79. Blouin K, Nadeau M, Perreault M, et al. (2010) Effects of androgens on adipocyte differentiation and adipose tissue explant metabolism in men and women. Clin Endocrinol (Oxf) 72, 176-188.

80. Bertin E, Arner P, Bolinder $\mathrm{J}$, et al. (2001) Action of glucagon and glucagon-like peptide-1-(7-36) amide on lipolysis in human subcutaneous adipose tissue and skeletal muscle in vivo. J Clin Endocrinol Metab 86, 1229-1234.

81. Gravholt CH, Moller N, Jensen MD, et al. (2001) Physiological levels of glucagon do not influence lipolysis in abdominal adipose tissue as assessed by microdialysis. J Clin Endocrinol Metab 86, 2085-2089.

82. Sancho V, Trigo MV, Martin-Duce A, et al. (2006) Effect of GLP-1 on d-glucose transport, lipolysis and lipogenesis in adipocytes of obese subjects. Int J Mol Med 17, 1133-1137.

83. Vendrell J, El Bekay R, Peral B, et al. (2011) Study of the potential association of adipose tissue GLP-1 receptor with obesity and insulin resistance. Endocrinology 152, 4072-4079.

84. Frühbeck G, Gómez-Ambrosi J, Muruzábal FJ, et al. (2001) The adipocyte: a model for integration of endocrine and metabolic signaling in energy metabolism regulation. $\mathrm{Am}$ $J$ Physiol Endocrinol Metab 280, E827-E847.

85. Frühbeck G \& Gómez Ambrosi J (2001) Rationale for the existence of additional adipostatic hormones. FASEB J 15, 1996-2006.

86. Trayhurn P (2007) Adipocyte biology. Obes Rev 8, Suppl. 1, 41-44.

87. Sun K, Kusminski CM \& Scherer PE (2011) Adipose tissue remodeling and obesity. J Clin Invest 121, 2094-2101.

88. Fortuño A, Rodríguez A, Gómez-Ambrosi J, et al. (2003) Adipose tissue as an endocrine organ: role of leptin and adiponectin in the pathogenesis of cardiovascular diseases. $J$ Physiol Biochem 59, 51-60.

89. Frühbeck $G$ (2006) Hunting for new pieces to the complex puzzle of obesity. Proc Nutr Soc 65, 329-347.

90. Ahima RS \& Lazar MA (2008) Adipokines and the peripheral and neural control of energy balance. Mol Endocrinol 22, $1023-1031$.

91. Gómez-Ambrosi J, Rodríguez A, Catalán V, et al. (2008) The bone-adipose axis in obesity and weight loss. Obes Surg 18, 1134-1143.

92. Liu Y, Song CY, Wu SS, et al. (2013) Novel adipokines and bone metabolism. Int J Endocrinol 2013, 895045.

93. Trayhurn P (2013) Hypoxia and adipose tissue function and dysfunction in obesity. Physiol Rev 93, 1-21.

94. Hefetz-Sela S \& Scherer PE (2013) Adipocytes: impact on tumor growth and potential sites for therapeutic intervention. Pharmacol Ther 138, 197-210.

95. Gómez-Ambrosi J \& Frühbeck G (2001) Do resistin and resistin-like molecules also link obesity to inflammatory diseases? Ann Intern Med 135, 306-307.

96. Gómez-Ambrosi J, Salvador J, Páramo JA, et al. (2002) Involvement of leptin in the association between percentage of body fat and cardiovascular risk factors. Clin Biochem 35, 315-320.

97. Fortuño A, Rodríguez A, Gómez-Ambrosi J, et al. (2002) Leptin inhibits angiotensin II-induced intracellular calcium increase and vasoconstriction in the rat aorta. Endocrinology 143, 3555-3560.

98. Rodríguez A, Catalán V, Becerril S, et al. (2008) Impaired adiponectin-AMPK signalling in insulin-sensitive tissues of hypertensive rats. Life Sci $\mathbf{8 3}, 540-549$.

99. Poulain-Godefroy O, Lecoeur C, Pattou F, et al. (2008) Inflammation is associated with a decrease of lipogenic factors in omental fat in women. Am J Physiol Regul Integr Comp Physiol 295, R1-R7.

100. Muruzábal FJ, Frühbeck G, Gómez-Ambrosi J, et al. (2002) Immunocytochemical detection of leptin in non-mammalian vertebrate stomach. Gen Comp Endocrinol 128, 149-152.

101. Martín M, Burrell MA, Gómez-Ambrosi J, et al. (2012) Short- and long-term changes in gastric morphology and histopathology following sleeve gastrectomy in diet-induced obese rats. Obes Surg 22, 634-640.

102. Seeley RJ \& Tschöp MH (2011) Uroguanylin: how the gut got another satiety hormone. J Clin Invest 121, 3384-3386. 
103. Frühbeck G (2012) Gastrointestinal hormones: uroguanylin - a new gut-derived weapon against obesity? Nat Rev Endocrinol 8, 5-6.

104. Campo A, Frühbeck G, Zulueta JJ, et al. (2007) Hyperleptinaemia, respiratory drive and hypercapnic response in obese patients. Eur Respir J 30, 223-231.

105. Fernández-Real JM, Valdés S, Manco M, et al. (2010) Surfactant protein D, a marker of lung innate immunity, is positively associated with insulin sensitivity. Diabetes Care 33, $847-853$.

106. Weng M, Raher MJ, Leyton P, et al. (2011) Adiponectin decreases pulmonary arterial remodeling in murine models of pulmonary hypertension. Am J Respir Cell Mol Biol 45, 340-347.

107. Sáinz N, Rodríguez A, Catalán V, et al. (2010) Leptin administration downregulates the increased expression levels of genes related to oxidative stress and inflammation in the skeletal muscle of ob/ob mice. Mediators Inflamm 2010, 784343

108. Sáinz N, Rodríguez A, Catalán V, et al. (2012) Leptin reduces the expression and increases the phosphorylation of the negative regulators of GLUT4 traffic TBC1D1 and TBC1D4 in muscle of $o b / o b$ mice. PLOS ONE 7, e29389.

109. Taube A, Lambernd S, van Echten-Deckert G, et al. (2012) Adipokines promote lipotoxicity in human skeletal muscle cells. Arch Physiol Biochem 118, 92-101.

110. Sáinz N, Rodríguez A, Catalán V, et al. (2009) Leptin administration favors muscle mass accretion by decreasing FoxO $3 \mathrm{a}$ and increasing PGC- $1 \alpha$ in $o b / o b$ mice. PLOS ONE 4, e6808.

111. Gannagé-Yared MH, Yaghi C, Habre B, et al. (2008) Osteoprotegerin in relation to body weight, lipid parameters insulin sensitivity, adipocytokines, and C-reactive protein in obese and non-obese young individuals: results from both cross-sectional and interventional study. Eur J Endocrinol 158, 353-359.

112. Trayhurn P, Drevon CA \& Eckel J (2011) Secreted proteins from adipose tissue and skeletal muscle - adipokines, myokines and adipose/muscle cross-talk. Arch Physiol Biochem 117, 47-56.

113. Berg AH \& Scherer PE (2005) Adipose tissue, inflammation, and cardiovascular disease. Circ Res 96, 939-949.

114. Qatanani M \& Lazar MA (2007) Mechanisms of obesityassociated insulin resistance: many choices on the menu. Genes Dev 21, 1443-1455.

115. Arner P, Bernard S, Salehpour M, et al. (2011) Dynamics of human adipose lipid turnover in health and metabolic disease. Nature 478, 110-113.

116. Arner E, Rydén M \& Arner P (2010) Tumor necrosis factor $\alpha$ and regulation of adipose tissue. N Engl J Med 362, 1151-1153.

117. Langin D \& Arner P (2006) Importance of $\mathrm{TNF} \alpha$ and neutral lipases in human adipose tissue lipolysis. Trends Endocrinol Metab 17, 314-320.

118. Laurencikiene J, van Harmelen V, Arvidsson Nordström E, et al. (2007) NF- $\mathrm{KB}$ is important for TNF- $\alpha$-induced lipolysis in human adipocytes. J Lipid Res 48, 1069-1077.

119. Cawthorn WP \& Sethi JK (2008) TNF- $\alpha$ and adipocyte biology. FEBS Lett 582, 117-131.

120. Ryden M \& Arner P (2007) Tumour necrosis factor- $\alpha$ in human adipose tissue - from signalling mechanisms to clinical implications. J Intern Med 262, 431-438.

121. González-Yanes C \& Sánchez-Margalet V (2006) Signalling mechanisms regulating lipolysis. Cell Signal 18, 401-408.

122. Botion LM, Brasier AR, Tian B, et al. (2001) Inhibition of proteasome activity blocks the ability of TNF $\alpha$ to downregulate $\mathrm{G}_{\mathrm{i}}$ proteins and stimulate lipolysis. Endocrinology 142, 5069-5075.
123. Xu H \& Hotamisligil GS (2001) Signaling pathways utilized by tumor necrosis factor receptor 1 in adipocytes to suppress differentiation. FEBS Lett 506, 97-102.

124. Xu H, Hirosumi J, Uysal KT, et al. (2002) Exclusive action of transmembrane TNF $\alpha$ in adipose tissue leads to reduced adipose mass and local but not systemic insulin resistance. Endocrinology 143, 1502-1511.

125. Zhang HH, Halbleib M, Ahmad F, et al. (2002) Tumor necrosis factor- $\alpha$ stimulates lipolysis in differentiated human adipocytes through activation of extracellular signal-related kinase and elevation of intracellular cAMP. Diabetes 51, 2929-2935.

126. Souza SC, Palmer HJ, Kang YH, et al. (2003) TNF- $\alpha$ induction of lipolysis is mediated through activation of the extracellular signal related kinase pathway in 3T3-L1 adipocytes. J Cell Biochem 89, 1077-1086.

127. Jager J, Gremeaux T, Gonzalez T, et al. (2010) Tpl2 kinase is upregulated in adipose tissue in obesity and may mediate interleukin- $1 \beta$ and tumor necrosis factor- $\alpha$ effects on extracellular signal-regulated kinase activation and lipolysis. Diabetes 59, 61-70.

128. van Hall G, Steensberg A, Sacchetti M, et al. (2003) Interleukin-6 stimulates lipolysis and fat oxidation in humans. $J$ Clin Endocrinol Metab 88, 3005-3010.

129. Yang Y, Ju D, Zhang M, et al. (2008) Interleukin-6 stimulates lipolysis in porcine adipocytes. Endocrine 33, 261-269.

130. Jensen MD (2003) Cytokine regulation of lipolysis in humans? J Clin Endocrinol Metab 88, 3003-3004.

131. Morisset AS, Huot C, Legare D, et al. (2008) Circulating IL-6 concentrations and abdominal adipocyte isoproterenolstimulated lipolysis in women. Obesity (Silver Spring) 16, $1487-1492$.

132. Holmes AG, Watt MJ \& Febbraio MA (2004) Suppressing lipolysis increases interleukin-6 at rest and during prolonged moderate-intensity exercise in humans. $J$ Appl Physiol 97, 689-696.

133. Hiscock N, Fischer CP, Sacchetti M, et al. (2005) Recombinant human interleukin-6 infusion during low-intensity exercise does not enhance whole body lipolysis or fat oxidation in humans. Am J Physiol Endocrinol Metab 289, E2-E7.

134. Carbo N, Lopez-Soriano J, Costelli $\mathrm{P}$, et al. (2001) Interleukin-15 mediates reciprocal regulation of adipose and muscle mass: a potential role in body weight control. Biochim Biophys Acta 1526, 17-24.

135. Ajuwon KM \& Spurlock ME (2004) Direct regulation of lipolysis by interleukin-15 in primary pig adipocytes. Am J Physiol Regul Integr Comp Physiol 287, R608-R611.

136. Quinn LS, Strait-Bodey L, Anderson BG, et al. (2005) Interleukin-15 stimulates adiponectin secretion by 3T3-L1 adipocytes: evidence for a skeletal muscle-to-fat signaling pathway. Cell Biol Int 29, 449-457.

137. Frühbeck G, Jebb SA \& Prentice AM (1998) Leptin: physiology and pathophysiology. Clin Physiol 18, 399-419.

138. Frühbeck G (2002) Peripheral actions of leptin and its involvement in disease. Nutr Rev 60, S47-S55.

139. Frühbeck G (2001) A heliocentric view of leptin. Proc Nutr Soc 60, 301-318.

140. Frühbeck G, Aguado M \& Martínez JA (1997) In vitro lipolytic effect of leptin on mouse adipocytes: evidence for a possible autocrine/paracrine role of leptin. Biochem Biophys Res Commun 240, 590-594.

141. Frühbeck G, Aguado M, Gómez-Ambrosi J, et al. (1998) Lipolytic effect of in vivo leptin administration on adipocytes of lean and $o b / o b$ mice, but not $d b / d b$ mice. Biochem Biophys Res Commun 250, 99-102.

142. Wang MY, Lee Y \& Unger RH (1999) Novel form of lipolysis induced by leptin. J Biol Chem 274, 17541-17544. 
143. Frühbeck G, Gómez Ambrosi J \& Salvador J (2001) Leptininduced lipolysis opposes the tonic inhibition of endogenous adenosine in white adipocytes. FASEB J 15, 333-340.

144. Honnor RC, Dhillon GS \& Londos C (1985) cAMPdependent protein kinase and lipolysis in rat adipocytes. I. Cell preparation, manipulation, and predictability in behavior. J Biol Chem 260, 15122-15129.

145. Honnor RC, Dhillon GS \& Londos C (1985) cAMPdependent protein kinase and lipolysis in rat adipocytes. II. Definition of steady-state relationship with lipolytic and antilipolytic modulators. J Biol Chem 260, 15130-15138.

146. Rice AM, Fain JN \& Rivkees SA (2000) A1 adenosine receptor activation increases adipocyte leptin secretion. Endocrinology 141, 1442-1445.

147. Greenberg AS, Taylor SI \& Londos C (1987) Presence of a functional inhibitory GTP-binding regulatory component, $\mathrm{G}_{\mathrm{i}}$, linked to adenylate cyclase in adipocytes of ob/ob mice. J Biol Chem 262, 4564-4568.

148. Vannucci SJ, Klim CM, Martin LF, et al. (1989) A1-adenosine receptor-mediated inhibition of adipocyte adenylate cyclase and lipolysis in Zucker rats. Am J Physiol 257, E871-E878.

149. Martin LF, Klim CM \& Vannucci SJ (1990) Alterations in adipocyte adenylate cyclase activity in morbidly obese and formerly morbidly obese humans. Surgery $\mathbf{1 0 8}$, 228-234, ; discussion 234-225.

150. Wang MY, Orci L, Ravazzola M, et al. (2005) Fat storage in adipocytes requires inactivation of leptin's paracrine activity: implications for treatment of human obesity. Proc Natl Acad Sci U S A 102, 18011-18016.

151. Gómez-Ambrosi J, Frühbeck G \& Martínez JA (1999) Leptin, but not a $\beta_{3}$-adrenergic agonist, upregulates muscle uncoupling protein-3 messenger RNA expression: shortterm thermogenic interactions. Cell Mol Life Sci 55, 992-997.

152. Frühbeck G \& Salvador J (2000) Relations between leptin and the regulation of glucose metabolism. Diabetologia 43, 3-12.

153. Elinson N, Amichay D \& Birk RZ (2006) Leptin directly regulates exocrine pancreas lipase and two related proteins in the rat. BrJ Nutr 96, 691-696.

154. Morioka T, Asilmaz E, Hu J, et al. (2007) Disruption of leptin receptor expression in the pancreas directly affects $\beta$ cell growth and function in mice. $J$ Clin Invest 117, 2860-2868.

155. Ren J, Dong F, Cai G-J, et al. (2010) Interaction between age and obesity on cardiomyocyte contractile function: role of leptin and stress signaling. PLOS ONE 5, e10085.

156. Becerril S, Gómez-Ambrosi J, Martin M, et al. (2013) Role of PRDM16 in the activation of brown fat programming. Relevance to the development of obesity. Histol Histopathol 28, 1411-1425.

157. Huynh FK, Neumann UH, Wang Y, et al. (2013) A role for hepatic leptin signaling in lipid metabolism via altered very low density lipoprotein composition and liver lipase activity in mice. Hepatology 57, 543-554.

158. Shapiro L \& Scherer PE (1998) The crystal structure of a complement-1q family protein suggests an evolutionary link to tumor necrosis factor. Curr Biol 8, 335-338.

159. Bullo M, Salas-Salvado J \& Garcia-Lorda P (2005) Adiponectin expression and adipose tissue lipolytic activity in lean and obese women. Obes Surg 15, 382-386.

160. Lavoie F, Frisch F, Brassard P, et al. (2009) Relationship between total and high molecular weight adiponectin levels and plasma nonesterified fatty acid tolerance during enhanced intravascular triacylglycerol lipolysis in men. J Clin Endocrinol Metab 94, 998-1004.

161. Wedellova Z, Dietrich J, Siklova-Vitkova M, et al. (2011) Adiponectin inhibits spontaneous and catecholamineinduced lipolysis in human adipocytes of non-obese subjects through AMPK-dependent mechanisms. Physiol Res 60, 139-148.

162. Qiao L, Kinney B, Schaack J, et al. (2011) Adiponectin inhibits lipolysis in mouse adipocytes. Diabetes 60, 1519-1527.

163. Kovacova Z, Tencerova M, Roussel B, et al. (2012) The impact of obesity on secretion of adiponectin multimeric isoforms differs in visceral and subcutaneous adipose tissue. Int J Obes 36, 1360-1365.

164. Wedellova Z, Kovacova Z, Tencerova M, et al. (2013) The impact of full-length, trimeric and globular adiponectin on lipolysis in subcutaneous and visceral adipocytes of obese and non-obese women. PLOS ONE 8, e66783.

165. Gaudiot N, Jaubert AM, Charbonnier E, et al. (1998) Modulation of white adipose tissue lipolysis by nitric oxide. J Biol Chem 273, 13475-13481.

166. Andersson K, Gaudiot N, Ribiere C, et al. (1999) A nitric oxide-mediated mechanism regulates lipolysis in human adipose tissue in vivo. Br J Pharmacol 126, 1639-1645.

167. Elizalde M, Ryden M, van Harmelen V, et al. (2000) Expression of nitric oxide synthases in subcutaneous adipose tissue of nonobese and obese humans. J Lipid Res 41, 1244-1251.

168. Engeli S, Janke J, Gorzelniak K, et al. (2004) Regulation of the nitric oxide system in human adipose tissue. J Lipid Res 45, 1640-1648.

169. Penfornis P \& Marette A (2005) Inducible nitric oxide synthase modulates lipolysis in adipocytes. J Lipid Res $\mathbf{4 6}$, 135-142.

170. Engeli S, Boschmann M, Adams F, et al. (2007) Dissociation between adipose nitric oxide synthase expression and tissue metabolism. J Clin Endocrinol Metab 92, 2706-2711.

171. Frühbeck G (1999) Pivotal role of nitric oxide in the control of blood pressure after leptin administration. Diabetes $\mathbf{4 8}$, 903-908.

172. Frühbeck G (2006) Intracellular signalling pathways activated by leptin. Biochem J 393, 7-20.

173. Frühbeck G \& Gómez-Ambrosi J (2001) Modulation of the leptin-induced white adipose tissue lipolysis by nitric oxide. Cell Signal 13, 827-833.

174. Becerril S, Rodríguez A, Catalán V, et al. (2010) Deletion of inducible nitric-oxide synthase in leptin-deficient mice improves brown adipose tissue function. PLOS ONE $\mathbf{5}$, e10962.

175. Becerril S, Rodríguez A, Catalán V, et al. (2012) Transcriptional analysis of brown adipose tissue in leptin-deficient mice lacking inducible nitric oxide synthase: evidence of the role of Med1 in energy balance. Physiol Genomics 44, 678-688.

176. Mehebik N, Jaubert AM, Sabourault D, et al. (2005) Leptininduced nitric oxide production in white adipocytes is mediated through PKA and MAP kinase activation. Am J Physiol Cell Physiol 289, C379-C387.

177. Lafontan M, Moro C, Berlan M, et al. (2008) Control of lipolysis by natriuretic peptides and cyclic GMP. Trends Endocrinol Metab 19, 130-137.

178. Sengenes C, Berlan M, De Glisezinski I, et al. (2000) Natriuretic peptides: a new lipolytic pathway in human adipocytes. FASEB J 14, 1345-1351.

179. Galitzky J, Sengenes C, Thalamas C, et al. (2001) The lipidmobilizing effect of atrial natriuretic peptide is unrelated to sympathetic nervous system activation or obesity in young men. J Lipid Res 42, 536-544.

180. Sengenes C, Bouloumie A, Hauner H, et al. (2003) Involvement of a cGMP-dependent pathway in the natriuretic peptide-mediated hormone-sensitive lipase phosphorylation in human adipocytes. J Biol Chem 278, 48617-48626. 
181. Moro C, Crampes F, Sengenes C, et al. (2004) Atrial natriuretic peptide contributes to physiological control of lipid mobilization in humans. FASEB J 18, 908-910.

182. Moro C, Galitzky J, Sengenes C, et al. (2004) Functional and pharmacological characterization of the natriuretic peptide-dependent lipolytic pathway in human fat cells. J Pharmacol Exp Ther 308, 984-992.

183. Moro C, Pillard F, de Glisezinski I, et al. (2008) Exerciseinduced lipid mobilization in subcutaneous adipose tissue is mainly related to natriuretic peptides in overweight men. Am J Physiol Endocrinol Metab 295, E505-E513.

184. Moro C, Pasarica M, Elkind-Hirsch K, et al. (2009) Aerobic exercise training improves atrial natriuretic peptide and catecholamine-mediated lipolysis in obese women with polycystic ovary syndrome. J Clin Endocrinol Metab 94, 2579-2586.

185. Birkenfeld AL, Budziarek P, Boschmann M, et al. (2008) Atrial natriuretic peptide induces postprandial lipid oxidation in humans. Diabetes 57, 3199-3204.

186. Moro C \& Lafontan M (2013) Natriuretic peptides and cGMP signaling control of energy homeostasis. Am J Physiol Heart Circ Physiol 304, H358-H368.

187. Horvath TL (2003) Endocannabinoids and the regulation of body fat: the smoke is clearing. J Clin Invest 112, 323-326.

188. Di Marzo V (2008) Targeting the endocannabinoid system: to enhance or reduce? Nat Rev Drug Discov 7, 438-455.

189. Moreno-Navarrete JM, Catalán V, Whyte L, et al. (2012) The $1-\alpha$-lysophosphatidylinositol/GPR55 system and its potential role in human obesity. Diabetes 61, 281-291.

190. Cota D, Marsicano G, Tschop M, et al. (2003) The endogenous cannabinoid system affects energy balance via central orexigenic drive and peripheral lipogenesis. J Clin Invest 112, 423-431.

191. Jbilo O, Ravinet-Trillou C, Arnone M, et al. (2005) The CB1 receptor antagonist rimonabant reverses the diet-induced obesity phenotype through the regulation of lipolysis and energy balance. FASEB J 19, 1567-1569.

192. Engeli S, Bohnke J, Feldpausch M, et al. (2005) Activation of the peripheral endocannabinoid system in human obesity. Diabetes 54, 2838-2843.

193. Matias I, Gonthier MP, Orlando P, et al. (2006) Regulation, function, and dysregulation of endocannabinoids in models of adipose and $\beta$-pancreatic cells and in obesity and hyperglycemia. J Clin Endocrinol Metab 91, 3171-3180.

194. Guzman M, Lo Verme J, Fu J, et al. (2004) Oleoylethanolamide stimulates lipolysis by activating the nuclear receptor peroxisome proliferator-activated receptor $\alpha$ (PPAR- $\alpha$ ). J Biol Chem 279, 27849-27854.

195. Martinez de Ubago M, Garcia-Oya I \& Perez-Perez A (2009) Oleoylethanolamide, a natural ligand for PPAR- $\alpha$, inhibits insulin receptor signalling in HTC rat hepatoma cells. Biochim Biophys Acta 1791, 740-745.

196. Muccioli G, Pons N, Ghe C, et al. (2004) Ghrelin and desacyl ghrelin both inhibit isoproterenol-induced lipolysis in rat adipocytes via a non-type 1a growth hormone secretagogue receptor. Eur J Pharmacol 498, 27-35.

197. Baragli A, Ghe C, Arnoletti E, et al. (2011) Acylated and unacylated ghrelin attenuate isoproterenol-induced lipolysis in isolated rat visceral adipocytes through activation of phosphoinositide 3-kinase $\gamma$ and phosphodiesterase 3B. Biochim Biophys Acta 1811, 386-396.

198. Vestergaard ET, Gormsen LC, Jessen N, et al. (2008) Ghrelin infusion in humans induces acute insulin resistance and lipolysis independent of growth hormone signaling. Diabetes 57, 3205-3210.

199. Rodríguez A, Gómez-Ambrosi J, Catalán V, et al. (2009) Acylated and desacyl ghrelin stimulate lipid accumulation in human visceral adipocytes. Int J Obes 33, 541-552.
200. Rodríguez A, Gómez-Ambrosi J, Catalán V, et al. (2012) The ghrelin $O$-acyltransferase-ghrelin system reduces TNF- $\alpha$ induced apoptosis and autophagy in human visceral adipocytes. Diabetologia 55, 3038-3050.

201. Carlson LA \& Oro L (1962) The effect of nicotinic acid on the plasma free fatty acid; demonstration of a metabolic type of sympathicolysis. Acta Med Scand 172, 641-645.

202. Carlson LA \& Hanngren A (1964) Initial distribution in mice of ${ }^{3} \mathrm{H}$-labeled nicotinic acid studied with autoradiography. Life Sci 3, 867-871.

203. Karpe F \& Frayn KN (2004) The nicotinic acid receptor - a new mechanism for an old drug. Lancet 363, 1892-1894.

204. Oh YT, Oh KS, Choi YM, et al. (2011) Continuous 24-h nicotinic acid infusion in rats causes FFA rebound and insulin resistance by altering gene expression and basal lipolysis in adipose tissue. Am J Physiol Endocrinol Metab 300, E1012-E1021.

205. Tisdale MJ (2009) Zinc- $\alpha_{2}$-glycoprotein in cachexia and obesity. Curr Opin Support Palliat Care 3, 288-293.

206. Bing C, Mracek T, Gao D, et al. (2010) Zinc- $\alpha_{2}$-glycoprotein: an adipokine modulator of body fat mass? Int J Obes (Lond) 34, 1559-1565.

207. Cabassi A \& Tedeschi S (2013) Zinc- $\alpha_{2}$-glycoprotein as a marker of fat catabolism in humans. Curr Opin Clin Nutr Metab Care 16, 267-271.

208. Bing C, Bao Y, Jenkins J, et al. (2004) Zinc- $\alpha_{2}$-glycoprotein, a lipid mobilizing factor, is expressed in adipocytes and is up-regulated in mice with cancer cachexia. Proc Natl Acad Sci U S A 101, 2500-2505.

209. Wargent ET, O'Dowd JF, Zaibi MS, et al. (2013) Contrasts between the effects of zinc- $\alpha_{2}$-glycoprotein, a putative $\beta_{3 / 2}$-adrenoceptor agonist and the $\beta_{3 / 2}$-adrenoceptor agonist BRL35135 in C57Bl/6 (ob/ob) mice. J Endocrinol 216, 157-168.

210. Eckardt K, Schober A, Platzbecker B, et al. (2011) The adipokine zinc- $\alpha_{2}$-glycoprotein activates AMP kinase in human primary skeletal muscle cells. Arch Physiol Biochem 117, 88-93.

211. Sarzani R, Salvi F, Dessi-Fulgheri P, et al. (2008) Reninangiotensin system, natriuretic peptides, obesity, metabolic syndrome, and hypertension: an integrated view in humans. J Hypertens 26, 831-843.

212. Goossens GH, Blaak EE, Saris WH, et al. (2004) Angiotensin II-induced effects on adipose and skeletal muscle tissue blood flow and lipolysis in normal-weight and obese subjects. J Clin Endocrinol Metab 89, 2690-2696.

213. Frühbeck G (2004) The adipose tissue as a source of vasoactive factors. Curr Med Chem Cardiovasc Hematol Agents 2, 197-208.

214. Juan CC, Chang CL, Lai YH, et al. (2005) Endothelin-1 induces lipolysis in 3T3-L1 adipocytes. Am J Physiol Endocrinol Metab 288, E1146-E1152.

215. Juan CC, Chang LW, Huang SW, et al. (2006) Effect of endothelin-1 on lipolysis in rat adipocytes. Obesity (Silver Spring) 14, 398-404.

216. van Harmelen V, Eriksson A, Astrom G, et al. (2008) Vascular peptide endothelin-1 links fat accumulation with alterations of visceral adipocyte lipolysis. Diabetes $\mathbf{5 7}$, 378-386.

217. Eriksson AK, van Harmelen V, Stenson BM, et al. (2009) Endothelin-1 stimulates human adipocyte lipolysis through the ET A receptor. Int J Obes (Lond) 33, 67-74.

218. Shichiri M, Fukai N, Ozawa N, et al. (2003) Adrenomedullin is an autocrine/paracrine growth factor for rat vascular smooth muscle cells. Regul Pept 112, 167-173.

219. Fukai N, Yoshimoto T, Sugiyama T, et al. (2005) Concomitant expression of adrenomedullin and its receptor 
components in rat adipose tissues. Am J Physiol Endocrinol Metab 288, E56-E62.

220. Harmancey R, Senard JM, Pathak A, et al. (2005) The vasoactive peptide adrenomedullin is secreted by adipocytes and inhibits lipolysis through NO-mediated $\beta$-adrenergic agonist oxidation. FASEB J 19, 1045-1047.

221. Iemura-Inaba C, Nishikimi T, Akimoto K, et al. (2008) Role of adrenomedullin system in lipid metabolism and its signaling mechanism in cultured adipocytes. Am J Physiol Regul Integr Comp Physiol 295, R1376-R1384.

222. Boucher J, Masri B, Daviaud D, et al. (2005) Apelin, a newly identified adipokine up-regulated by insulin and obesity. Endocrinology 146, 1764-1771.

223. Attane C, Daviaud D, Dray C, et al. (2011) Apelin stimulates glucose uptake but not lipolysis in human adipose tissue ex vivo. J Mol Endocrinol 46, 21-28.

224. Yue P, Jin H, Xu S, et al. (2011) Apelin decreases lipolysis via $G_{q}, G_{i}$, and AMPK-dependent mechanisms. Endocrinology 152, 59-68.

225. Than A, Cheng Y, Foh LC, et al. (2012) Apelin inhibits adipogenesis and lipolysis through distinct molecular pathways. Mol Cell Endocrinol 362, 227-241.

226. Crowe S, Wu LE, Economou C, et al. (2009) Pigment epithelium-derived factor contributes to insulin resistance in obesity. Cell Metab 10, 40-47.

227. Sabater M, Moreno-Navarrete JM, Ortega FJ, et al. (2010) Circulating pigment epithelium-derived factor levels are associated with insulin resistance and decrease after weight loss. J Clin Endocrinol Metab 95, 4720-4728.

228. Borg ML, Andrews ZB, Duh EJ, et al. (2011) Pigment epithelium-derived factor regulates lipid metabolism via adipose triglyceride lipase. Diabetes 60, 1458-1466.

229. Yamagishi S, Amano S, Inagaki Y, et al. (2003) Pigment epithelium-derived factor inhibits leptin-induced angiogenesis by suppressing vascular endothelial growth factor gene expression through anti-oxidative properties. Microvasc Res 65, 186-190.

230. Wang M, Wang JJ, Li J, et al. (2009) Pigment epitheliumderived factor suppresses adipogenesis via inhibition of the MAPK/ERK pathway in 3T3-L1 preadipocytes. Am J Physiol Endocrinol Metab 297, E1378-E1387.

231. Moreno-Navarrete JM, Touskova V, Sabater M, et al. (2013) Liver, but not adipose tissue PEDF gene expression is associated with insulin resistance. Int J Obes (Lond) 37, 1230-1237.

232. Gómez-Ambrosi J, Salvador J, Rotellar F, et al. (2006) Increased serum amyloid A concentrations in morbid obesity decrease after gastric bypass. Obes Surg $\mathbf{1 6}$ 262-269.

233. Catalán V, Gómez-Ambrosi J, Rotellar F, et al. (2007) The obestatin receptor (GPR39) is expressed in human adipose tissue and is down-regulated in obesity-associated type 2 diabetes mellitus. Clin Endocrinol 66, 598-601.

234. Catalán V, Gómez-Ambrosi J, Ramírez B, et al. (2007) Proinflammatory cytokines in obesity: impact of type 2 diabetes mellitus and gastric bypass. Obes Surg 17, 1464-1474.

235. Catalán V, Gómez-Ambrosi J, Rodríguez A, et al. (2009) Increased adipose tissue expression of lipocalin-2 in obesity is related to inflammation and matrix metalloproteinase- 2 and -9 activity in humans. $J \mathrm{Mol}$ Med 87, 803-813.

236. Catalán V, Gómez-Ambrosi J, Rodríguez A, et al. (2011) Up-regulation of the novel proinflammatory adipokines lipocalin-2, chitinase-3 like-1 and osteopontin as well as angiogenic-related factors in visceral adipose tissue of patients with colon cancer. J Nutr Biochem 22, 634-641.

237. Catalán V, Gómez-Ambrosi J, Rodríguez A, et al. (2011) Association of increased Visfatin/PBEF/NAMPT circulating concentrations and gene expression levels in peripheral blood cells with lipid metabolism and fatty liver in human morbid obesity. Nutr Metab Cardiovasc Dis 21, 245-253.

238. Moreno-Navarrete JM, Catalán V, Ortega F, et al. (2010) Circulating omentin concentration increases after weight loss. Nutr Metab 7, 27.

239. Catalán V, Gómez-Ambrosi J, Rodríguez A, et al. (2012) Increased tenascin $\mathrm{C}$ and toll-like receptor 4 levels in visceral adipose tissue as a link between inflammation and extracellular matrix remodeling in obesity. I Clin Endocrinol Metab 97, E1880-E1889.

240. Catalán V, Gomez-Ambrosi J, Rodríguez A, et al. (2013) Increased levels of chemerin and its receptor, chemokinelike receptor-1, in obesity are related to inflammation: tumor necrosis factor- $\alpha$ stimulates mRNA levels of chemerin in visceral adipocytes from obese patients. Surg Obes Relat Dis 9, 306-314.

241. Gómez-Ambrosi J, Rodríguez A, Catalán V, et al. (2008) Serum retinol-binding protein 4 is not increased in obesity or obesity-associated type 2 diabetes mellitus, but is reduced after relevant reductions in body fat following gastric bypass. Clin Endocrinol 69, 208-215.

242. Ding C, Gao D, Wilding J, et al. (2012) Vitamin D signalling in adipose tissue. Br J Nutr 108, 1915-1923.

243. Possenti R, Muccioli G, Petrocchi P, et al. (2012) Characterization of a novel peripheral pro-lipolytic mechanism in mice: role of VGF-derived peptide TLQP-21. Biochem $J$ 441, 511-522.

244. Gómez-Ambrosi J, Catalán V, Ramírez B, et al. (2007) Plasma osteopontin levels and expression in adipose tissue are increased in obesity. J Clin Endocrinol Metab 92, 3719-3727.

245. Fernández-Real JM, Izquierdo M, Ortega F, et al. (2009) The relationship of serum osteocalcin concentration to insulin secretion, sensitivity, and disposal with hypocaloric diet and resistance training. J Clin Endocrinol Metab 94, 237-245.

246. Bays HE, González-Campoy JM, Bray GA, et al. (2008) Pathogenic potential of adipose tissue and metabolic consequences of adipocyte hypertrophy and increased visceral adiposity. Expert Rev Cardiovasc Ther 6, 343-368.

247. Wood IS \& Trayhurn P (2006) Adipokines and the signaling role of adipose tissue in inflammation and obesity. Future Lipidol 1, 81-89.

248. Haemmerle G, Lass A, Zimmermann R, et al. (2006) Defective lipolysis and altered energy metabolism in mice lacking adipose triglyceride lipase. Science 312, 734-737.

249. Reynisdottir S, Dauzats M, Thorne A, et al. (1997) Comparison of hormone-sensitive lipase activity in visceral and subcutaneous human adipose tissue. J Clin Endocrinol Metab 82, 4162-4166.

250. Osuga J-I, Ishibashi S, Oka T, et al. (2000) Targeted disruption of hormone-sensitive lipase results in male sterility and adipocyte hypertrophy, but not in obesity. Proc Natl Acad Sci U S A 97, 787-792.

251. Fredrikson G, Tornqvist H \& Belfrage P (1986) Hormonesensitive lipase and monoacylglycerol lipase are both required for complete degradation of adipocyte triacylglycerol. Biochim Biophys Acta 876, 288-293.

252. Osuga J, Ishibashi S, Oka T, et al. (2000) Targeted disruption of hormone-sensitive lipase results in male sterility and adipocyte hypertrophy, but not in obesity. Proc Natl Acad Sci U S A 97, 787-792.

253. Shi Y \& Burn P (2004) Lipid metabolic enzymes: emerging drug targets for the treatment of obesity. Nat Rev Drug Discov 3, 695-710.

254. Granneman JG \& Moore HP (2008) Location, location: protein trafficking and lipolysis in adipocytes. Trends Endocrinol Metab 19, 3-9. 
255. Bezaire V \& Langin D (2009) Regulation of adipose tissue lipolysis revisited. Proc Nutr Soc 68, 350-360.

256. Zimmermann R, Strauss JG, Haemmerle G, et al. (2004) Fat mobilization in adipose tissue is promoted by adipose triglyceride lipase. Science 306, 1383-1386.

257. Zechner R, Kienesberger PC, Haemmerle G, et al. (2009) Adipose triglyceride lipase and the lipolytic catabolism of cellular fat stores. J Lipid Res 50, 3-21.

258. Schweiger M, Schreiber R, Haemmerle G, et al. (2006) Adipose triglyceride lipase and hormone-sensitive lipase are the major enzymes in adipose tissue triacylglycerol catabolism. J Biol Chem 281, 40236-40241.

259. Thompson BR, Lobo S \& Bernlohr DA (2010) Fatty acid flux in adipocytes: the in's and out's of fat cell lipid trafficking. Mol Cell Endocrinol 318, 24-33.

260. Schweiger M, Schoiswohl G, Lass A, et al. (2008) The C-terminal region of human adipose triglyceride lipase affects enzyme activity and lipid droplet binding. J Biol Chem 283, 17211-17220.

261. Lass A, Zimmermann R, Oberer M, et al. (2011) Lipolysis - a highly regulated multi-enzyme complex mediates the catabolism of cellular fat stores. Prog Lipid Res 50, 14-27.

262. Chakrabarti P, Kim JY, Singh M, et al. (2013) Insulin inhibits lipolysis in adipocytes via the evolutionary conserved mTORC1-Egr1-ATGL-mediated pathway. Mol Cell Biol 33, 3659-3666.

263. Haemmerle G, Moustafa T, Woelkart G, et al. (2011) ATGLmediated fat catabolism regulates cardiac mitochondrial function via PPAR- $\alpha$ and PGC-1. Nat Med 17, 1076-1085.

264. Chakrabarti P \& Kandror KV (2009) FoxO1 controls insulindependent adipose triglyceride lipase (ATGL) expression and lipolysis in adipocytes. J Biol Chem 284, 13296-13300.

265. Chakrabarti P, English T, Shi J, et al. (2010) Mammalian target of rapamycin complex 1 suppresses lipolysis, stimulates lipogenesis, and promotes fat storage. Diabetes 59, 775-781.

266. Chakrabarti P, English T, Karki S, et al. (2011) SIRT1 controls lipolysis in adipocytes via FOXO1-mediated expression of ATGL. J Lipid Res 52, 1693-1701.

267. Yin W, Mu J \& Birnbaum MJ (2003) Role of AMP-activated protein kinase in cyclic AMP-dependent lipolysis in 3T3-L1 adipocytes. J Biol Chem 278, 43074-43080.

268. Daval M, Diot-Dupuy F, Bazin R, et al. (2005) Anti-lipolytic action of AMP-activated protein kinase in rodent adipocytes. J Biol Chem 280, 25250-25257.

269. Gauthier MS, Miyoshi H, Souza SC, et al. (2008) AMPactivated protein kinase is activated as a consequence of lipolysis in the adipocyte: potential mechanism and physiological relevance. J Biol Chem 283, 16514-16524.

270. Gaidhu MP, Fediuc S, Anthony NM, et al. (2009) Prolonged AICAR-induced AMP-kinase activation promotes energy dissipation in white adipocytes: novel mechanisms integrating HSL and ATGL. J Lipid Res 50, 704-715.

271. Gaidhu MP, Bikopoulos G \& Ceddia RB (2012) Chronic AICAR-induced AMP-kinase activation regulates adipocyte lipolysis in a time-dependent and fat depotspecific manner in rats. Am J Physiol Cell Physiol 303, C1192-C1197.

272. Yang $X$, Lu X, Lombès $M$, et al. (2010) The $G_{0} / G_{1}$ switch gene 2 regulates adipose lipolysis through association with adipose triglyceride lipase. Cell Metab 11, 194-205.

273. Schweiger M, Paar M, Eder C, et al. (2012) $G_{0} / G_{1}$ switch gene-2 regulates human adipocyte lipolysis by affecting activity and localization of adipose triglyceride lipase. J Lipid Res 53, 2307-2317.

274. Mayer N, Schweiger M, Romauch M, et al. (2013) Development of small-molecule inhibitors targeting adipose triglyceride lipase. Nat Chem Biol 9, 785-787.
275. Okazaki H, Osuga J, Tamura Y, et al. (2002) Lipolysis in the absence of hormone-sensitive lipase: evidence for a common mechanism regulating distinct lipases. Diabetes 51, 3368-3375.

276. Haemmerle G, Zimmermann R, Strauss JG, et al. (2002) Hormone-sensitive lipase deficiency in mice changes the plasma lipid profile by affecting the tissue-specific expression pattern of lipoprotein lipase in adipose tissue and muscle. J Biol Chem 277, 12946-12952.

277. Holm C (2003) Molecular mechanisms regulating hormonesensitive lipase and lipolysis. Biochem Soc Trans 31, 1120-1124.

278. Peyot ML, Nolan CJ, Soni K, et al. (2004) Hormone-sensitive lipase has a role in lipid signaling for insulin secretion but is nonessential for the incretin action of glucagon-like peptide 1. Diabetes 53, 1733-1742.

279. Tansey JT, Sztalryd C, Gruia-Gray J, et al. (2001) Perilipin ablation results in a lean mouse with aberrant adipocyte lipolysis, enhanced leptin production, and resistance to diet-induced obesity. Proc Natl Acad Sci U S A $\mathbf{9 8}$ 6494-6499.

280. Tansey JT, Sztalryd C, Hlavin EM, et al. (2004) The central role of perilipin A in lipid metabolism and adipocyte lipolysis. IUBMB Life 56, 379-385.

281. Sztalryd C, Xu G, Dorward H, et al. (2003) Perilipin A is essential for the translocation of hormone-sensitive lipase during lipolytic activation. J Cell Biol 161, 1093-1103.

282. Belfrage P, Fredrikson G, Olsson H, et al. (1984) Regulation of adipose tissue lipolysis through reversible phosphorylation of hormone-sensitive lipase. Adv Cyclic Nucleotide Protein Phosphorylation Res 17, 351-359.

283. Ray H, Beylot M, Arner P, et al. (2003) The presence of a catalytically inactive form of hormone-sensitive lipase is associated with decreased lipolysis in abdominal subcutaneous adipose tissue of obese subjects. Diabetes 52, 1417-1422.

284. Greenberg AS, Shen WJ, Muliro K, et al. (2001) Stimulation of lipolysis and hormone-sensitive lipase via the extracellular signal-regulated kinase pathway. J Biol Chem 276, 45456-45461.

285. Kralisch S, Klein J, Lossner U, et al. (2005) Isoproterenol, $\mathrm{TNF} \alpha$, and insulin downregulate adipose triglyceride lipase in 3T3-L1 adipocytes. Mol Cell Endocrinol 240, 43-49.

286. Kershaw EE, Hamm JK, Verhagen LA, et al. (2006) Adipose triglyceride lipase: function, regulation by insulin, and comparison with adiponutrin. Diabetes 55, 148-157.

287. Scherer T, O'Hare J, Diggs-Andrews K, et al. (2011) Brain insulin controls adipose tissue lipolysis and lipogenesis. Cell Metab 13, 183-194.

288. Taschler U, Radner FP, Heier C, et al. (2011) Monoglyceride lipase deficiency in mice impairs lipolysis and attenuates diet-induced insulin resistance. $J$ Biol Chem 286, $17467-17477$.

289. Soni KG, Lehner R, Metalnikov P, et al. (2004) Carboxylesterase 3 (EC 3.1.1.1) is a major adipocyte lipase. J Biol Chem 279, 40683-40689.

290. Wei E, Ben Ali Y, Lyon J, et al. (2010) Loss of TGH/Ces3 in mice decreases blood lipids, improves glucose tolerance, and increases energy expenditure. Cell Metab 11, 183-193.

291. Kienesberger PC, Oberer M, Lass A, et al. (2009) Mammalian patatin domain containing proteins: a family with diverse lipolytic activities involved in multiple biological functions. J Lipid Res 50, S63-S68.

292. Polson DA \& Thompson MP (2003) Adiponutrin mRNA expression in white adipose tissue is rapidly induced by meal-feeding a high-sucrose diet. Biochem Biophys Res Commun 301, 261-266. 
293. Lake AC, Sun Y, Li JL, et al. (2005) Expression, regulation, and triglyceride hydrolase activity of adiponutrin family members. J Lipid Res 46, 2477-2487.

294. Johansson LE, Lindblad U, Larsson CA, et al. (2008) Polymorphisms in the adiponutrin gene are associated with increased insulin secretion and obesity. Eur J Endocrinol 159, 577-583.

295. Basantani MK, Sitnick MT, Cai L, et al. (2011) Pnpla3/ adiponutrin deficiency in mice does not contribute to fatty liver disease or metabolic syndrome. J Lipid Res $\mathbf{5 2}$, 318-329.

296. Brasaemle DL (2007) The perilipin family of structural lipid droplet proteins: stabilization of lipid droplets and control of lipolysis. J Lipid Res 48, 2547-2559.

297. Brasaemle DL, Subramanian V, Garcia A, et al. (2009) Perilipin A and the control of triacylglycerol metabolism. Mol Cell Biochem 326, 15-21.

298. Robenek H, Robenek MJ, Buers I, et al. (2005) Lipid droplets gain PAT family proteins by interaction with specialized plasma membrane domains. J Biol Chem 280, $26330-26338$.

299. Robenek H, Robenek MJ \& Troyer D (2005) PAT family proteins pervade lipid droplet cores. J Lipid Res $\mathbf{4 6}$, $1331-1338$.

300. Londos C, Brasaemle DL, Schultz CJ, et al. (1999) Perilipins, ADRP, and other proteins that associate with intracellular neutral lipid droplets in animal cells. Semin Cell Dev Biol 10, $51-58$.

301. Martínez-Botas J, Anderson JB, Tessier D, et al. (2000) Absence of perilipin results in leanness and reverses obesity in Lepr (db/db) mice. Nat Genet 26, 474-479.

302. Brasaemle DL, Rubin B, Harten IA, et al. (2000) Perilipin A increases triacylglycerol storage by decreasing the rate of triacylglycerol hydrolysis. J Biol Chem 275, 38486-38493.

303. Kovsan J, Ben-Romano R, Souza SC, et al. (2007) Regulation of adipocyte lipolysis by degradation of the perilipin protein: nelfinavir enhances lysosome-mediated perilipin proteolysis. J Biol Chem 282, 21704-21711.

304. Miyoshi H, Perfield JWII, Souza SC, et al. (2007) Control of adipose triglyceride lipase action by serine 517 of perilipin A globally regulates protein kinase A-stimulated lipolysis in adipocytes. J Biol Chem 282, 996-1002.

305. Miyoshi H, Souza SC, Zhang HH, et al. (2006) Perilipin promotes hormone-sensitive lipase-mediated adipocyte lipolysis via phosphorylation-dependent and -independent mechanisms. J Biol Chem 281, 15837-15844.

306. Miyoshi H, Souza SC, Endo M, et al. (2010) Perilipin overexpression in mice protects against diet-induced obesity. J Lipid Res 51, 975-982.

307. McDonough PM, Maciejewski-Lenoir D, Hartig SM, et al. (2013) Differential phosphorylation of perilipin 1A at the initiation of lipolysis revealed by novel monoclonal antibodies and high content analysis. PLOS ONE 8, e55511.

308. Yang X, Heckmann BL, Zhang X, et al. (2013) Distinct mechanisms regulate ATGL-mediated adipocyte lipolysis by lipid droplet coat proteins. Mol Endocrinol 27, 116-126.

309. Skinner JR, Harris LA, Shew TM, et al. (2013) Perilipin 1 moves between the fat droplet and the endoplasmic reticulum. Adipocyte 2, 80-86.

310. Takahashi Y, Shinoda A, Furuya N, et al. (2013) Perilipinmediated lipid droplet formation in adipocytes promotes sterol regulatory element-binding protein-1 processing and triacylglyceride accumulation. PLOS ONE 8, e64605.

311. Beller M, Sztalryd C, Southall N, et al. (2008) COPI complex is a regulator of lipid homeostasis. PLOS Biol 6, e292.

312. Guo Y, Walther TC, Rao M, et al. (2008) Functional genomic screen reveals genes involved in lipid-droplet formation and utilization. Nature 453, 657-661.
313. Takashima K, Saitoh A, Hirose S, et al. (2011) GBF1-ArfCOPI-ArfGAP-mediated Golgi-to-ER transport involved in regulation of lipid homeostasis. Cell Struct Funct 36, $223-235$.

314. Zhou Z, Yon Toh S, Chen Z, et al. (2003) Cidea-deficient mice have lean phenotype and are resistant to obesity. Nat Genet 35, 49-56.

315. Li JZ, Ye J, Xue B, et al. (2007) Cideb regulates diet-induced obesity, liver steatosis, and insulin sensitivity by controlling lipogenesis and fatty acid oxidation. Diabetes $\mathbf{5 6}$, 2523-2532.

316. Qi J, Gong J, Zhao T, et al. (2008) Downregulation of AMPactivated protein kinase by Cidea-mediated ubiquitination and degradation in brown adipose tissue. EMBO $J \mathbf{2 7}$, $1537-1548$.

317. Ye J, Li JZ, Liu Y, et al. (2009) Cideb, an ER- and lipid droplet-associated protein, mediates VLDL lipidation and maturation by interacting with apolipoprotein B. Cell Metab 9, 177-190.

318. Tiwari S, Siddiqi S \& Siddiqi SA (2013) Cideb protein is required for the biogenesis of very low density lipoprotein (VLDL) transport vesicle. J Biol Chem 288, 5157-5165.

319. Nordstrom EA, Ryden M, Backlund EC, et al. (2005) A human-specific role of cell death-inducing DFFA (DNA fragmentation factor- $\alpha$ )-like effector A (CIDEA) in adipocyte lipolysis and obesity. Diabetes 54, 1726-1734.

320. Pettersson AT, Laurencikiene J, Nordstrom EA, et al. (2008) Characterization of the human CIDEA promoter in fat cells. Int J Obes (Lond) 32, 1380-1387.

321. Christianson JL, Boutet E, Puri V, et al. (2010) Identification of the lipid droplet targeting domain of the Cidea protein. J Lipid Res 51, 3455-3462.

322. Puri V, Ranjit S, Konda S, et al. (2008) Cidea is associated with lipid droplets and insulin sensitivity in humans. Proc Natl Acad Sci U S A 105, 7833-7838.

323. Laurencikiene J, Stenson BM, Arvidsson Nordstrom E, et al. (2008) Evidence for an important role of CIDEA in human cancer cachexia. Cancer Res 68, 9247-9254.

324. Magnusson B, Gummesson A, Glad CA, et al. (2008) Cell death-inducing DFF45-like effector $\mathrm{C}$ is reduced by caloric restriction and regulates adipocyte lipid metabolism. Metabolism 57, 1307-1313.

325. Ranjit S, Boutet E, Gandhi P, et al. (2011) Regulation of fat specific protein 27 by isoproterenol and TNF- $\alpha$ to control lipolysis in murine adipocytes. J Lipid Res 52, 221-236.

326. Kim YJ, Cho SY, Yun $\mathrm{CH}$, et al. (2008) Transcriptional activation of Cidec by PPAR 2 in adipocyte. Biochem Biophys Res Commun 377, 297-302.

327. Gong J, Sun Z, Wu L, et al. (2011) Fsp27 promotes lipid droplet growth by lipid exchange and transfer at lipid droplet contact sites. J Cell Biol 195, 953-963.

328. Grahn TH, Zhang Y, Lee MJ, et al. (2013) FSP27 and PLIN1 interaction promotes the formation of large lipid droplets in human adipocytes. Biochem Biophys Res Commun 432, 296-301.

329. Nian Z, Sun Z, Yu L, et al. (2010) Fat-specific protein 27 undergoes ubiquitin-dependent degradation regulated by triacylglycerol synthesis and lipid droplet formation. J Biol Chem 285, 9604-9615.

330. Barneda D, Frontini A, Cinti S, et al. (2013) Dynamic changes in lipid droplet-associated proteins in the "browning" of white adipose tissues. Biochim Biophys Acta 1831, 924-933.

331. Muller G, Wied S, Walz N, et al. (2008) Translocation of glycosylphosphatidylinositol-anchored proteins from plasma membrane microdomains to lipid droplets in rat adipocytes is induced by palmitate, $\mathrm{H}_{2} \mathrm{O}_{2}$, and the sulfonylurea drug glimepiride. Mol Pharmacol 73, 1513-1529. 
332. Muller G, Jung C, Wied S, et al. (2009) Induced translocation of glycosylphosphatidylinositol-anchored proteins from lipid droplets to adiposomes in rat adipocytes. Br J Pharmacol 158, 749-770.

333. Muller G (2011) Control of lipid storage and cell size between adipocytes by vesicle-associated glycosylphosphatidylinositol-anchored proteins. Arch Physiol Biochem 117, $23-43$.

334. Adeyo O, Goulbourne CN, Bensadoun A, et al. (2012) Glycosylphosphatidylinositol-anchored high-density lipoprotein-binding protein 1 and the intravascular processing of triglyceride-rich lipoproteins. J Intern Med 272, 528-540.

335. Peinado JR, Pardo M, de la Rosa O, et al. (2012) Proteomic characterization of adipose tissue constituents, a necessary step for understanding adipose tissue complexity. Proteomics 12, 607-620.

336. Malagon MM, Cruz D, Vazquez-Martinez R, et al. (2005) Analysis of Rab18 and a new golgin in the secretory pathway. Ann N Y Acad Sci 1040, 137-139.

337. Pulido MR, Diaz-Ruiz A, Jimenez-Gomez Y, et al. (2011) Rab18 dynamics in adipocytes in relation to lipogenesis, lipolysis and obesity. PLOS ONE 6, e22931.

338. Pulido MR, Rabanal-Ruiz Y, Almabouada F, et al. (2013) Nutritional, hormonal, and depot-dependent regulation of the expression of the small GTPase Rab18 in rodent adipose tissue. J Mol Endocrinol 50, 19-29.

339. Frühbeck G (2005) Obesity: aquaporin enters the picture. Nature 438, 436-437.

340. Frühbeck G, Catalán V, Gómez-Ambrosi J, et al. (2006) Aquaporin-7 and glycerol permeability as novel obesity drug-target pathways. Trends Pharmacol Sci 27, 345-347.

341. Walker CG, Holness MJ, Gibbons GF, et al. (2007) Fastinginduced increases in aquaporin 7 and adipose triglyceride lipase mRNA expression in adipose tissue are attenuated by peroxisome proliferator-activated receptor $\alpha$ deficiency. Int J Obes (Lond) 31, 1165-1171.

342. Hara-Chikuma M, Sohara E, Rai T, et al. (2005) Progressive adipocyte hypertrophy in aquaporin-7-deficient mice: adipocyte glycerol permeability as a novel regulator of fat accumulation. J Biol Chem 280, 15493-15496.

343. Hibuse T, Maeda N, Nagasawa A, et al. (2006) Aquaporins and glycerol metabolism. Biochim Biophys Acta 1758, 1004-1011.

344. Rodríguez A, Catalán V, Gómez-Ambrosi J, et al. (2011) Insulin- and leptin-mediated control of aquaglyceroporins in human adipocytes and hepatocytes is mediated via the $\mathrm{PI} 3 \mathrm{~K} / \mathrm{Akt} / \mathrm{mTOR}$ signaling cascade. J Clin Endocrinol Metab 96, E586-E597.

345. Frühbeck G, López M \& Diéguez C (2007) Role of caveolins in body weight and insulin resistance regulation. Trends Endocrinol Metab 18, 177-182.

346. Trigatti BL, Anderson RG \& Gerber GE (1999) Identification of caveolin-1 as a fatty acid binding protein. Biochem Biophys Res Commun 255, 34-39.

347. Meshulam T, Simard JR, Wharton J, et al. (2006) Role of caveolin-1 and cholesterol in transmembrane fatty acid movement. Biochemistry (Mosc) 45, 2882-2893.

348. Meshulam T, Breen MR, Liu L, et al. (2011) Caveolins/ caveolae protect adipocytes from fatty acid-mediated lipotoxicity. J Lipid Res 52, 1526-1532.

349. Cohen AW, Razani B, Schubert W, et al. (2004) Role of caveolin-1 in the modulation of lipolysis and lipid droplet formation. Diabetes 53, 1261-1270.

350. Covey SD, Brunet RH, Gandhi SG, et al. (2007) Cholesterol depletion inhibits fatty acid uptake without affecting CD36 or caveolin-1 distribution in adipocytes. Biochem Biophys Res Commun 355, 67-71.
351. Cohen AW, Razani B, Wang XB, et al. (2003) Caveolin-1deficient mice show insulin resistance and defective insulin receptor protein expression in adipose tissue. Am J Physiol Cell Physiol 285, C222-C235.

352. Ring A, Le Lay S, Pohl J, et al. (2006) Caveolin-1 is required for fatty acid translocase (FAT/CD36) localization and function at the plasma membrane of mouse embryonic fibroblasts. Biochim Biophys Acta 1761, 416-423.

353. Zhou D, Samovski D, Okunade AL, et al. (2012) CD36 level and trafficking are determinants of lipolysis in adipocytes. FASEB J 26, 4733-4742.

354. Vroegrijk IO, van Klinken JB, van Diepen JA, et al. (2013) CD36 is important for adipocyte recruitment and affects lipolysis. Obesity (Silver Spring) 21, 2037-2045.

355. Scheja L, Makowski L, Uysal KT, et al. (1999) Altered insulin secretion associated with reduced lipolytic efficiency in $a P 2^{-/}$mice. Diabetes 48, 1987-1994.

356. Lan H, Cheng CC, Kowalski TJ, et al. (2011) Small-molecule inhibitors of FABP $4 / 5$ ameliorate dyslipidemia but not insulin resistance in mice with diet-induced obesity. J Lipid Res 52, 646-656.

357. Wei S, Zan L, Wang H, et al. (2013) Adenovirus-mediated interference of FABP 4 regulates mRNA expression of ADIPOQ, LEP and LEPR in bovine adipocytes. Genet Mol Res 12, 494-505.

358. Wu Q, Ortegon AM, Tsang B, et al. (2006) FATP1 is an insulin-sensitive fatty acid transporter involved in dietinduced obesity. Mol Cell Biol 26, 3455-3467.

359. Richards MR, Harp JD, Ory DS, et al. (2006) Fatty acid transport protein 1 and long-chain acyl coenzyme A synthetase 1 interact in adipocytes. $J$ Lipid Res $\mathbf{4 7}$, 665-672.

360. Liu Q, Gauthier MS, Sun L, et al. (2010) Activation of AMPactivated protein kinase signaling pathway by adiponectin and insulin in mouse adipocytes: requirement of acyl-CoA synthetases FATP1 and Acsl1 and association with an elevation in AMP/ATP ratio. FASEB J 24, 4229-4239.

361. Lenz LS, Marx J, Chamulitrat W, et al. (2011) Adipocytespecific inactivation of acyl-CoA synthetase fatty acid transport protein 4 (Fatp4) in mice causes adipose hypertrophy and alterations in metabolism of complex lipids under high fat diet. J Biol Chem 286, 35578-35587.

362. Phillips CM, Goumidi L, Bertrais S, et al. (2010) Gene-nutrient interactions with dietary fat modulate the association between genetic variation of the ACSL1 gene and metabolic syndrome. J Lipid Res 51, 1793-1800.

363. Rodríguez A, Catalán V, Gómez-Ambrosi J, et al. (2007) Visceral and subcutaneous adiposity: are both potential therapeutic targets for tackling the metabolic syndrome? Curr Pharm Des 13, 2169-2175.

364. Tchkonia T, Thomou T, Zhu Y, et al. (2013) Mechanisms and metabolic implications of regional differences among fat depots. Cell Metab 17, 644-656.

365. Lafontan M \& Berlan M (2003) Do regional differences in adipocyte biology provide new pathophysiological insights? Trends Pharmacol Sci 24, 276-283.

366. Caesar R, Manieri M, Kelder T, et al. (2010) A combined transcriptomics and lipidomics analysis of subcutaneous, epididymal and mesenteric adipose tissue reveals marked functional differences. PLOS ONE 5, e11525.

367. Martin ML \& Jensen MD (1991) Effects of body fat distribution on regional lipolysis in obesity. J Clin Invest 88, 609-613.

368. Nielsen S, Guo Z, Johnson CM, et al. (2004) Splanchnic lipolysis in human obesity. J Clin Invest 113, 1582-1588.

369. Ibrahim MM (2010) Subcutaneous and visceral adipose tissue: structural and functional differences. Obes Rev 11, $11-18$. 
370. Arner P (1995) Differences in lipolysis between human subcutaneous and omental adipose tissues. Ann Med 27, 435-438.

371. Hoffstedt J, Arner P, Hellers G, et al. (1997) Variation in adrenergic regulation of lipolysis between omental and subcutaneous adipocytes from obese and non-obese men. J Lipid Res 38, 795-804.

372. Zierath JR, Livingston JN, Thorne A, et al. (1998) Regional difference in insulin inhibition of non-esterified fatty acid release from human adipocytes: relation to insulin receptor phosphorylation and intracellular signalling through the insulin receptor substrate-1 pathway. Diabetologia 41, $1343-1354$

373. Bolinder J, Kager L, Ostman J, et al. (1983) Differences at the receptor and postreceptor levels between human omental and subcutaneous adipose tissue in the action of insulin on lipolysis. Diabetes 32, 117-123.

374. Rebuffe-Scrive M, Lonnroth P, Marin P, et al. (1987) Regional adipose tissue metabolism in men and postmenopausal women. Int J Obes 11, 347-355.

375. Pedersen SB, Kristensen K, Hermann PA, et al. (2004) Estrogen controls lipolysis by up-regulating $\alpha_{2} \mathrm{~A}$-adrenergic receptors directly in human adipose tissue through the estrogen receptor $\alpha$. Implications for the female fat distribution. J Clin Endocrinol Metab 89, 1869-1878.

376. Frühbeck G \& Gómez-Ambrosi J (2002) Depot-specific differences in the lipolytic effect of leptin on isolated white adipocytes. Med Sci Monit 8, BR47-BR55.

377. Dessi-Fulgheri P, Sarzani R \& Rappelli A (2003) Role of the natriuretic peptide system in lipogenesis/lipolysis. Nutr Metab Cardiovasc Dis 13, 244-249.

378. Dicker A, Astrom G, Wahlen K, et al. (2009) Primary differences in lipolysis between human omental and subcutaneous adipose tissue observed using in vitro differentiated adipocytes. Horm Metab Res 41, 350-355.

379. Karelis AD (2011) To be obese - does it matter if you are metabolically healthy? Nat Rev Endocrinol 7, 699-700.

380. de Gusmao Correia ML (2013) Is 'metabolically healthy' obesity a benign condition? J Hypertens 31, 39-41.

381. Ahima RS \& Lazar MA (2013) Physiology. The health risk of obesity - better metrics imperative. Science 341, 856-858.

382. Czaja MJ (2011) Functions of autophagy in hepatic and pancreatic physiology and disease. Gastroenterology 140, 1895-1908.

383. Singh R \& Cuervo AM (2011) Autophagy in the cellular energetic balance. Cell Metab 13, 495-504.

384. Singh R (2012) Autophagy in the control of food intake. Adipocyte 1, 75-79.

385. Russell RC, Tian Y, Yuan H, et al. (2013) ULK1 induces autophagy by phosphorylating Beclin-1 and activating VPS34 lipid kinase. Nat Cell Biol 15, 741-750.

386. Kanazawa T, Taneike I, Akaishi R, et al. (2004) Amino acids and insulin control autophagic proteolysis through different signaling pathways in relation to $\mathrm{mTOR}$ in isolated rat hepatocytes. J Biol Chem 279, 8452-8459.

387. Pattingre S, Espert L, Biard-Piechaczyk M, et al. (2008) Regulation of macroautophagy by mTOR and Beclin 1 complexes. Biochimie 90, 313-323.

388. Moscat J \& Diaz-Meco MT (2012) Feedback on fat: p62-mTORC1-autophagy connections. Cell 147, 724-727.

389. Singh R, Xiang Y, Wang Y, et al. (2009) Autophagy regulates adipose mass and differentiation in mice. J Clin Invest $\mathbf{1 1 9}$, 3329-3339.

390. Zhang Y, Goldman S, Baerga R, et al. (2009) Adiposespecific deletion of autophagy-related gene 7 (atg7) in mice reveals a role in adipogenesis. Proc Natl Acad Sci U S A 106, 19860-19865.
391. Wu J, Bostrom P, Sparks LM, et al. (2012) Beige adipocytes are a distinct type of thermogenic fat cell in mouse and human. Cell 150, 366-376.

392. Martinez-Lopez N, Athonvarangkul D, Sahu S, et al. (2013) Autophagy in Myf5 + progenitors regulates energy and glucose homeostasis through control of brown fat and skeletal muscle development. EMBO Rep 14, 795-803.

393. Kovsan J, Blüher M, Tarnovscki T, et al. (2011) Altered autophagy in human adipose tissues in obesity. J Clin Endocrinol Metab 96, E268-E277.

394. Nuñez CE, Rodrigues VS, Gomes FS, et al. (2013) Defective regulation of adipose tissue autophagy in obesity. Int J Obes (Lond) 37, 1473-1480

395. Ost A, Svensson K, Ruishalme I, et al. (2010) Attenuated mTOR signaling and enhanced autophagy in adipocytes from obese patients with type 2 diabetes. Mol Med 16, $235-246$.

396. Kawakami M, Murase T, Ogawa H, et al. (1987) Human recombinant TNF suppresses lipoprotein lipase activity and stimulates lipolysis in 3T3-L1 cells. J Biochem 101, 331-338.

397. López M, Lage R, Saha AK, et al. (2008) Hypothalamic fatty acid metabolism mediates the orexigenic action of ghrelin. Cell Metab 7, 389-399.

398. Murano I, Rutkowski JM, Wang QA, et al. (2013) Time course of histomorphological changes in adipose tissue upon acute lipoatrophy. Nutr Metab Cardiovasc Dis 23, $723-731$.

399. Giordano A, Murano I, Mondini E, et al. (2013) Obese adipocytes show ultrastructural features of stressed cells and die of pyroptosis. J Lipid Res 54, 2423-2436.

400. Hotamisligil GS, Shargill NS \& Spiegelman BM (1993) Adipose expression of tumor necrosis factor-91.

401. Mauriege P, Despres JP, Prud'homme D, et al. (1991) Regional variation in adipose tissue lipolysis in lean and obese men. J Lipid Res 32, 1625-1633.

402. Jocken JW, Goossens GH, van Hees AM, et al. (2008) Effect of $\beta$-adrenergic stimulation on whole-body and abdominal subcutaneous adipose tissue lipolysis in lean and obese men. Diabetologia 51, 320-327.

403. Dahlman I \& Arner P (2007) Obesity and polymorphisms in genes regulating human adipose tissue. Int $J$ Obes (Lond) 31, 1629-1641

404. Terra SG, McGorray SP, Wu R, et al. (2005) Association between $\beta$-adrenergic receptor polymorphisms and their G-protein-coupled receptors with body mass index and obesity in women: a report from the NHLBI-sponsored WISE study. Int J Obes (Lond) 29, 746-754.

405. Hoffstedt J, Iliadou A, Pedersen NL, et al. (2001) The effect

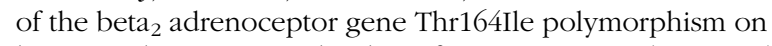
human adipose tissue lipolytic function. Br J Pharmacol 133, 708-712.

406. Eriksson P, Dahlman I, Ryden M, et al. (2004) Relationship between $\beta_{2}$-adrenoceptor gene haplotypes and adipocyte lipolysis in women. Int $J$ Obes Relat Metab Disord 28, 185-190.

407. Ryden M, Hoffstedt J, Eriksson P, et al. (2001) The Arg 389 Gly $\beta_{1}$-adrenergic receptor gene polymorphism and human fat cell lipolysis. Int $J$ Obes Relat Metab Disord 25, 1599-1603.

408. Tafel J, Branscheid I, Skwarna B, et al. (2004) Variants in the human $\beta_{1^{-}}, \beta_{2^{-}}$, and $\beta_{3}$-adrenergic receptor genes are not associated with morbid obesity in children and adolescents. Diabetes Obes Metab 6, 452-455.

409. Li LS, Lönnqvist F, Luthman H, et al. (1996) Phenotypic characterization of the Trp64Arg polymorphism in the $\beta_{3}$-adrenergic receptor gene in normal weight and obese subjects. Diabetologia 39, 857-860. 
410. Buettner R, Schaffler A, Arndt H, et al. (1998) The Trp64Arg polymorphism of the $\beta_{3}$-adrenergic receptor gene is not associated with obesity or type 2 diabetes mellitus in a large population-based Caucasian cohort. J Clin Endocrinol Metab 83, 2892-2897.

411. Snitker S, Odeleye OE, Hellmer J, et al. (1997) No effect of the $\operatorname{Trp} 64 \mathrm{Arg} \beta_{3}$-adrenoceptor variant on in vivo lipolysis in subcutaneous adipose tissue. Diabetologia 40, 838-842.

412. Jocken JW, Goossens GH, Boon H, et al. (2013) Insulinmediated suppression of lipolysis in adipose tissue and skeletal muscle of obese type 2 diabetic men and men with normal glucose tolerance. Diabetologia 56, 2255-2265.

413. Mairal A, Langin D, Arner P, et al. (2006) Human adipose triglyceride lipase (PNPLA2) is not regulated by obesity and exhibits low in vitro triglyceride hydrolase activity. Diabetologia 49, 1629-1636.

414. Large V, Reynisdottir S, Langin D, et al. (1999) Decreased expression and function of adipocyte hormone-sensitive lipase in subcutaneous fat cells of obese subjects. J Lipid Res 40, 2059-2066.

415. Tinahones FJ, Garrido-Sanchez L, Miranda M, et al. (2010) Obesity and insulin resistance-related changes in the expression of lipogenic and lipolytic genes in morbidly obese subjects. Obes Surg 20, 1559-1567.

416. Gandotra S, Le Dour C, Bottomley W, et al. (2011) Perilipin deficiency and autosomal dominant partial lipodystrophy. $N$ Engl J Med 364, 740-748.

417. Gandotra S, Lim K, Girousse A, et al. (2011) Human frame shift mutations affecting the carboxyl terminus of perilipin increase lipolysis by failing to sequester the adipose triglyceride lipase (ATGL) coactivator AB-hydrolase-containing 5 (ABHD5). J Biol Chem 286, 34998-35006.

418. Cusano NE, Kiel DP, Demissie S, et al. (2012) A polymorphism in a gene encoding perilipin 4 is associated with height but not with bone measures in individuals from the Framingham Osteoporosis Study. Calcif Tissue Int 90, 96-107.

419. Magné J, Aminoff A, Sundelin JP, et al. (2013) The minor allele of the missense polymorphism Ser251Pro in perilipin 2 (PLIN2) disrupts an $\alpha$-helix, affects lipolysis, and is associated with reduced plasma triglyceride concentration in humans. FASEB J 27, 3090-3099.

420. Lass A, Zimmermann R, Haemmerle G, et al. (2006) Adipose triglyceride lipase-mediated lipolysis of cellular fat stores is activated by CGI-58 and defective in Chanarin-Dorfman syndrome. Cell Metab 3, 309-319.

421. Yamaguchi $\mathrm{T}$ \& Osumi $\mathrm{T}$ (2009) Chanarin-Dorfman syndrome: deficiency in CGI-58, a lipid droplet-bound coactivator of lipase. Biochim Biophys Acta 1791, 519-523.

422. Bezaire V, Mairal A, Ribet C, et al. (2009) Contribution of adipose triglyceride lipase and hormone-sensitive lipase to lipolysis in hMADS adipocytes. J Biol Chem 284, 18282-18291.
423. Rodríguez A, Catalán V, Gómez-Ambrosi J, et al. (2011) Aquaglyceroporins serve as metabolic gateways in adiposity and insulin resistance control. Cell Cycle 10, 1548-1556.

424. Kishida K, Kuriyama H, Funahashi T, et al. (2000) Aquaporin adipose, a putative glycerol channel in adipocytes. J Biol Chem 275, 20896-20902.

425. Yasui H, Kubota M, Iguchi K, et al. (2008) Membrane trafficking of aquaporin 3 induced by epinephrine. Biochem Biophys Res Commun 373, 613-617.

426. Rodríguez A, Catalán V, Gómez-Ambrosi J, et al. (2006) Role of aquaporin-7 in the pathophysiological control of fat accumulation in mice. FEBS Lett 580, 4771-4776.

427. Catalán V, Gómez-Ambrosi J, Pastor C, et al. (2008) Influence of morbid obesity and insulin resistance on gene expression levels of AQP7 in visceral adipose tissue and AQP9 in liver. Obes Surg 18, 695-701.

428. Lafontan M (2012) Historical perspectives in fat cell biology: the fat cell as a model for the investigation of hormonal and metabolic pathways. Am J Physiol Cell Physiol 302, C327-C359.

429. Zhang Y, Proenca R, Maffei M, et al. (1994) Positional cloning of the mouse obese gene and its human homologue. Nature 372, 425-432.

430. Zierler KA, Jaeger D, Pollak NM, et al. (2013) Functional cardiac lipolysis in mice critically depends on comparative gene identification-58. J Biol Chem 288, 9892-9904.

431. Harant I, Beauville M, Crampes F, et al. (1994) Response of fat cells to growth hormone (GH): effect of long term treatment with recombinant human $\mathrm{GH}$ in $\mathrm{GH}$-deficient adults. J Clin Endocrinol Metab 78, 1392-1395.

432. Miegueu P, Pierre DS, Broglio F, et al. (2011) Effect of desacyl ghrelin, obestatin and related peptides on triglyceride storage, metabolism and GHSR signaling in 3T3-L1 adipocytes. J Cell Biochem 112, 704-714.

433. Granata R, Gallo D, Luque RM, et al. (2012) Obestatin regulates adipocyte function and protects against dietinduced insulin resistance and inflammation. FASEB $J \mathbf{2 6}$, 3393-3411.

434. Hauner H, Petruschke T, Russ M, et al. (1995) Effects of tumour necrosis factor $\alpha$ (TNF $\alpha)$ on glucose transport and lipid metabolism of newly-differentiated human fat cells in cell culture. Diabetologia 38, 764-771.

435. Path G, Bornstein SR, Gurniak M, et al. (2001) Human breast adipocytes express interleukin-6 (IL-6) and its receptor system: increased IL- 6 production by $\beta$-adrenergic activation and effects of IL- 6 on adipocyte function. $J$ Clin Endocrinol Metab 86, 2281-2288.

436. Grisouard J, Bouillet E, Timper K, et al. (2012) Both inflammatory and classical lipolytic pathways are involved in lipopolysaccharide-induced lipolysis in human adipocytes. Innate Immun 18, 25-34. 